\title{
Systematic review of the impact of emissions from aviation on current and future climate
}

A technical report by the University of Southampton
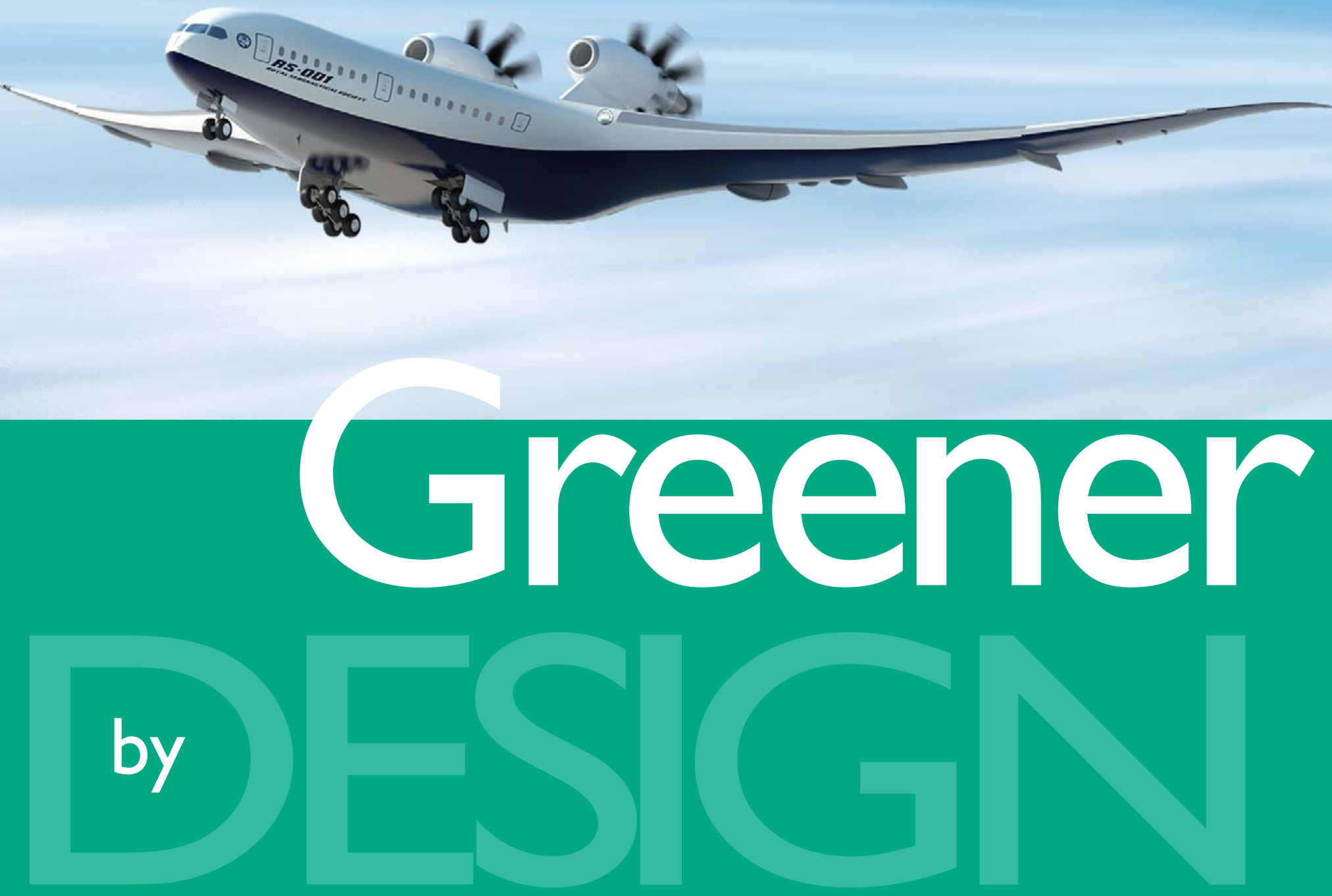


\section{Systematic review of the impact of emissions from aviation on current and future climate}

Contributions of authors

Development of protocol

Background

Literature searching

Inclusion screening

Data extraction / critical appraisal

Drafting of report

IRC $=$ information resources centre, Wessex Institute for Health Research and Development

Conflicts of interest

None declared.

Source of funding

This report was partly funded by the Royal Aeronautical Society.

\section{Acknowledgements}

We are grateful to staff of the Greener By Design team for assistance with the initial stages of this project, and to Karen Welch at the Wessex Institute for Health Research and Development for assistance with the searches. We would also like to thank Dr John Green and Professor Hugh Sommerville for helping to develop the protocol.

This report should be cited as follows:

Takeda, K, Takeda, A.L, Bryant, J, Clegg, A, C., Systematic review of the impact of emissions from aviation on current and future climate, Southampton, UK, University of Southampton, 86pp. (School of Engineering Sciences Aerospace Engineering AFM Technical Reports, AFM 07/08)

K Takeda, A Takeda, J Bryant, A Clegg

K Takeda, A Takeda, J Bryant, A Clegg

K Takeda, A Takeda

K Takeda, A Takeda

K Takeda

IRC, A Takeda, K Takeda

(1) 


\section{EXECUTIVE SUMMARY}

Aviation emissions have an impact on the global climate, and this is consequently an active area of research worldwide. By adapting replicable and transparent systematic review methods from the field of evidence-based medicine, we aim to synthesise available data on the effects of aviation emissions on climate. From these data, we aim to calculate lower and upper bounds for estimates of the effect of aviation on climate in an objective manner.

For the systematic review an appropriate protocol was developed and applied by two independent reviewers, to identify research that met the inclusion criteria. These included all aviation types, original research studies, climate models with aviation as a specific component, with outcomes for emissions, radiative forcing, global warming potential and/or surface temperature changes. These studies were prioritised and data extracted using a standard process. The 35 studies reviewed here reported radiative forcing, global warming potential and/or temperature changes as outcomes, allowing direct comparisons to be made.

Tabulated results and a narrative commentary were provided for overall effects on climate, and the individual effects of carbon dioxide, water, contrails, cirrus clouds, ozone, nitrogen oxides, methane, soot and sulphur oxides. Lower and upper bounds for these effects, and their relative contributions compared to overall radiative forcing and surface temperature changes, have been described.

This review shows that the most recent estimates for the contribution of aviation to global climate are highly dependent on the level of scientific understanding and modelling, and predicted scenarios for social and economic growth. Estimates for the future contribution of aviation to global radiative forcing in 2015 range from $5.31 \%$ to $8.04 \%$. For 2050 the estimates have a wider spread, from $2.12 \%$ to $17.33 \%$, the latter being for the most extreme technology and growth scenario. These global estimates should be considered within the context of uncertainties in accounting for the direct and indirect effects of different contributions. Variations between lower and upper bounds for estimates of radiative forcing are relatively low for carbon dioxide, around $131 \%$, to $800 \%$ for cirrus clouds effects, and $1044 \%$ for soot. Advances in climate research, particularly in the area of contrail and cloud effects, has led to some revision of the 1999 IPCC estimates ${ }^{1}$, and demonstrates that the research community is actively working to further understand the underlying science.

The approaches assumptions, limitations and future work were discussed in detail. We have demonstrated how the systematic review methodology can be applied to climate science, in a replicable and transparent manner. 
Percentage variation of radiative forcing results (high versus low bound)

\begin{tabular}{|l|c|c|c|c|}
\hline Effect & \multicolumn{2}{|c|}{ Percentage variation of radiative forcing results (high versus low bound) } \\
\hline & $\mathbf{1 9 9 0}$ & $\mathbf{2 0 0 0}$ & $\mathbf{2 0 1 5}$ & $\mathbf{2 0 5 0}$ \\
\hline $\mathrm{CO}_{2}$ & $131 \%$ & $116 \%$ & $121 \%$ & $112 \%$ \\
\hline Water & - & - & $375 \%$ & $420 \%$ \\
\hline Contrails & - & $340 \%$ & $588 \%$ & $676 \%$ \\
\hline Cirrus & - & - & $800 \%$ & - \\
\hline Ozone & - & $132 \%$ & $135 \%$ & $1071 \%$ \\
\hline $\mathrm{NO}_{\mathrm{x}}$ & $186 \%$ & - & $195 \%$ & - \\
\hline $\mathrm{Methane}$ & - & $173 \%$ & $133 \%$ & $1044 \%$ \\
\hline Soot & - & $160 \%$ & $150 \%$ & $150 \%$ \\
\hline $\mathrm{SO}_{\mathrm{x}}$ & - & $114 \%$ & - & - \\
\hline Overall & - & $\mathbf{1 4 9 \%}$ & $\mathbf{1 4 2 \%}$ & $\mathbf{5 5 1 \%}$ \\
\hline
\end{tabular}

\section{Aviation's contribution to global emissions}

\begin{tabular}{|c|c|c|c|c|c|c|c|c|}
\hline \multirow[t]{3}{*}{ Effect } & \multicolumn{8}{|c|}{ Percentage of global radiative forcing } \\
\hline & \multicolumn{2}{|c|}{1990} & \multicolumn{2}{|c|}{2000} & \multicolumn{2}{|c|}{2015} & \multicolumn{2}{|c|}{2050} \\
\hline & Low & High & Low & High & Low & High & Low & High \\
\hline$\%$ global RF, A1F1 ${ }^{1}$ & $4.66 \%$ & - & $3.59 \%$ & $5.34 \%$ & $5.34 \%{ }^{\dagger}$ & $7.56 \%{ }^{\dagger}$ & $2.12 \%$ & $11.68 \%$ \\
\hline$\%$ global RF, B $1^{1}$ & $4.66 \%$ & - & $3.59 \%$ & $5.34 \%$ & $5.31 \%^{\dagger}$ & $7.67 \%^{\dagger}$ & $3.10 \%$ & $17.09 \%$ \\
\hline$\%$ global RF, IS92a ${ }^{1}$ & $4.66 \%$ & - & $3.65 \%$ & $5.42 \%$ & $5.67 \%{ }^{\dagger}$ & $8.04 \%{ }^{\dagger}$ & $3.15 \%$ & $17.35 \%$ \\
\hline
\end{tabular}


TABLE OF CONTENTS

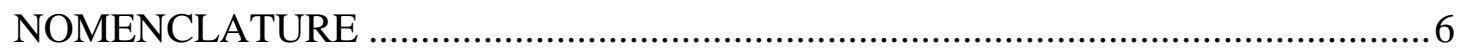

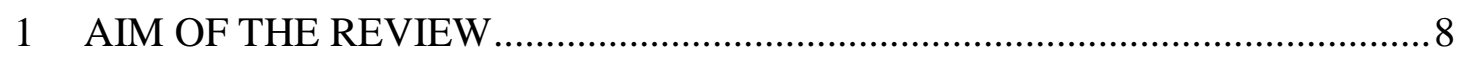

2 INTRODUCTION

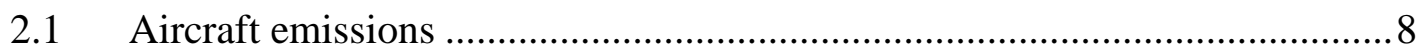

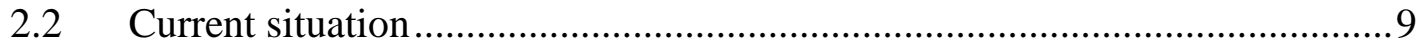

2.3 Systematic review - a novel approach in this field ......................................

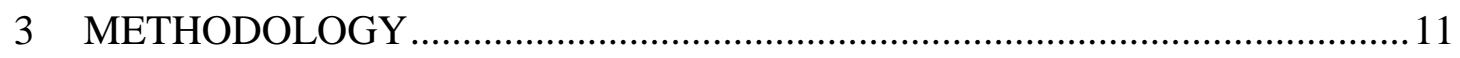

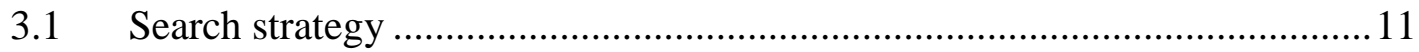

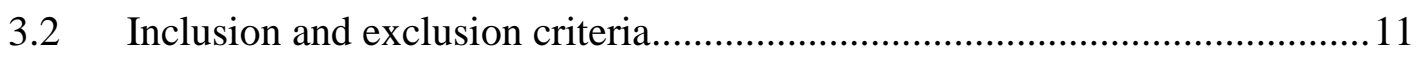

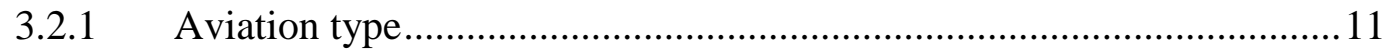

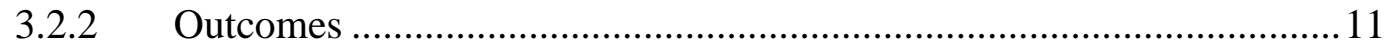

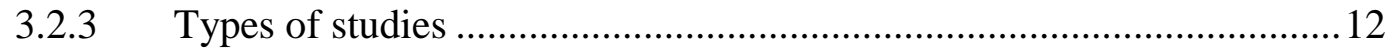

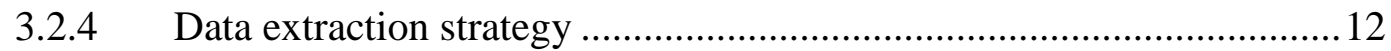

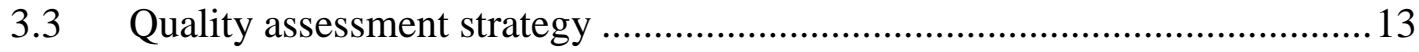

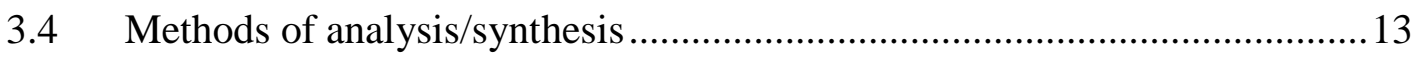

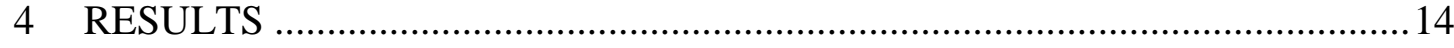

4.1 Quantity and quality of literature .......................................................... 14

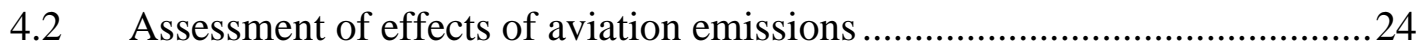

4.2.1 Overall effect of aviation on RF, GWP and temperature ......................24

4.2.2 Effects of carbon dioxide on RF, GWP and temperature ....................25

4.2.3 Effects of water, contrails and cirrus clouds on RF, GWP and

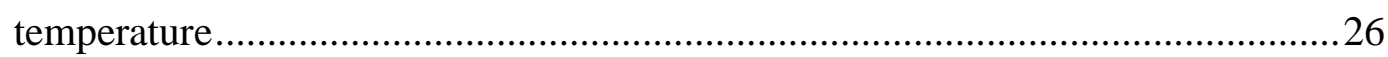

4.2.4 Effects of ozone, $\mathrm{NO}_{\mathrm{x}}$ and aerosols from aviation on RF, GWP and

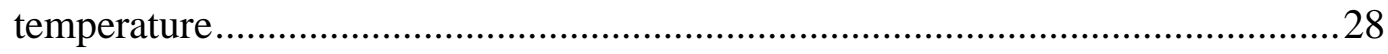

4.2.5 Summary of effects of aviation emissions ..........................................59

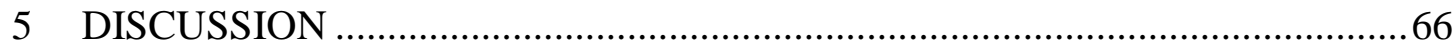

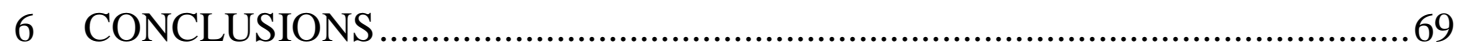

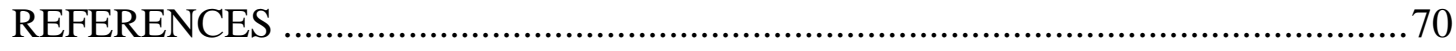

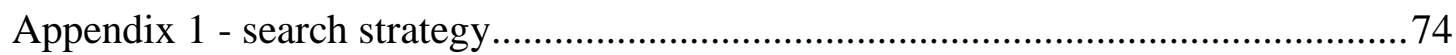

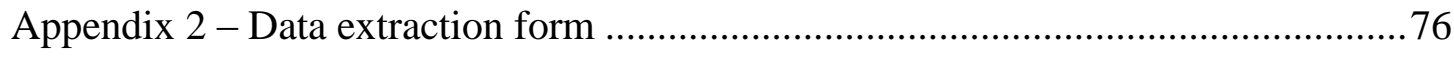

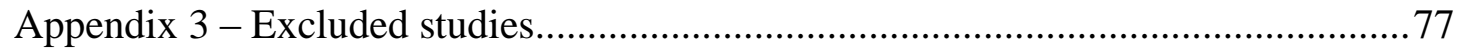

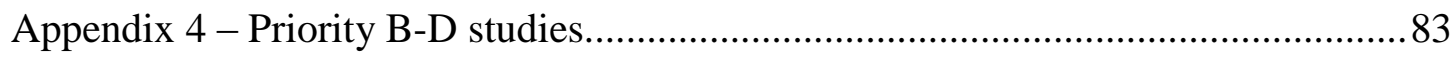




\section{LIST OF TABLES}

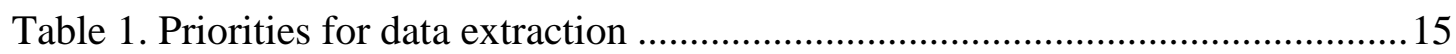

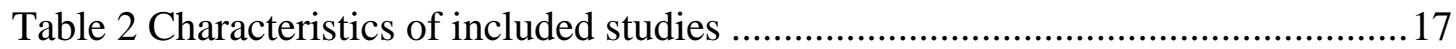

Table 3 Quality assessment of included studies ranked by quality assessment score .21

Table 4 Overall effect of aviation on RF, GWP and temperature .............................31

Table 5 Effect of aviation's $\mathrm{CO}_{2}$ on RF, GWP and temperature …............................35

Table 6 Effect of aviation's $\mathrm{H}_{2} \mathrm{O}$ on RF, GWP and temperature ................................38

Table 7 Effect of contrails on RF, GWP and temperature ..........................................43

Table 8 Effect of aviation-induced cirrus clouds' effect on RF, GWP and temperature

Table 9 Effects of ozone, $\mathrm{NO}_{\mathrm{x}}$ and aerosols on RF, GWP and temperature................51

Table 10. Lower and upper bounds for radiative forcing results .............................62

Table 11. Percentage variation of radiative forcing results (high versus low bound) .63

Table 12. Aviation's contribution to global emissions ...............................................64

Table 13. Lower and upper bounds for surface temperature results ..........................65

\section{LIST OF FIGURES}

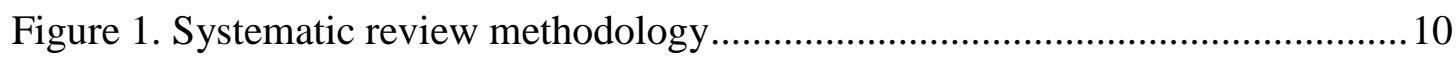

Figure 2. Number of studies identified at each stage of the review............................ 14

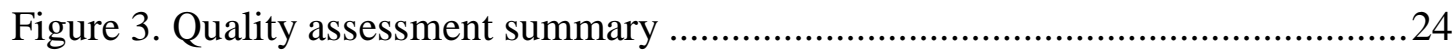




\section{NOMENCLATURE}

\begin{tabular}{|c|c|}
\hline $1 \mathrm{D}, 2 \mathrm{D}, 3 \mathrm{D}$ & One dimensional, two dimensional, three dimensional \\
\hline A1F1 & IPCC scenario \\
\hline AGWP & Absolute global warming potential \\
\hline AMIP & Atmospheric model intercomparison project \\
\hline ARPEGE/Climat & Météo France climate model \\
\hline B1 & IPCC scenario \\
\hline $\mathrm{BC}$ & Black carbon \\
\hline $\mathrm{C}$ & carbon \\
\hline CAB & Commonwealth Agricultural Bureaux \\
\hline $\mathrm{CCI}$ & Cirrus cloud insertion \\
\hline $\mathrm{CO}_{2}$ & Carbon dioxide \\
\hline CTM & Chemical transport model \\
\hline cryo & cryoplane \\
\hline cryo1-cryo3 & Model scenarios (cryoplanes) \\
\hline DfT & Department for Transport (UK) \\
\hline DLR & Deutsche Zentrum für Luft- und Raumfahrt \\
\hline Dyn. & dynamical \\
\hline EDF & Environmental defence fund \\
\hline Edh & IPCC scenario \\
\hline GCM & General circulation model or global climate model \\
\hline GCMAM & Global climate middle atmosphere model \\
\hline GISS & Goddard Institute for Space Studies \\
\hline GWP & Global warming potential \\
\hline Eab & IPCC scenario \\
\hline ECHAM & European Centre Hamburg Model \\
\hline ECMWF & European Centre for Medium range Weather Forecasting \\
\hline EU & European Union \\
\hline Fa1 & IPCC scenario \\
\hline $\mathrm{Fa} 2$ & IPCC scenario \\
\hline FA1H & IPCC scenario \\
\hline FAST & Aviation forecast model \\
\hline $\mathrm{Fc} 1$ & IPCC scenario \\
\hline $\mathrm{Fe} 1$ & IPCC scenario \\
\hline FESG & Forecasting and economic support group \\
\hline $\mathrm{g}$ & grams \\
\hline HadAM3-STOCHEM & Hadley Centre climate model \\
\hline $\mathrm{HCC}$ & High cloud cover \\
\hline $\mathrm{hPa}$ & Hectopascal (1 millibar) \\
\hline HSCT & High speed civil transport \\
\hline ICAO & International Civil Aviation Organization \\
\hline IEA & International Energy Agency \\
\hline IPCC & Intergovernmental Panel on Climate Change \\
\hline IRC & Information Resources Centre, University of Southampton, UK \\
\hline
\end{tabular}




\begin{tabular}{|c|c|}
\hline IS92a & IPCC scenario \\
\hline $\mathrm{K}$ & Kelvin \\
\hline ke & kerosene \\
\hline Ker & Model scenario (kerosene aircraft) \\
\hline $\mathrm{Kft}$ & 1000 feet \\
\hline $\mathrm{Kg}$ & kilogram \\
\hline $\mathrm{km}$ & kilometre \\
\hline KNMI & $\begin{array}{l}\text { Koninklijk Nederlands Meteorologisch Instituut (Royal Dutch } \\
\text { Meteorological Institute) }\end{array}$ \\
\hline LMDz-INCA & le Modèle de Circulation Générale du LMD chemistry model \\
\hline MLO & Mixed layer ocean (model) \\
\hline MOGUNTIA & Model of the Global Universal Tracer transport In the Atmosphere \\
\hline $\mathrm{mg}$ & milligrams \\
\hline $\mathrm{mK}$ & milliKelvin $\left(10^{-3}\right.$ Kelvin $)$ \\
\hline $\mathrm{N}$ & nitrogen \\
\hline NA & Not applicable \\
\hline NASA & National Aeronautics and Space Administration \\
\hline NCEP & National Centers for Environmental Prediction \\
\hline NO & Nitric oxide \\
\hline $\mathrm{NO}_{2}$ & Nitrogen dioxide \\
\hline $\mathrm{NO}_{\mathrm{x}}$ & Nitrogen oxides \\
\hline $\mathrm{n} / \mathrm{s}$ & Not (statistically) significant \\
\hline ppbv & Parts per billion volume \\
\hline ppmv & Parts per million volume \\
\hline $\mathrm{R}$ & Model scenario \\
\hline $\mathrm{RCM}$ & Radiative convective model \\
\hline REPROBUS & $\begin{array}{l}\text { le Modèle de Circulation Générale du LMD 3D chemistry transport } \\
\text { model }\end{array}$ \\
\hline $\mathrm{RF}$ & Radiative forcing \\
\hline RFI & Radiative forcing index \\
\hline RIVM & National Institute for Public Health and the Environment (Dutch) \\
\hline RTM & Radiative transfer model \\
\hline S & Scaling factor \\
\hline SD & Standard deviation \\
\hline $\mathrm{SO}_{4}$ & sulphate \\
\hline $\mathrm{SO}_{\mathrm{x}}$ & Sulphur oxides \\
\hline SRES & IPCC scenario \\
\hline SUNNYA-CCM3 & Global climate model \\
\hline $\mathrm{Tg}$ & Teragram $\left(10^{12} \mathrm{~g}\right)$ \\
\hline TOMCAT & Chemistry Transport Model \\
\hline TRADEOFF & $\begin{array}{l}\text { EU Fifth Framework project. "Aircraft emissions: contribution of } \\
\text { different climate components to changes in radiative forcing - } \\
\text { TRADEOFF to reduce atmospheric impact" }\end{array}$ \\
\hline ULAQ & University of L'Aquila chemistry transport model \\
\hline Yror $y$ & year \\
\hline$\mu \mathrm{m}$ & Micrometer $\left(10^{-6} \mathrm{~m}\right)$ \\
\hline
\end{tabular}




\section{AIM OF THE REVIEW}

Aviation emissions have an impact on the global climate, and this is consequently an active area of research worldwide. By adapting replicable and transparent systematic review methods from the field of evidence-based medicine, we aim to synthesise available data on the effects of aviation emissions on climate. From these data, we aim to calculate lower and upper bounds for estimates of the effect of aviation on climate in an objective manner.

\section{INTRODUCTION}

The global climate is sensitive to greenhouse gases, and indirect effects of other compounds. This is of concern for future evolution of the climate, with global temperature increases being predicted to have a significant effect on the planet. The ecosystem is complex, and both natural and anthropogenic effects can be significant, with coupling of the atmosphere, ocean and landmass behaviour all contributing to the overall climate response. Computer simulation models can be used to investigate future scenarios, and show how different contributions to the overall climate behave. This information is useful to help guide policymakers to make decisions about how best to mitigate climate change. ${ }^{2}$ There are, however, different levels of uncertainty regarding the underlying science that must be taken into account in any discussion. It is only by looking at the full range of research that meaningful conclusions can be drawn. The aim of this systematic review is to provide an objective account of the current state-of-the-art research on the effects of aviation on the global environment. It is hoped that this will help to provide a more solid foundation for discussions on this topic.

\subsection{Aircraft emissions}

Aircraft, like other forms of transport, produce emissions that can have an impact on the global climate. Carbon dioxide $\left(\mathrm{CO}_{2}\right)$ and water vapour are the main emissions from aircraft, with nitric oxide, nitrogen dioxide (collectively termed $\mathrm{NO}_{\mathrm{x}}$ ), sulphur oxides $\left(\mathrm{SO}_{\mathrm{x}}\right)$ and soot also contributing. ${ }^{1}$ Gases and particles from aircraft are emitted directly into the upper troposphere and lower stratosphere. Here, they alter concentrations of carbon dioxide, ozone $\left(\mathrm{O}_{3}\right)$ and methane $\left(\mathrm{CH}_{4}\right)$. Other climatic effects include the formation of condensation trails (contrails), and possible increases in cirrus cloudiness. ${ }^{1}$

Radiative forcing, measured in $\mathrm{Wm}^{-2}$, is a calculation of impact on the energy balance of the Earth-atmosphere system. A positive value implies a global warming effect, and a negative value indicates cooling. ${ }^{1} \mathrm{CO}_{2}$ remains in the atmosphere for around 100 years, and so $\mathrm{CO}_{2}$ from aircraft emissions becomes mixed with $\mathrm{CO}_{2}$ from other sources, having a global warming effect. However, water vapour, $\mathrm{NO}_{\mathrm{X}}$ and other emissions have shorter residence times, and they remain concentrated around flight routes. This leads to more localized increases in radiative forcing. ${ }^{1}$

$\mathrm{NO}_{\mathrm{x}}$ has an effect at cruising altitudes, typically in the upper troposphere and lower stratosphere, which enhances ozone production and reduces methane concentrations. 
Residence times of ozone are a few months. The effect of ozone in this region of the atmosphere is to enhance the radiative forcing. The effect of reducing methane levels has a negative radiative forcing effect, although the residence time of methane is of the order of a decade.

Evaluation of the effects of aviation emissions on climate provides a range of uncertainties, based on current climate research. This ranges from relatively confident assessments of $\mathrm{CO}_{2}$ effects, to poor confidence in the effect of contrails and cirrus clouds. The relative importance of different contributors means that overall levels of uncertainty on the combined effect on climate are substantial, and a major focus of current efforts is to improve fundamental understanding of atmospheric processes, to help reduce these uncertainties.

Climate models provide a way of predicting future climate behaviour, and allow different scenarios to be investigated. Such simulations rely on representative input data and accurate mathematical modelling of physical processes. Both of these factors are sources of uncertainty that cannot be eliminated.

\subsection{Current situation}

The Intergovernmental Panel on Climate Change (IPCC) produced a report on aviation and the global atmosphere in 1999. ${ }^{1}$ Since then, numerous reports, review articles and newspaper columns have debated the link between aviation and global warming. There is often a lack of clarity surrounding the underlying data used in reviews, particularly with regard to the large error margins and variety of scenarios which are often assumed with climate models. High quality scientific research in the area of aviation and the environment is being carried out worldwide, and it is apparent that the level of scientific understanding on this subject is variable. The prediction of future scenarios as the basis for policymaking is an area in which levels of uncertainty should be well defined and understood. This is particularly true where changes in aircraft operational and design goals are put forward based on the climate science. Continuous progress through research programmes, particularly in Europe and the USA, means that the science is improving.

\subsection{Systematic review - a novel approach in this field}

The aim of this study is to provide an objective, quantitative survey of recent research into the effects of aviation on climate. Formal systematic review methodology is well established in the field of evidence-based medicine, ${ }^{3 ; 4}$ but has not yet been widely adopted in engineering and climate sciences. Systematic reviews aim to minimise bias by using well-documented, reproducible methodology to synthesise available data on a particular research question. There are four key stages to a review (development of a protocol, identification of studies, quality assessment, data extraction and synthesis of data), as shown in Figure 1.

This study applies the systematic review methodology to the subject of aviation's effect on the global environment. The development of the full methodology for this review is discussed in more detail in Section 3. The results from the data extraction stage are described in Section 3. A general discussion of the methodology, results and suggestions for future work are given in Section 4, followed by conclusions in Section 5. 


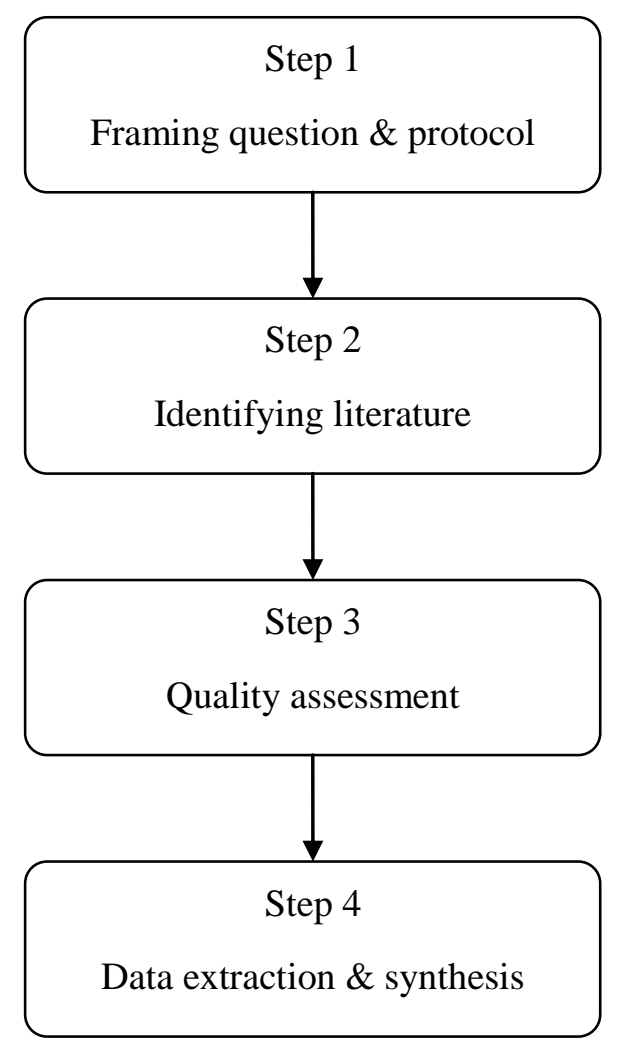

Figure 1. Systematic review methodology 


\section{METHODOLOGY}

The study aims to perform a systematic review of the effects of aviation emissions on the global environment for current and future scenarios. The first stage of the systematic review process was to develop a research protocol, outlining the review's proposed search strategy and methodology. The protocol was circulated to experts in the field, and amended in light of their comments. A key part of the protocol was the development of criteria for deciding which studies to include in the review.

\subsection{Search strategy}

An experienced information officer developed and tested a search strategy, designed to identify studies reporting aviation emissions and their effect on climate and climate models. This was then applied to key databases and sources of information to retrieve a list of titles and abstracts of relevance to the systematic review. The search strategy for Web of Science is included in Appendix 1. A number of electronic databases were searched, including: Web of Science; Engineering Village; Scopus; CAB Abstracts; DfT Research Database. Other webbased resources included the Tyndall Centre; the Environmental Change Institute and the United Nations Framework Convention on Climate Change.

\subsection{Inclusion and exclusion criteria}

References retrieved during the searches were stored in a database using the Reference Manager software package. Two reviewers independently scanned through the titles and abstracts to discard any articles which clearly did not meet the inclusion criteria pre-defined in the protocol, and outlined in Sections 3.2.1-3.2.3. References which were likely to be suitable for the review were retrieved as full papers for closer inspection. The retrieved full papers were then screened by two independent reviewers checking against the inclusion criteria. By scanning the database independently, the risk of selection bias in study selection was minimised. In cases where reviewers disagreed on whether to include/exclude on the basis of the abstract, the issue was resolved through discussion.

\subsubsection{Aviation type}

- Commercial passenger aircraft

- Freight

- General, unspecified aviation

- Military aviation, where data are available

All types of aviation were included, although not all papers necessarily refer to all types of aviation.

\subsubsection{Outcomes}

Studies reporting one or more of the following outcomes were initially included in the systematic review: 
- Carbon dioxide $\left(\mathrm{CO}_{2}\right)$

- nitric oxide $(\mathrm{NO})$ and nitrogen dioxide $\left(\mathrm{NO}_{2}\right)$, collectively known as nitrogen oxides $\left(\mathrm{NO}_{\mathrm{X}}\right)$

- Water vapour, including clouds and contrails

- Particulates, including sulphur oxides $\left(\mathrm{SO}_{\mathrm{X}}\right)$ and soot

- Radiative forcing (RF)

- Global warming potential (GWP)

- Effect of emissions on global climate models

However, as will be discussed in Section 4.1, it became necessary to amend the protocol and prioritise the retrieved studies so that only those reporting radiative forcing, global warming potential or temperature effects were included in this stage of the review. This prioritisation was done after the screening stage, and hence did not influence study identification. This is discussed further in Section 4.

\subsubsection{Types of studies}

The following types of study were included:

- Climate models with aviation as a specific component

- Only original research articles were included, whether these presented original data or were review papers presenting an interpretation of existing model data. Editorials and newspaper articles reporting the results of other reviews were not included.

- Conference abstracts from the last two years were screened, and were considered for inclusion where sufficient data were presented.

It was initially intended to include studies reporting emissions from aircraft, but the sheer volume of references made this impractical for the present study. The protocol's inclusion criteria were therefore amended to exclude studies which reported emissions estimates but did not include a climate model. Although these studies were excluded from the present review, they were marked in the database for any future work in this area.

It was not possible to include non-English language studies in the present review, due to the extra resources that would be required for translation. The potential for publication bias is discussed in Section 5.

\subsubsection{Data extraction strategy}

A standard data extraction template was used to standardise the information taken from the papers included in this study. This required reviewers to record details of the studies' methodology, key results and quality. Studies were data extracted by one reviewer, and checked by a second reviewer to minimise the risk of errors in reporting results. The data extraction form was developed at the protocol stage of the review. A typical form is shown in Appendix 2. 


\subsection{Quality assessment strategy}

Quality assessment is an important part of the systematic review methodology. By assessing the studies' quality against standard criteria, the results of the studies contributing to the review can be assessed in the context of any limitations of the underlying model structure. Unlike systematic reviews in medicine, no standard quality assessment criteria exist for this area. Review-specific criteria were therefore developed for this review, using an adaptation of the Drummond Checklist ${ }^{5}$ for evaluating models of cost-effectiveness in the field of healthcare. The original checklist developed for this review was circulated to experts for comment and revision before being used in the review. Quality assessment criteria were applied by one reviewer and checked by a second, with any differences of opinion being resolved through discussion. The criteria developed for this review are shown below:

- Did the study use a validated climate model?

- Was the study reporting an original model/ novel analysis?

- Did the study involve a comparison of alternatives?

- Was the potential bias of input data established?

- Did the study investigate/ report variability around emissions?

- Did the study report variability around the climate model's physical inputs and assumptions?

- Were all the important and relevant parameters for each alternative scenario identified?

- Were the results compared with those of others who have investigated the same question?

\subsection{Methods of analysis/synthesis}

Evidence from the systematic review was synthesised through tabulation of results and a narrative review. Standard methodology and software ${ }^{a}$ exist for performing meta-analysis of clinical trials of pharmaceutical drugs. ${ }^{3 ; 6}$ However, heterogeneity in study design, model type, parameters and time horizons meant that meta-analysis of key outcomes would have been inappropriate here. Section 3 contains the narrative review and tabulated results, with a general discussion of the results, limitations and assumptions given in Section 4.

\footnotetext{
${ }^{\text {a }}$ Review Manager software, available via the Cochrane Library
} 


\section{RESULTS}

\subsection{Quantity and quality of literature}

Scoping searches for this project identified over 2000 references. Inclusion criteria were therefore made more restrictive to include a requirement that the study mentioned results of models/simulations (see search strategy for Web of Science, Appendix 1). Searches of the scientific literature and of relevant government reports/websites identified 579 such references. The number of references identified at each stage of the review is shown in Figure 2. References which were retrieved as full papers for further inspection but which did not meet the inclusion criteria are listed in Appendix 3, with reasons for exclusion.

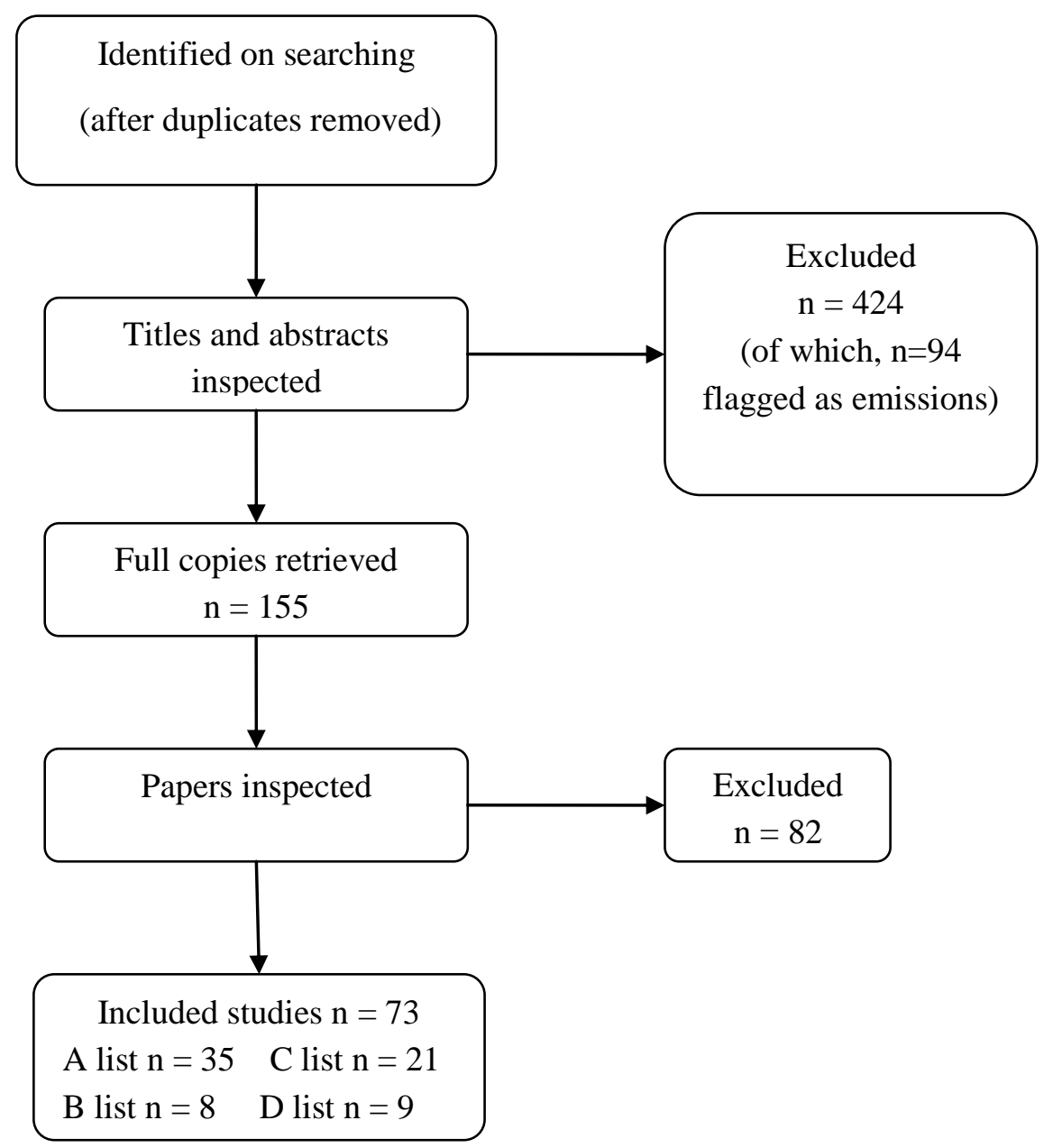

Figure 2. Number of studies identified at each stage of the review

After screening, papers were prioritised into categories shown in Table 1, due to the large number of references and limited resources available to the project. Due to these constraints, only results for the priority A papers are included in this study. This included papers that specifically reported temperature, radiative forcing and/or global warming potential as outcomes. 
Table 1. Priorities for data extraction

\begin{tabular}{|l|l|}
\hline Priority & Description \\
\hline A & Climate model with RF/GWP/temperature as outcome \\
\hline B & $\begin{array}{l}\text { Modelled } \mathrm{CO}_{2} \text {, black carbon, sulphur, contrails etc. but no specific } \\
\text { RF/GWP/temperature output }\end{array}$ \\
\hline C & $\begin{array}{l}\text { Modelled } \mathrm{NO}_{\mathrm{x}} \text { or ozone but no RF/temperature output (e.g. chemistry transport } \\
\text { models) }\end{array}$ \\
\hline D & \begin{tabular}{l} 
HSCT/cryoplanes with no current technology scenarios \\
\hline
\end{tabular}
\end{tabular}

Systematic reviews of clinical trials are more straight forward, as trial design and reporting of outcomes is usually more standardised. In the case of aviation and climate research, researchers present different metrics for their research output, making it difficult, if not impossible, to make direct comparisons. The priority A papers do, at least, provide common outcome metrics, even though the input data and model design may differ. Section 3.2 attempts to group the results so that direct comparisons can be made, where possible. It is hoped that this shows that the systematic review concept is valid in this domain, even if the review methodology is less straightforward to implement than in more established fields in which this approach is used. Data extraction, analysis and commentary for the priority B-D papers are areas for future investigation, although the more disparate nature of the research outcomes will make this a challenging task.

Given the high number of studies meeting the inclusion criteria, we prioritised them using the criteria in Table 1. The present review covers priority A papers, with papers classified as priorities $\mathrm{B}, \mathrm{C}$ and $\mathrm{D}$ listed in Appendix 4.

The present review covers priority A papers, with papers classified as priorities $\mathrm{B}, \mathrm{C}$ and $\mathrm{D}$ listed in Appendix 4. The characteristics of the 35 priority ' $A$ ' studies which met the inclusion criteria are shown in Table 2 . The quality assessment results for the priority A papers are shown in Table 3, with papers ranked by how many quality criteria were met. The data is summarised in Figure 3.

The quality of input data, methodology and reporting was generally of a high standard when compared against the assessment criteria developed for this study's protocol, with over $28 \%$ meeting all quality criteria, and $40 \%$ of the papers meeting three-quarters of the quality criteria. All of the papers included original models or novel data analysis, which was part of the inclusion criteria. $74 \%$ reported some comparison of alternative modes or scenarios. These studies were sensitive to the input data, and the assumed future growth scenarios. In $74 \%$ of the papers any potential bias of the input results was established, with $46 \%$ reporting the variability around emissions. $63 \%$ of the papers reported relevant parameters that were used for any alternative scenarios that were investigated. $89 \%$ included some comparison with other studies looking at the same research question.

The priority A studies identified during the systematic review reported the results of a variety of models. The majority of the studies included in this systematic review were from peerreviewed journals. A number of them were concerned with modelling the effect of current and future aircraft emissions on the global climate, reporting RF, GWP or temperature changes. 
These typically made use of global climate models, and aimed to include the major atmospheric chemistry. Of the 35 included studies, 28 used a validated climate model (80\%). Papers which did not use a validated climate model tended to be reports of $1 \mathrm{D}$ or $2 \mathrm{D}$ numerical parameterisation studies, often with a focus on chemistry tracing. A number of offline chemistry transport and radiative transfer models were used to investigate the particular effect of certain emissions. Parametric studies, sometimes using unrealistically high input values, were included that illustrate particular climate response. Section 4.2 discusses the results presented in the included studies. 
Table 2 Characteristics of included studies

\begin{tabular}{|c|c|c|c|}
\hline $\begin{array}{l}\text { First author and } \\
\text { date }\end{array}$ & Model used & Description of study & Key climate output(s) \\
\hline $\begin{array}{l}\text { Bernsten et al. } \\
2000^{7}\end{array}$ & OsloCTM-1 (Oslo university CTM) & Model of radiative forcing associated with tropospheric ozone & $\mathrm{RF}$ \\
\hline$\underset{8}{\text { Danilin et al., } 1998}$ & Eleven $2 \mathrm{D}$ and $3 \mathrm{D}$ models & $\begin{array}{l}\text { Aviation fuel tracer simulations to calculate an upper limit for aircraft- } \\
\text { produced effects, and uncertainty ranges }\end{array}$ & $\begin{array}{l}\text { paper focussed on fuel } \\
\text { tracer results (not data } \\
\text { extracted) but RF also } \\
\text { mentioned. }\end{array}$ \\
\hline$\underset{9}{\text { Dessens } \text { et al. } 2002}$ & $\begin{array}{l}\text { REPROBUS 3D CTM, with ARPEGE/climat } \\
\text { GCM }\end{array}$ & $\begin{array}{l}\text { The effects of NOx from future subsonic and supersonic planes on } \\
\text { atmospheric ozone, and the related change in mean annual zonal } \\
\text { temperatures }\end{array}$ & $\begin{array}{l}\text { Mean annual zonal } \\
\text { temperatures }\end{array}$ \\
\hline $\begin{array}{l}\text { Fichter et al. } \\
2005^{10}\end{array}$ & ECHAM GCM & Impact of cruise altitude on contrails, and related radiative forcing & Contrail coverage; $\mathrm{RF}$ \\
\hline Forster et al., 2006 & $\begin{array}{l}\text { Numerical model and carbon cycle model (no } \\
\text { details given) }\end{array}$ & $\begin{array}{l}\text { An investigation into the appropriateness of emission trading schemes, and } \\
\text { in particular the inappropriate use of the radiative forcing index (RFI) }\end{array}$ & $\begin{array}{l}\text { Absolute GWP; emissions } \\
\text { weighting factor }\end{array}$ \\
\hline $\begin{array}{l}\text { Fortuin } \text { et al., } 1995 \\
12\end{array}$ & Radiative transfer model based on ECMWF & Model of greenhouse effect of aircraft emissions & $\begin{array}{l}\text { fixed temperature forcing; } \\
\text { fixed dynamical heating } \\
\text { forcing }\end{array}$ \\
\hline Fuglesvedt $1996^{13}$ & 2D photochemistry transport model & $\begin{array}{l}\text { Model of the effects of changed emissions on the levels of ozone, hydroxyl } \\
\text { radicals and methane. }\end{array}$ & sustained GWP \\
\hline Gauss et al. $2003^{14}$ & OSLO CTM-2; SUNNYA-CCM3 GCM & $\begin{array}{l}\text { Perturbations in } \mathrm{H}_{2} \mathrm{O} \text { caused by aircraft in the year } 2015 \text { are calculated } \\
\text { with a CTM and used as input for radiative forcing calculation in a GCM. } \\
\text { Main focus is on cryoplanes, but kerosene scenarios also included. }\end{array}$ & $\begin{array}{l}\mathrm{H}_{2} \mathrm{O} \text { from CTM; RF from } \\
\text { GCM }\end{array}$ \\
\hline
\end{tabular}




\begin{tabular}{|c|c|c|c|}
\hline $\begin{array}{l}\text { First author and } \\
\text { date }\end{array}$ & Model used & Description of study & Key climate output(s) \\
\hline${ }_{15}^{\text {Isaksen } \text { et al., } 2001}$ & OSLO CTM & $\begin{array}{l}\text { Model of the impact of aircraft emissions on atmospheric ozone and } \\
\text { methane lifetime. Calculated changes in the global distribution of ozone } \\
\text { and methane then used to calculate RF of current and future ( } 2015 \text { and } \\
\text { 2050) fleets of subsonic aircraft. }\end{array}$ & $\mathrm{RF}$ \\
\hline $\begin{array}{l}\text { Johnson et al., } \\
1996^{16}\end{array}$ & 2D CTM & $\begin{array}{l}\text { Model of transport of trace gases and calculation of their radiative } \\
\text { impact/global warming potential. }\end{array}$ & GWP; RF \\
\hline $\begin{array}{l}\text { Marquart et al., } \\
20011_{17}\end{array}$ & $\begin{array}{l}\text { Calculations of RF, methods vary depending } \\
\text { on emission type. Some based on ECHAM } \\
\text { climate model. }\end{array}$ & Model of kerosene vs. hydrogen planes, future scenarios & $\begin{array}{l}\mathrm{RF} \text {, overall and due to: } \\
\mathrm{CO}_{2}, \mathrm{O}_{3}, \mathrm{CH}_{4}, \mathrm{H}_{2} \mathrm{O} \\
\text { contrails, sulphates, soot }\end{array}$ \\
\hline $\begin{array}{l}\text { Marquart et al., } \\
2003^{18}\end{array}$ & Calculations added to ECHAM GCM & Development of a contrail parameterization for the ECHAM GCM & contrail cover; RF \\
\hline $\begin{array}{l}\text { Marquart et al., } \\
2005^{19}\end{array}$ & $\begin{array}{l}\text { GCM with contrail parameterisation } \\
\text { [ECHAM4.L39 (DLR)] }\end{array}$ & $\begin{array}{l}\text { An updated estimate of the radiative forcing of a hypothetical fleet of } \\
\text { cryoplanes compared with a conventional aircraft fleet (update of } \\
\text { Marquart et al 2001). }\end{array}$ & $\mathrm{RF}$ \\
\hline $\begin{array}{l}\text { Meerkötter et al. } \\
1999^{20}\end{array}$ & Radiative transfer model & Parametric study of the instantaneous radiative impact of contrails & RF \\
\hline$\underset{21}{\operatorname{Minnis} \text { et al., } 1999}$ & Radiative transfer model & Model of radiative forcing by persistent linear contrails & $\mathrm{RF}$ \\
\hline 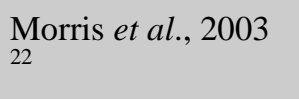 & Trajectory model & $\begin{array}{l}\text { Model of the effect of aircraft exhaust on water vapour in the lower } \\
\text { stratosphere, and calculations of radiative forcing. }\end{array}$ & water vapour; RF \\
\hline 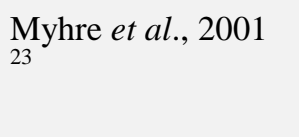 & Multistream model & $\begin{array}{l}\text { Global calculations of radiative forcing due to contrails from aircraft. } \\
\text { Contrail distribution was computed based on aviation fuel consumption } \\
\text { and radiative transfer models for solar and thermal infrared radiation. }\end{array}$ & $\mathrm{RF}$ \\
\hline Penner et al. $1999^{1}$ & $\begin{array}{l}\text { 3D chemical transport models (online \& } \\
\text { offline) }\end{array}$ & IPCC intercomparison of models & $\begin{array}{l}\text { RF, greenhouse gas } \\
\text { emissions and }\end{array}$ \\
\hline
\end{tabular}




\begin{tabular}{|c|c|c|c|}
\hline $\begin{array}{l}\text { First author and } \\
\text { date }\end{array}$ & Model used & Description of study & Key climate output(s) \\
\hline & & & concentrations \\
\hline Pitari et al $2002^{24}$ & 3D CTM (ULAQ model) & Modelling the effect of sulphate particles on RF & $\mathrm{RF}$ \\
\hline $\begin{array}{l}\text { Ponater } \text { et al., } 1996 \\
25\end{array}$ & ECHAM 3D GCM & $\begin{array}{l}\text { Model of the global atmospheric response to aircraft water vapour } \\
\text { emissions and contrails }\end{array}$ & $\begin{array}{l}\text { solar radiation; thermal } \\
\text { radiation; net radiation }\end{array}$ \\
\hline$\underset{26}{\text { Ponater } \text { et al., } 1999}$ & $\begin{array}{l}\text { Atmospheric GCM (ECHAM4) coupled to a } \\
\text { mixed layer ocean model (MLO) CTMs used } \\
\text { for ozone data - MOGUNTIA used as basis for } \\
\text { some of the scenarios }\end{array}$ & $\begin{array}{l}\text { Modelled effect on the climate of ozone changes caused by present and } \\
\text { future air traffic. }\end{array}$ & $\begin{array}{l}\text { climate response; surface } \\
\text { air temperature; RF }\end{array}$ \\
\hline $\begin{array}{l}\text { Ponater } \text { et al., } 2002 \\
27\end{array}$ & $\begin{array}{l}\text { Novel parameterization of contrails added to } \\
\text { ECHAM4 }\end{array}$ & $\begin{array}{l}\text { Parameterization of contrails for use in global climate models, and } \\
\text { resulting modelled radiative forcing of contrails. }\end{array}$ & $\mathrm{RF}$ \\
\hline $\begin{array}{l}\text { Ponater } \text { et al., } 2005 \\
28\end{array}$ & $\begin{array}{l}\text { ECHAM4 GCM with amendments for } \\
\text { contrails and with a mixed layer ocean model }\end{array}$ & Model of climate sensitivity parameter to contrail cirrus & $\begin{array}{l}\text { climate sensitivity } \\
\text { parameter; mean surface } \\
\text { temperature }\end{array}$ \\
\hline${ }_{29}^{\text {Ponater } \text { et al., } 2006}$ & ECHAM4 GCM & $\begin{array}{l}\text { Model of the potential reduction in climate impact by switching from } \\
\text { kerosene to liquid hydrogen fuelled planes }\end{array}$ & RF; surface temperature \\
\hline Rind et al., $1995^{30}$ & $\begin{array}{l}\text { Goddard Institute for Space Studies } \\
\text { climate/middle atmosphere model } \\
\text { (GISS/GCMAM). }\end{array}$ & $\begin{array}{l}\text { Modelled experiments of ozone and water vapour perturbations. One } \\
\text { scenario includes an aircraft component. }\end{array}$ & $\begin{array}{l}\text { sea surface temperature, } \\
\text { air temperature }\end{array}$ \\
\hline Rind et al., $1996^{31}$ & $\begin{array}{l}\text { Goddard Institute for Space Studies (GISS) } \\
\text { global climate middle atmosphere model }\end{array}$ & Model of the climatic effect of water vapour release & surface air temperature \\
\hline Rind et al., $2000^{32}$ & $\begin{array}{l}\text { Goddard Institute for Space Studies (GISS) } \\
\text { global climate middle-atmosphere model } \\
\text { (GCMAM). }\end{array}$ & $\begin{array}{l}\text { Model of the climatic impact of cirrus cloud increases along aircraft flight } \\
\text { paths }\end{array}$ & $\begin{array}{l}\text { surface air temperature; } \\
\text { RF }\end{array}$ \\
\hline Sausen et al., 1997 & ECHAM4 GCM & Modelling the effect of aircraft induced ozone changes on the global & mean temperatures \\
\hline
\end{tabular}




\begin{tabular}{|c|c|c|c|}
\hline $\begin{array}{l}\text { First author and } \\
\text { date }\end{array}$ & Model used & Description of study & Key climate output(s) \\
\hline 33 & & climate & \\
\hline$\underset{34}{\text { Sausen } \text { et al., } 2000}$ & Combination of linear response models & Model of climate response to emissions scenarios & $\begin{array}{l}\mathrm{CO}_{2} \text { concentration, global } \\
\text { mean sea surface } \\
\text { temperatures, sea level } \\
\text { changes }\end{array}$ \\
\hline $\begin{array}{l}\text { Sausen } \text { et al., } 2005 \\
\text { S5 }\end{array}$ & $\begin{array}{l}\text { Five CTMs and Climate Chemistry Models: } \\
\text { TOMCAT, CTM-2, ECHAM4.L39, LMDz- } \\
\text { INCA, ULAQ }\end{array}$ & $\begin{array}{l}\text { New estimates of RF from number of climate models, to update IPCC } \\
\text { (1999) estimates for } 2000 .\end{array}$ & $\begin{array}{l}\text { RF, with and without } \\
\text { cirrus cloud forcing }\end{array}$ \\
\hline $\begin{array}{l}\text { Stevenson et al., } \\
2004^{36}\end{array}$ & $\begin{array}{l}\text { HadAM3-STOCHEM climate-chemistry } \\
\text { model. }\end{array}$ & $\begin{array}{l}\text { Model of radiative forcings generated by aircraft NOx emissions through } \\
\text { changes in ozone and methane. }\end{array}$ & RF \\
\hline $\begin{array}{l}\text { Stordal et al., } 2005 \\
37\end{array}$ & $\begin{array}{l}\text { Regression analysis between trends in cirrus } \\
\text { cloud and aircraft traffic density; cirrus cloud } \\
\text { cover then multiplied by RF of cirrus to get } \\
\text { overall RF from aviation. Based on FAST }\end{array}$ & $\begin{array}{l}\text { An investigation of trends in cirrus cloud cover due to aircraft traffic, and } \\
\text { calculations of RF from this. }\end{array}$ & $\mathrm{RF}$ \\
\hline $\begin{array}{l}\text { Strauss et al., } 1997 \\
38\end{array}$ & 1D radiative convective model (RCM) & $\begin{array}{l}\text { Model investigating the impact of contrail-induced cirrus clouds on } \\
\text { regional climate (southern Germany). }\end{array}$ & $\begin{array}{l}\text { solar and ice cloud } \\
\text { radiative properties }\end{array}$ \\
\hline$\underset{39}{\text { Valks et al., } 1999}$ & CTM - RIVM version of MOGUNTIA & $\begin{array}{l}\text { Model of the effect of present and future NOx emissions from aircraft on } \\
\text { the atmosphere, and the corresponding RF }\end{array}$ & RF \\
\hline $\begin{array}{l}\text { Williams et al., } \\
2002^{40}\end{array}$ & Numerical model (no further details) & $\begin{array}{l}\text { Model of the effect of cruising altitude on the climate change impacts of } \\
\text { aviation. The rationale for restricting cruising altitude is to reduce contrail } \\
\text { formation. }\end{array}$ & $\begin{array}{l}\% \text { change in fuel burn; } \\
\text { altered flight times; } \\
\text { RF estimated, but not } \\
\text { really an output of model } \\
\text { calculations. }\end{array}$ \\
\hline
\end{tabular}

$\mathrm{RF}=$ radiative forcing; $\mathrm{GWP}=$ global warming potential; $\mathrm{GCM}=$ global climate model $\mathrm{CTM}=$ chemistry transport model 
Table 3 Quality assessment of included studies ranked by quality assessment score

\begin{tabular}{|c|c|c|c|c|c|c|c|c|c|}
\hline & $\begin{array}{l}\text { Did the } \\
\text { study use a } \\
\text { validated } \\
\text { climate } \\
\text { model? }\end{array}$ & $\begin{array}{l}\text { Was the } \\
\text { study } \\
\text { reporting } \\
\text { an original } \\
\text { model/ } \\
\text { novel } \\
\text { analysis? }\end{array}$ & $\begin{array}{l}\text { Did the } \\
\text { study } \\
\text { involve a } \\
\text { comparison } \\
\text { of } \\
\text { alternatives } \\
?\end{array}$ & $\begin{array}{l}\text { Was the } \\
\text { potential } \\
\text { bias of } \\
\text { input data } \\
\text { established } \\
?\end{array}$ & $\begin{array}{l}\text { Did the } \\
\text { study } \\
\text { investigate/ } \\
\text { report } \\
\text { variability } \\
\text { around } \\
\text { emissions? }\end{array}$ & $\begin{array}{l}\text { Did the study } \\
\text { report } \\
\text { variability } \\
\text { around the } \\
\text { climate } \\
\text { model's } \\
\text { physical } \\
\text { inputs and } \\
\text { assumptions? }\end{array}$ & $\begin{array}{l}\text { Were all the } \\
\text { important } \\
\text { and relevant } \\
\text { parameters } \\
\text { for each } \\
\text { alternative } \\
\text { scenario } \\
\text { identified? }\end{array}$ & $\begin{array}{l}\text { Were the } \\
\text { results } \\
\text { compared } \\
\text { with those } \\
\text { of others } \\
\text { who have } \\
\text { investigated } \\
\text { the same } \\
\text { question? }\end{array}$ & $\begin{array}{l}\text { Overall } \\
\text { assessment } \\
\text { score (total } \\
\text { no. of ' } Y \text { ' } \\
\text { scores) }\end{array}$ \\
\hline Fichter et al. $2005^{10}$ & $\mathrm{Y}$ & Y & Y & $\mathrm{Y}$ & $\mathrm{Y}$ & Y & $\mathrm{Y}$ & $\mathrm{Y}$ & 8 \\
\hline Gauss et al. $2003^{14}$ & $\mathrm{Y}$ & $\mathrm{Y}$ & $\mathrm{Y}$ & $\mathrm{Y}$ & $\mathrm{Y}$ & $\mathrm{Y}$ & $\mathrm{Y}$ & $\mathrm{Y}$ & 8 \\
\hline Marquart et al., $2003^{18}$ & Y & Y & Y & Y & Y & Y & $\mathrm{Y}$ & $\mathrm{Y}$ & 8 \\
\hline Minnis et al., $1999^{21}$ & $\mathrm{Y}$ & $\mathrm{Y}$ & $\mathrm{Y}$ & $\mathrm{Y}$ & $\mathrm{Y}$ & $\mathrm{Y}$ & $\mathrm{Y}$ & $\mathrm{Y}$ & 8 \\
\hline Penner et al. $1999^{1}$ & $\mathrm{Y}$ & $\mathrm{Y}$ & $\mathrm{Y}$ & $\mathrm{Y}$ & $\mathrm{Y}$ & $\mathrm{Y}$ & $\mathrm{Y}$ & $\mathrm{Y}$ & 8 \\
\hline Ponater et al., $1996^{25}$ & $\mathrm{Y}$ & $\mathrm{Y}$ & $\mathrm{Y}$ & $\mathrm{Y}$ & $\mathrm{Y}$ & $\mathrm{Y}$ & $\mathrm{Y}$ & $\mathrm{Y}$ & 8 \\
\hline Ponater et al., $2002^{27}$ & $\mathrm{Y}$ & $\mathrm{Y}$ & $\mathrm{Y}$ & $\mathrm{Y}$ & $\mathrm{Y}$ & $\mathrm{Y}$ & $\mathrm{Y}$ & $\mathrm{Y}$ & 8 \\
\hline Ponater et al., $2006^{29}$ & $\mathrm{Y}$ & $\mathrm{Y}$ & $\mathrm{Y}$ & $\mathrm{Y}$ & $\mathrm{Y}$ & $\mathrm{Y}$ & $\mathrm{Y}$ & $\mathrm{Y}$ & 8 \\
\hline Sausen et al., $2000^{34}$ & $\mathrm{Y}$ & $\mathrm{Y}$ & $\mathrm{Y}$ & $\mathrm{Y}$ & $\mathrm{Y}$ & $\mathrm{Y}$ & $\mathrm{Y}$ & $\mathrm{Y}$ & 8 \\
\hline Strauss et al., $1997^{38}$ & $\mathrm{Y}$ & $\mathrm{Y}$ & $\mathrm{Y}$ & $\mathrm{Y}$ & $\mathrm{Y}$ & $\mathrm{Y}$ & $\mathrm{Y}$ & $\mathrm{Y}$ & 8 \\
\hline Bernsten et al. $2000^{7}$ & Y & $\mathrm{Y}$ & $\mathrm{N}$ & $\mathrm{Y}$ & Y & Y & $\mathrm{Y}$ & $\mathrm{Y}$ & 7 \\
\hline Pitari et al $2002^{24}$ & $\mathrm{Y}$ & $\mathrm{Y}$ & Y & $\mathrm{N}$ & $\mathrm{Y}$ & Y & $\mathrm{Y}$ & $\mathrm{Y}$ & 7 \\
\hline Rind et al., $1996^{31}$ & $\mathrm{Y}$ & $\mathrm{Y}$ & $\mathrm{Y}$ & $\mathrm{Y}$ & NA & $\mathrm{Y}$ & $\mathrm{Y}$ & $\mathrm{Y}$ & 7 \\
\hline Sausen et al., $2005^{35}$ & $\mathrm{Y}$ & $\mathrm{Y}$ & $\mathrm{N}$ & $\mathrm{Y}$ & $\mathrm{Y}$ & $\mathrm{Y}$ & $\mathrm{Y}$ & $\mathrm{Y}$ & 7 \\
\hline
\end{tabular}




\begin{tabular}{|c|c|c|c|c|c|c|c|c|c|}
\hline & $\begin{array}{l}\text { Did the } \\
\text { study use a } \\
\text { validated } \\
\text { climate } \\
\text { model? }\end{array}$ & $\begin{array}{l}\text { Was the } \\
\text { study } \\
\text { reporting } \\
\text { an original } \\
\text { model/ } \\
\text { novel } \\
\text { analysis? }\end{array}$ & $\begin{array}{l}\text { Did the } \\
\text { study } \\
\text { involve a } \\
\text { comparison } \\
\text { of } \\
\text { alternatives } \\
?\end{array}$ & $\begin{array}{l}\text { Was the } \\
\text { potential } \\
\text { bias of } \\
\text { input data } \\
\text { established } \\
\text { ? }\end{array}$ & $\begin{array}{l}\text { Did the } \\
\text { study } \\
\text { investigate/ } \\
\text { report } \\
\text { variability } \\
\text { around } \\
\text { emissions? }\end{array}$ & $\begin{array}{l}\text { Did the study } \\
\text { report } \\
\text { variability } \\
\text { around the } \\
\text { climate } \\
\text { model's } \\
\text { physical } \\
\text { inputs and } \\
\text { assumptions? }\end{array}$ & $\begin{array}{l}\text { Were all the } \\
\text { important } \\
\text { and relevant } \\
\text { parameters } \\
\text { for each } \\
\text { alternative } \\
\text { scenario } \\
\text { identified? }\end{array}$ & $\begin{array}{l}\text { Were the } \\
\text { results } \\
\text { compared } \\
\text { with those } \\
\text { of others } \\
\text { who have } \\
\text { investigated } \\
\text { the same } \\
\text { question? }\end{array}$ & $\begin{array}{l}\text { Overall } \\
\text { assessment } \\
\text { score (total } \\
\text { no. of ' } Y \text { ' } \\
\text { scores) }\end{array}$ \\
\hline Dessens et al. $2002^{9}$ & $\mathrm{Y}$ & $\mathrm{Y}$ & $\mathrm{Y}$ & $?$ & $?$ & $\mathrm{Y}$ & $\mathrm{Y}$ & $\mathrm{Y}$ & 6 \\
\hline Marquart et al., $2005^{19}$ & $\mathrm{Y}$ & $\mathrm{Y}$ & $\mathrm{Y}$ & $\mathrm{Y}$ & $?$ & $?$ & $\mathrm{Y}$ & $\mathrm{Y}$ & 6 \\
\hline Ponater et al., $1999^{26}$ & Y & Y & $\mathrm{Y}$ & Y & $?$ & $?$ & Y & $\mathrm{Y}$ & 6 \\
\hline Ponater et al., $2005^{28}$ & $\mathrm{Y}$ & $\mathrm{Y}$ & $\mathrm{N}$ & $\mathrm{Y}$ & $\mathrm{Y}$ & $\mathrm{Y}$ & $?$ & $\mathrm{Y}$ & 6 \\
\hline Rind et al., $2000^{32}$ & $\mathrm{Y}$ & $\mathrm{Y}$ & $\mathrm{Y}$ & $\mathrm{Y}$ & NA & $\mathrm{Y}$ & $?$ & $\mathrm{Y}$ & 6 \\
\hline Valks et al., $1999^{39}$ & $\mathrm{Y}$ & $\mathrm{Y}$ & $\mathrm{Y}$ & $?$ & $\mathrm{~N}$ & $\mathrm{Y}$ & $\mathrm{Y}$ & $\mathrm{Y}$ & 6 \\
\hline Fuglesvedt $1996^{13}$ & $\mathrm{Y}$ & $\mathrm{Y}$ & $\mathrm{N}$ & $?$ & $\mathrm{Y}$ & $\mathrm{Y}$ & $\mathrm{N}$ & $\mathrm{Y}$ & 5 \\
\hline Morris et al., $2003^{22}$ & $\mathrm{~N}$ & $\mathrm{Y}$ & $\mathrm{Y}$ & $?$ & $\mathrm{~N}$ & $\mathrm{Y}$ & $\mathrm{Y}$ & $\mathrm{Y}$ & 5 \\
\hline Myhre et al., $2001^{23}$ & $\mathrm{~N}$ & $\mathrm{Y}$ & $\mathrm{Y}$ & $?$ & $\mathrm{~N}$ & $\mathrm{Y}$ & $\mathrm{Y}$ & $\mathrm{Y}$ & 5 \\
\hline Rind et al., $1995^{30}$ & $\mathrm{Y}$ & $\mathrm{Y}$ & $\mathrm{Y}$ & $\mathrm{Y}$ & $\mathrm{N}$ & $\mathrm{Y}$ & $?$ & $?$ & 5 \\
\hline Stevenson et al., $2004^{36}$ & $\mathrm{Y}$ & Y & $\mathrm{Y}$ & $\mathrm{Y}$ & $\mathrm{N}$ & $?$ & $?$ & $\mathrm{Y}$ & 5 \\
\hline Stordal et al., $2005^{37}$ & $\mathrm{~N}$ & $\mathrm{Y}$ & $\mathrm{N}$ & $\mathrm{Y}$ & $\mathrm{Y}$ & $?$ & $\mathrm{Y}$ & $\mathrm{Y}$ & 5 \\
\hline Isaksen et al., $2001^{15}$ & $\mathrm{Y}$ & $\mathrm{Y}$ & $\mathrm{Y}$ & $\mathrm{N}$ & $\mathrm{N}$ & $\mathrm{N}$ & $\mathrm{N}$ & $\mathrm{Y}$ & 4 \\
\hline Marquart et al., $2001^{17}$ & $\mathrm{Y}$ & $\mathrm{Y}$ & $\mathrm{Y}$ & $\mathrm{N}$ & $?$ & $?$ & $\mathrm{Y}$ & $\mathrm{N}$ & 4 \\
\hline Sausen et al., $1997^{33}$ & $\mathrm{Y}$ & $\mathrm{Y}$ & $\mathrm{Y}$ & $\mathrm{N}$ & $?$ & $?$ & $?$ & $\mathrm{Y}$ & 4 \\
\hline
\end{tabular}




\begin{tabular}{|c|c|c|c|c|c|c|c|c|c|}
\hline & $\begin{array}{l}\text { Did the } \\
\text { study use a } \\
\text { validated } \\
\text { climate } \\
\text { model? }\end{array}$ & $\begin{array}{l}\text { Was the } \\
\text { study } \\
\text { reporting } \\
\text { an original } \\
\text { model/ } \\
\text { novel } \\
\text { analysis? }\end{array}$ & $\begin{array}{l}\text { Did the } \\
\text { study } \\
\text { involve a } \\
\text { comparison } \\
\text { of } \\
\text { alternatives } \\
?\end{array}$ & $\begin{array}{l}\text { Was the } \\
\text { potential } \\
\text { bias of } \\
\text { input data } \\
\text { established } \\
\text { ? }\end{array}$ & $\begin{array}{l}\text { Did the } \\
\text { study } \\
\text { investigate/ } \\
\text { report } \\
\text { variability } \\
\text { around } \\
\text { emissions? }\end{array}$ & $\begin{array}{l}\text { Did the study } \\
\text { report } \\
\text { variability } \\
\text { around the } \\
\text { climate } \\
\text { model's } \\
\text { physical } \\
\text { inputs and } \\
\text { assumptions? }\end{array}$ & $\begin{array}{l}\text { Were all the } \\
\text { important } \\
\text { and relevant } \\
\text { parameters } \\
\text { for each } \\
\text { alternative } \\
\text { scenario } \\
\text { identified? }\end{array}$ & $\begin{array}{l}\text { Were the } \\
\text { results } \\
\text { compared } \\
\text { with those } \\
\text { of others } \\
\text { who have } \\
\text { investigated } \\
\text { the same } \\
\text { question? }\end{array}$ & $\begin{array}{l}\text { Overall } \\
\text { assessment } \\
\text { score (total } \\
\text { no. of 'Y' } \\
\text { scores) }\end{array}$ \\
\hline Danilin et al., $1998^{8}$ & $\mathrm{Y}$ & $\mathrm{Y}$ & $\mathrm{N}$ & $\mathrm{N}$ & $\mathrm{N}$ & $\mathrm{N}$ & $\mathrm{N}$ & $\mathrm{Y}$ & 3 \\
\hline Forster et al., $2006^{11}$ & $\mathrm{~N}$ & $\mathrm{Y}$ & $\mathrm{Y}$ & $\mathrm{N}$ & $\mathrm{N}$ & $\mathrm{N}$ & $?$ & $\mathrm{Y}$ & 3 \\
\hline Fortuin et al., $1995^{12}$ & $\mathrm{~N}$ & $\mathrm{Y}$ & $\mathrm{N}$ & $\mathrm{N}$ & $\mathrm{N}$ & $\mathrm{N}$ & $?$ & $\mathrm{Y}$ & 2 \\
\hline Johnson et al., $1996^{16}$ & $\mathrm{Y}$ & $\mathrm{Y}$ & $\mathrm{N}$ & $?$ & $\mathrm{~N}$ & $\mathrm{~N}$ & $\mathrm{~N}$ & $\mathrm{~N}$ & 2 \\
\hline Meerkötter et al. $1999^{20}$ & $\mathrm{~N}$ & Y & $\mathrm{N}$ & $?$ & $\mathrm{~N}$ & $\mathrm{~N}$ & $?$ & $\mathrm{Y}$ & 2 \\
\hline Williams et al., $2002^{40}$ & $\mathrm{~N}$ & $\mathrm{Y}$ & $\mathrm{Y}$ & $\mathrm{N}$ & $\mathrm{N}$ & $\mathrm{N}$ & $\mathrm{N}$ & $\mathrm{N}$ & 2 \\
\hline
\end{tabular}




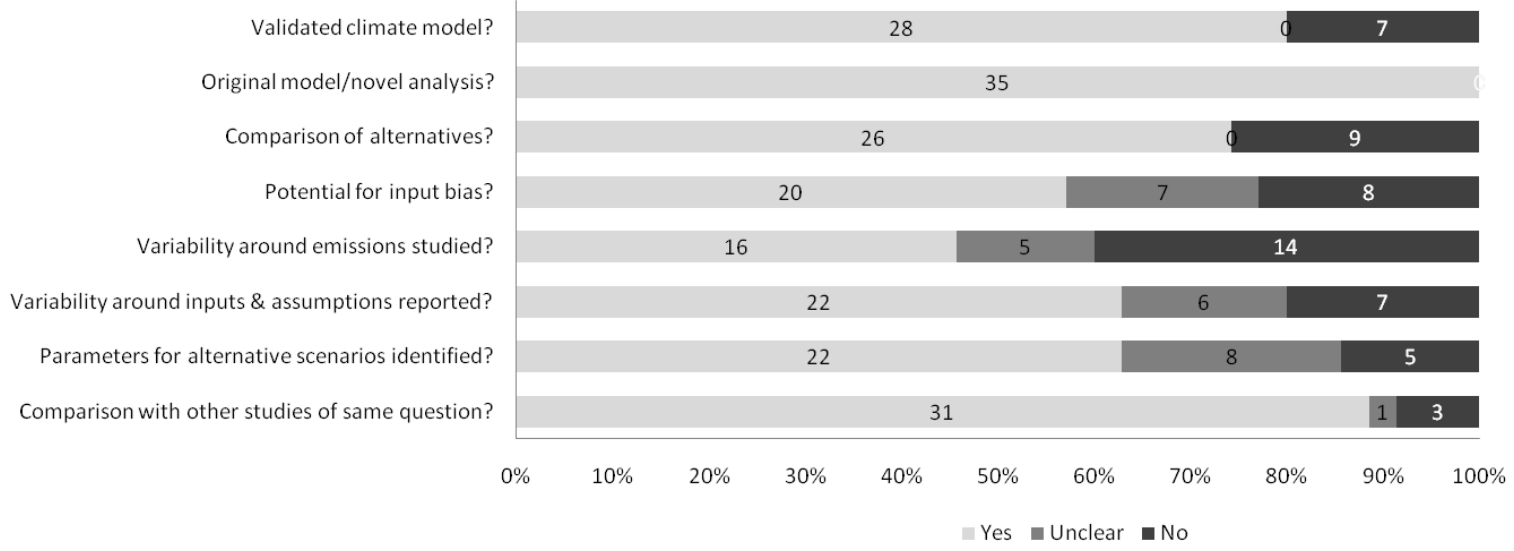

Figure 3. Quality assessment summary

\subsection{Assessment of effects of aviation emissions}

Results of the included studies are presented in this section. These 35 papers covered a range of original research studies that modelled the effect of aviation on the atmosphere, with outcomes measured in terms of RF, GWP or temperature changes. A range of scenarios was used, in terms of aircraft traffic, model types and parameters. The inputs and major outcomes are summarised in Table 4 - Table 9. The review aims to synthesise the results of these studies in a coherent manner, so that the reader is able to gain an understanding of the current state of the science. This section is sub-divided to separately describe papers presenting results of aviation's overall effect on RF, GWP and temperature, and that due to carbon dioxide; water, contrails and cirrus clouds; and ozone and aerosols. Where papers are relevant to more than one sub-section they are discussed in turn. While the issue of hydrogen fuelled cryoplanes was not the focus of this review, results from studies which presented data for both cryoplanes and kerosene-fuelled fleets are included, and discussed as a matter of interest for the reader. An overall summary of the results is given in section 3.2.5.

\subsubsection{Overall effect of aviation on RF, GWP and temperature}

The overall effect of aircraft emissions on the atmosphere, in terms of RF, GWP or temperature variations, is modelled in the five papers reviewed here. The key inputs and outcomes are presented in Table 4.

The IPCC report of Penner $e t a l^{1}$ is a detailed cross-comparison of several climate models, and is the most comprehensive study of different aviation scenarios to date. Overall radiative forcing was modelled from 1990 to 2050, with a breakdown of individual effects also described; these are discussed separately in the following sections. The IPCC predictions for 2000 were updated by Sausen $e t a l^{35}$ using five different CTM and climate chemistry models, as part of the EU TRADEOFF project, from 0.0713 to $0.0478 \mathrm{Wm}^{-2}$ (excluding cirrus cloud effects). The reduction in RF for 2000 was due to the strongly reduced effect from linear contrails, reflecting progress in the underlying scientific understanding of this area since 
Penner $e t a l^{1}$. This is discussed in more detail, and the context of other similar research, in section 3.2.2. The IPCC Fal reference scenario developed by the ICAO Forecasting and Economic Support Group (FESG) using a mid-range growth forecast (3.1\% per year) and assuming technology for improved fuel efficiency and $\mathrm{NO}_{\mathrm{x}}$ reduction, resulted in $\mathrm{RF}$ of 0.114 $\mathrm{Wm}^{-2}$ for 2015 , and $0.193 \mathrm{Wm}^{-2}$ for 2050 .

In addition to the baseline case, a number of other scenarios were presented by Penner et al ${ }^{1}$. These included the effect of different air traffic growth rates, introduction of a supersonic fleet of airliners (scenario $\mathrm{FalH}$ ), and focussing on certain emission reduction technologies above others. The lower bound was for scenario $F c 1$, representing a low-growth rate of $2.2 \%$ per year with a subsonic-only airliner fleet, resulting in an RF of $0.129 \mathrm{Wm}^{-2}$ for 2050 . The upper bound was for scenario $E d h$, representing a high growth rate $(4.7 \%$ per year) and focussed on low $\mathrm{NO}_{\mathrm{x}}$ technology, giving an $\mathrm{RF}$ of $0.564 \mathrm{Wm}^{-2}$ in 2050.

Marquart $e a^{17}$ focussed on assessing the impact of the introduction of a fleet of hydrogenpowered cryoplanes in 2015, but also reported kerosene fuelled aircraft as a baseline: 0.111 $\mathrm{Wm}^{-2}$ for $2015 ; 0.132 \mathrm{Wm}^{-2}$ for 2050 ; and $0.137 \mathrm{Wm}^{-2}$ for 2100 . In this study, aviation growth was assumed to stop in 2015, accounting for the difference in RF figures for 2050 and 2100 between this study and that by Penner et $a l^{1}$. In a similar study, Ponater et al ${ }^{29}$ also investigated cryoplanes, and produced a baseline RF prediction for a pure kerosene fleet of $0.128 \mathrm{Wm}^{-2}$. The predictions for the introduction of cryoplanes in 2015 reduced the RF in 2050 to $0.109-0.115 \mathrm{Wm}^{-2}$ from Marquart et $a l^{17}$, or 0.0904 to $0.1074 \mathrm{Wm}^{-2}$ from Ponater et $a l^{29}$.

A surface temperature increase of $0.052 \mathrm{~K}$ was predicted for 2050 by the IPCC Fal reference scenario. Sausen $e t a l^{34}$ used a combination of linear response models to assess temperature changes since 1950 , predicting an increase of $0.025 \mathrm{~K}$ in 2050 , leading to $0.047 \mathrm{~K}$ in 2100 . Ponater $e t a l^{29}$ estimated temperature increase of $0.041 \mathrm{~K}$ in 2050 for a kerosene aircraft scenario.

The papers reviewed here represent the key studies for global effects of major aviation emissions on the environment using a range of different growth and technology scenarios. The effects of component emissions and their chemistry on the environment are discussed in more detail in sections 3.2.2 to 3.2.4.

\subsubsection{Effects of carbon dioxide on RF, GWP and temperature}

Papers specifically investigating the effect of carbon dioxide on RF, GWP and temperature are discussed in this section. The key inputs and outcomes are shown in Table 5.

The IPCC paper of Penner $e t$ al $^{1}$ provided a breakdown of the component contributions to its global predictions. Results for 1992 indicated RF of $0.018 \mathrm{Wm}^{-2}$ due to $\mathrm{CO}_{2}$. Sausen $e$ t $a l^{35}$ scaled the IPCC results to $2000\left(0.025 \mathrm{Wm}^{-2}\right)$ to compare them with their own updated results from the TRADEOFF project of $0.0253 \mathrm{Wm}^{-2}$. An RF due to $\mathrm{CO}_{2}$ of $0.074 \mathrm{Wm}^{-2}$ in 2050 was predicted by Penner $e t a l^{1}$ for the mid-range $\mathrm{Fal}$ scenario. This compares well with the results of Ponater $e t a l^{29}$, which predicted $0.0729 \mathrm{Wm}^{-2}$ in 2050. Marquart et $a l^{17}$ predicted a lower RF of $0.061 \mathrm{Wm}^{-2}$ for 2050 and $0.066 \mathrm{Wm}^{-2}$ in 2100 for a kerosene fleet. These last two studies also computed the RF with introduction of a cryoplane fleet in 2015, showing an RF 
in 2050 due to $\mathrm{CO}_{2}$ of $0.025 \mathrm{Wm}^{-2}$ (Marquart et $\mathrm{el}^{17}$ ) and between 0.0196 and $0.020 \mathrm{Wm}^{-2}$ (Ponater et $_{a l^{29}}$ ).

Fortuin et al ${ }^{12}$ investigated the effect of RF due to $\mathrm{CO}_{2}$ from 1943 to 1990 , using fixed temperature and fixed dynamical heating assumptions, and reported results for mid-latitude summer and winter. The RF was 0.023 to $0.029 \mathrm{Wm}^{-2}$ for the mid-latitude summer case and 0.018 to $0.023 \mathrm{Wm}^{-2}$ for mid-latitude winter. The study also investigated contributions from water vapour, contrails and aerosols, which are discussed in sections 3.2.3 and 3.2.4.

Forster $e a^{11}$ discussed the use of a radiative forcing index (RFI) as a metric for assessing the impact of non- $\mathrm{CO}_{2}$ emissions on the environment. Emissions from 1950 to 2000 were modelled using an exponential growth model, and emissions were then held constant over a 500 year timescale. The Absolute Global Warming Potential (AGWP) was then calculated for 1, 20, 100 and 500 years, and the effect of $\mathrm{CO}_{2}$ and non- $\mathrm{CO}_{2}$ effects on the AGWP highlighted. From this the RFI was shown to change significantly with time, highlighting the danger in using RFI to account for non- $\mathrm{CO}_{2}$ effects in any assessment of aviation emissions.

The results of Sausen $e t a l^{34}$ used the IPCC Fal scenario and predicted a temperature increase due to $\mathrm{CO}_{2}$ of $0.024 \mathrm{~K}$ by 2050 , and $0.047 \mathrm{~K}$ by 2100 . This compares well to an increase of $0.026 \mathrm{~K}$ by 2050 predicted by Ponater $e t a l^{29}$.

\subsubsection{Effects of water, contrails and cirrus clouds on RF, GWP and temperature}

A significant amount of recent research has focussed on the science of water, contrails and cirrus cloud formation from aircraft at altitude. This is a major source of uncertainty in assessing the impact of aircraft emissions on the global environment, as highlighted by Penner $e t a l^{1}$. In this section 20 papers are reviewed that present original research, with the key inputs and outcomes of each shown in Table 6 - Table 8.

The effect of water vapour on RF in 2000 was studied by Sausen $e t a l^{35}$, and was calculated to be $0.002 \mathrm{Wm}^{-2}$, which is the same as that reported in the IPCC report by Penner et al ${ }^{1}$. The radiative transfer model (RTM) study by Fortuin et $a l^{12}$ used simulations up to 1990 and reported $\mathrm{RF}$ for mid-latitude regions of between 0.006 and $0.023 \mathrm{Wm}^{-2}$ in summer, and 0.028 and $0.131 \mathrm{Wm}^{-2}$ in mid winter using a fixed dynamical heating assumption. Ponater $e t a l^{25}$ performed a detailed study of the effect of water vapour, using factors of 10, 100, 1000 and 10000 , along with sensitivity studies of cloud cover increase by $0.10,0.05$ and 0.02 . The study noted that the effect of clouds was much more than that of the water vapour itself, which produced no detectable large-scale climate signal. It was noted that the experiment used was highly artificial and a much stronger enhancement than would ever occur in reality. Rind $e t a l^{31}$ performed a parametric study of water vapour effects on RF using a global climate middle atmosphere model. Experiments using water vapour 0.35, 1.5, 35 and 700 times the 1990 aircraft release values showed a measurable effect in the latter two cases only. The cases of 0.35 and 1.5 times 1990 release amounts showed no consistent trend, and the paper therefore concluded that the effect of water vapour does not have a global impact.

Marquart $e t a l^{17}$ calculated the RF effect for kerosene and hydrogen fuelled aircraft. The RF induced by water vapour in 2015 was predicted to be $0.0008 \mathrm{Wm}^{-2}$ for kerosene and $0.0019 \mathrm{Wm}^{-2}$ for hydrogen fuelled aircraft respectively, with near identical results for 2050 
and 2100. Ponater et $a l^{29}$ reported $\mathrm{RF}$ of $0.0019 \mathrm{Wm}^{-2}$ for kerosene fuelled aircraft in 2050, compared with between 0.0018 and $0.0107 \mathrm{Wm}^{-2}$ for three cryoplane scenarios. Gauss et $\mathrm{al}^{14}$ investigated water vapour effects of cryoplanes for 2015 using a variety of scenarios. Their baseline study for kerosene aircraft resulted in an RF of $0.0026 \mathrm{Wm}^{-2}$, compared with a baseline cryoplane case of $0.0065 \mathrm{Wm}^{-2}$ and a worst case RF of $0.0625 \mathrm{Wm}^{-2}$ when cryoplane cruising altitude was increased by $3 \mathrm{~km}$. The major source of uncertainty was the estimated tropospheric lifetime of aircraft emitted water. The CTM model used here was found to be very sensitive to variations of this parameter. This study only considered water vapour, and not contrail effects.

The overall IPCC assessment of Penner et al ${ }^{1}$ calculated the RF due to contrails to be 0.100 $\mathrm{Wm}^{-2}$ in 2050 , and $\mathrm{RF}$ due to water to be $0.004 \mathrm{Wm}^{-2}$. The level of uncertainty associated with the effect of cirrus clouds caused it to be excluded from the reported results. Sausen et al ${ }^{35}$ used a number of climate models in the TRADEOFF project to update the results of Penner et $a l^{1}$ due to contrails, scaled for $2000\left(0.039 \mathrm{Wm}^{-2}\right)$, to $0.010 \mathrm{Wm}^{-2}$. The effect of cirrus clouds was estimated to be $0.030 \mathrm{Wm}^{-2}$, but with an upper bound of $0.080 \mathrm{Wm}^{-2}$, which was reported in more detail by Stordal et $a l^{37}$. Rind et $a l^{32}$ investigated increases in cirrus cloud coverage along aircraft flight paths using a global climate model. For increases in high-level cloud cover from $0.5 \%$ to $5 \%$, RF changed from 0.00 to $2.4 \mathrm{Wm}^{-2}$. Ponater et al ${ }^{28}$ used artificially elevated traffic levels ( $20 \mathrm{x} \mathrm{Fal}$ inventory) to highlight the effect of cirrus clouds; $3.2 \%$ contrail coverage produced an RF of $0.29 \mathrm{Wm}^{-2}$.

Fichter et $a l^{10}$ calculated the mean net RF due to contrails as part of the TRADEOFF project, and the effect of changing cruise altitude on this for 1992 air traffic data. The baseline case showed an RF, corrected for long wave radiation effects, of $0.0029 \mathrm{Wm}^{-2}$. Increasing cruising altitude by 2000 feet increased RF to $0.0031 \mathrm{Wm}^{-2}$. Reducing altitude reduced RF, with a 6000 feet lower cruising altitude resulting in an RF of $0.0016 \mathrm{Wm}^{-2}$. Fortuin et al ${ }^{12}$ used a radiative transfer model to investigate a range of emission effects for 1990. They calculated a local RF due to contrails at mid-latitudes of between -0.15 and $0.30 \mathrm{Wm}^{-2}$ in summer, and 0.05 and $0.30 \mathrm{Wm}^{-2}$ in winter.

Future projections of the effect of contrails were included in the cryoplane studies of Marquart $e a^{17}$ and Ponater et $a l^{29}$. Marquart et $a l^{17}$ predicted kerosene fuelled aircraft to contribute an RF of $0.052 \mathrm{Wm}^{-2}$ in 2015 and 2050, compared with between 0.0191 and $0.0929 \mathrm{Wm}^{-2}$ in 2050 , calculated by Ponater $e t a l^{29}$. These studies highlight the increased effect of contrails due to the introduction of cryoplanes, with Marquart et al ${ }^{17}$ estimating RF of $0.081 \mathrm{Wm}^{-2}$ in 2015 and 2050, compared with between 0.0156 and $0.0783 \mathrm{Wm}^{-2}$ for the three different cryoplane scenarios reported by Ponater $e t a l^{29}$.

More recent results from Marquart et $a l^{19}$ investigated the effect of different contrail particle properties. For non-spherical particles, the estimate for RF due to contrails in 2015 by kerosene fuelled aircraft was $0.0098 \mathrm{Wm}^{-2}$, compared with $0.012 \mathrm{Wm}^{-2}$ for non-spherical, half-size particles, and $0.0127 \mathrm{Wm}^{-2}$ for spherical, half-size particles. The cryoplane RF in 2015 was $0.008 \mathrm{Wm}^{-2}$ for the non-spherical particles, and $0.013 \mathrm{Wm}^{-2}$ for non-spherical, halfsized particles. The effect of ice water content on future contrail effects was studied by Minnis et $a l^{21}$. They showed how ice water content of between 0.1 and 0.5 causes corresponding RF due to contrails of $0.049 \mathrm{Wm}^{-2}$ and $0.122 \mathrm{Wm}^{-2}$, respectively. Meerkötter et $a l^{20}$ compared three different radiative transfer models, varying ice water content. They 
showed that varying the optical depth of the contrails from 0.2 to 0.5 gave an RF of between 0.01 and $0.03 \mathrm{Wm}^{-2}$ for a $0.1 \%$ global mean contrail cover case. A key conclusion of the paper was that the uncertainty of the effect of contrail forcing is a factor of five, due to lack of knowledge of contrail cover and optical depth values.

Myhre $e t a l^{23}$ investigated the short wave and long wave contributions to contrail RF using an artificially high $1 \%$ contrail cover experiment, and a more realistic $0.09 \%$ cover scenario. They highlighted that while short wave radiation provided a negative RF, on balance the net RF was positive, resulting in net RF of 0.12 for both the cloudy and clear condition cases with $1 \%$ contrail cover. For the realistic cirrus cloud cover case of $0.09 \%$, the effect of including the diurnal cycle was studied. The net RF dropped from $0.011 \mathrm{Wm}^{-2}$ to $0.009 \mathrm{Wm}^{-2}$ when the diurnal cycle was included. Marquart et $a l^{18}$ performed a similar study, showing RF due to contrails rising from $0.0023 \mathrm{Wm}^{-2}$ in 1992 to $0.0148 \mathrm{Wm}^{-2}$ in 2050.

Ponater $e a^{27}$ developed a parameterised model for including contrails within the ECHAM4 GCM, relating the contrail coverage and optical properties to the state of the atmosphere at any given time. It also allowed feedback of the contrails on the net climate effect. This paper was one of the first attempts to include such a detailed contrail model in a GCM.

As discussed in Section 3.2.2, Forster et al ${ }^{11}$ investigated the use of RFI as a metric for climate change. They calculated an AGWP due to contrails, showing that it remains constant with time due to their short-lived nature and hence non-cumulative effect.

Rind $e t a l^{32}$ investigated increases in cirrus cloud coverage along aircraft flight paths using a global climate model. The global temperature response was shown to be linear for increases in high-level cloud cover from $0.5 \%$ to $5 \%$, with global surface temperature changing by between $0.1^{\circ} \mathrm{C}$ and $2.2^{\circ} \mathrm{C}$ respectively. Ponater $e t a l^{28}$ used artificially elevated traffic levels (20 x Fal inventory) and reported that a $3.2 \%$ contrail coverage produced a surface temperature increase of $0.082 \mathrm{~K}$.

Strauss et $a l^{38}$ developed a $1 \mathrm{D}$ radiative convective model and studied the effect of increased cloud cover over Southern Germany, varying the ice particle size from $2 \mu \mathrm{m}$ to $2000 \mu \mathrm{m}$. A $10 \%$ increase in cloud cover was reported to lead to a surface temperature increase of 1.1 to $1.2 \mathrm{~K}$ in July, and from 0.8 to $0.9 \mathrm{~K}$ in October. Their model of current contrail cloud cover over Europe, near $0.5 \%$, results in a surface temperature increase of $0.05 \mathrm{~K}$.

\subsubsection{Effects of ozone, $\mathrm{NO}_{\mathrm{x}}$ and aerosols from aviation on $\mathrm{RF}$, GWP and temperature}

The direct and indirect effect of aerosols, $\mathrm{NO}_{\mathrm{x}}$ and ozone on the atmosphere are studied in the 18 papers included in this section. Nitrogen oxides enhance ozone production and reduce methane concentrations. Soot and sulphur dioxide also affect the climate response, both directly and indirectly. The effect of water vapour is discussed in section 3.2.3. The key input and outcomes are presented in Table 9.

The IPCC report of Penner et al provides a breakdown of RF due to ozone, methane, sulphate aerosol and soot aerosol for the period 1990 to 2050. The values for the Fal scenario for ozone and methane for 2015 , from $\mathrm{NO}_{\mathrm{x}}$, are $0.040 \mathrm{Wm}^{-2}$ and $-0.027 \mathrm{Wm}^{-2}$ respectively. These compare with the figures from Marquart et $a l^{17}$ of $0.054 \mathrm{Wm}^{-2}$ for ozone and -0.036 $\mathrm{Wm}^{-2}$ for methane over the same period. Results from Valks et $a l^{39}$ indicate an RF due to 
ozone of between 0.019 and $0.037 \mathrm{Wm}^{-2}$ in January and July 2015. Isaksen $e$ et $a l^{15}$ predicted $\mathrm{RF}$ in 2015 due to ozone to be $0.047 \mathrm{Wm}^{-2}$, and that due to methane as $-0.032 \mathrm{Wm}^{-2}$. Ponater et $a l^{29}$ computed a global RF of between 0.0175 and $0.182 \mathrm{Wm}^{-2}$ for ozone and between -0.0082 and $-0.0856 \mathrm{Wm}^{-2}$ for methane in 2050 , indicating the significant level of variability in the simulations. These resulted in a global temperature change of between 0.0114 and $0.0764 \mathrm{~K}$ due to ozone, and between -0.0046 and $-0.039 \mathrm{~K}$ for methane. Sausen et $a l^{34}$ predicted a temperature change of between 0.010 and $0.097 \mathrm{~K}$ for 2015 due to ozone using different scaling factors. The study of Rind $e t a l^{30}$ showed decreases in stratospheric ozone and increases in tropospheric ozone in 2005. Desssens et $a l^{9}$ also looked at ozone effects using five different scenarios, with mixtures of subsonic and supersonic fleets. For the subsonic only case the ozone decrease was shown to cool the lower stratosphere by $-1.6 \mathrm{~K}$ at $22 \mathrm{~km}$ over the North Pole. Bernsten et $\mathrm{l}^{7}$ investigated tropospheric ozone and RF from 1900 to 1990 , giving a global mean RF of $0.34 \mathrm{Wm}^{-2}$ in 1990 .

Fortuin et $\mathrm{al}^{12}$ performed a global simulation up to 1990 using a radiative transfer model and showed an RF due to $\mathrm{NO}_{2}$ of $0.003 \mathrm{Wm}^{-2}$ in summer and $-0.001 \mathrm{Wm}^{-2}$ in winter. The RF due to ozone was between 0.034 and $0.135 \mathrm{Wm}^{-2}$ in summer and 0.012 to $0.046 \mathrm{Wm}^{-2}$ in winter, using a fixed temperature model assumption. Sausen $e t a l^{35}$ provided an updated estimate for 2000. Compared with IPCC results scaled to 2000, an RF due to ozone was $0.0129 \mathrm{Wm}^{-2}$, compared with $0.0289 \mathrm{Wm}^{-2}$ using IPCC data. The methane RF also differed, the new results showed $-0.0104 \mathrm{Wm}^{-2}$ versus $-0.0185 \mathrm{Wm}^{-2}$ from scaled IPCC figures.

Forster $e$ a $a l^{11}$ explored the suitability of using RFI as a metric for non- $\mathrm{CO}_{2}$ effects of aviation. Their simulations for 1 to 500 years, with no growth in aviation, showed that the net GWP due to ozone and methane changes from 2.0 to $-0.009 \times 10^{-14} \mathrm{Wm}^{-2} \mathrm{kgCO}_{2}^{-1} \mathrm{yr}$. Fuglesvedt et $a l^{13}$ showed sustained GWP due to $\mathrm{NO}_{\mathrm{x}}$ to reduce from 1576 over 20 years, to 148 over 500 years. Johnson et al ${ }^{16}$ investigated climate sensitivity to a step change of $1 \mathrm{Tg}^{-1}{ }^{-1}$ in $\mathrm{NO}_{\mathrm{x}}$ emissions. They reported an increase in RF due to ozone of $0.019594 \mathrm{Wm}^{-2}$ in 10 years, and an overall step change in GWP of 456.0 after 100 years.

Pitari $e t a l^{24}$ investigated the effect of excluding or including sulphur emissions in a climate model, showing a difference of $\mathrm{RF}$ due to $\mathrm{SO}_{4}$ from 0.00 to $-0.007 \mathrm{Wm}^{-2}$. This induced changes in RF due to ozone from 0.027 to $0.015 \mathrm{Wm}^{-2}$, although no change in RF due to methane was seen $\left(-0.008 \mathrm{Wm}^{-2}\right.$ in both cases). The effect of sulphate aerosol on RF was included in the predictions of Penner et al ${ }^{1}$, giving $-0.006 \mathrm{Wm}^{-2}$ for 2015 . This compares well to the results of Marquart et $a l^{17}$ of $-0.006 \mathrm{Wm}^{-2}$ for 2015 . The TRADEOFF estimates for sulphate aerosol RF effects in 2000 from Sausen et $a l^{35}$ showed a slight reduction from those of IPCC (Penner et al scaled to 2000, from $\quad-0.004$ to $-0.0035 \mathrm{Wm}^{-2}$. Danilin et $a l^{8}$ performed aviation tracer fuel simulations for 1992 using 11 different global atmosphere models and concluded that the upper limit for RF due to sulphates is $-0.013 \mathrm{Wm}^{-2}$. The simulations of Fortuin et $\mathrm{al}^{12}$ from 1943 to 1990 revealed an RF due to sulphate aerosol of between -0.182 and $-0.550 \mathrm{Wm}^{-2}$ for mid-latitude summer, and between -0.141 and -0.421 $\mathrm{Wm}^{-2}$ for mid-latitude winter, using a fixed temperature model assumption.

Soot can have a direct forcing effect on climate. The results of 11 global atmosphere models presented by Danilin et $a l^{8}$ for 1992 data gave an RF due to soot of $0.006 \mathrm{Wm}^{-2}$. This compares with the value from Penner et $a l^{1}$ of $0.003 \mathrm{Wm}^{-2}$ for the same period. Sausen et $a l^{35}$ estimated RF due to soot for 2000 to be $0.0025 \mathrm{Wm}^{-2}$, compared with $0.004 \mathrm{Wm}^{-2}$ from the 
IPCC data of Penner et al ${ }^{1}$ scaled to 2000. Prediction of soot RF for 2015 were $0.006 \mathrm{Wm}^{-2}$ from IPCC (Penner et $a l^{1}$ ), which compares well with the $0.006 \mathrm{Wm}^{-2}$ result of Marquart et $a l^{17}$. 
Table 4 Overall effect of aviation on RF, GWP and temperature

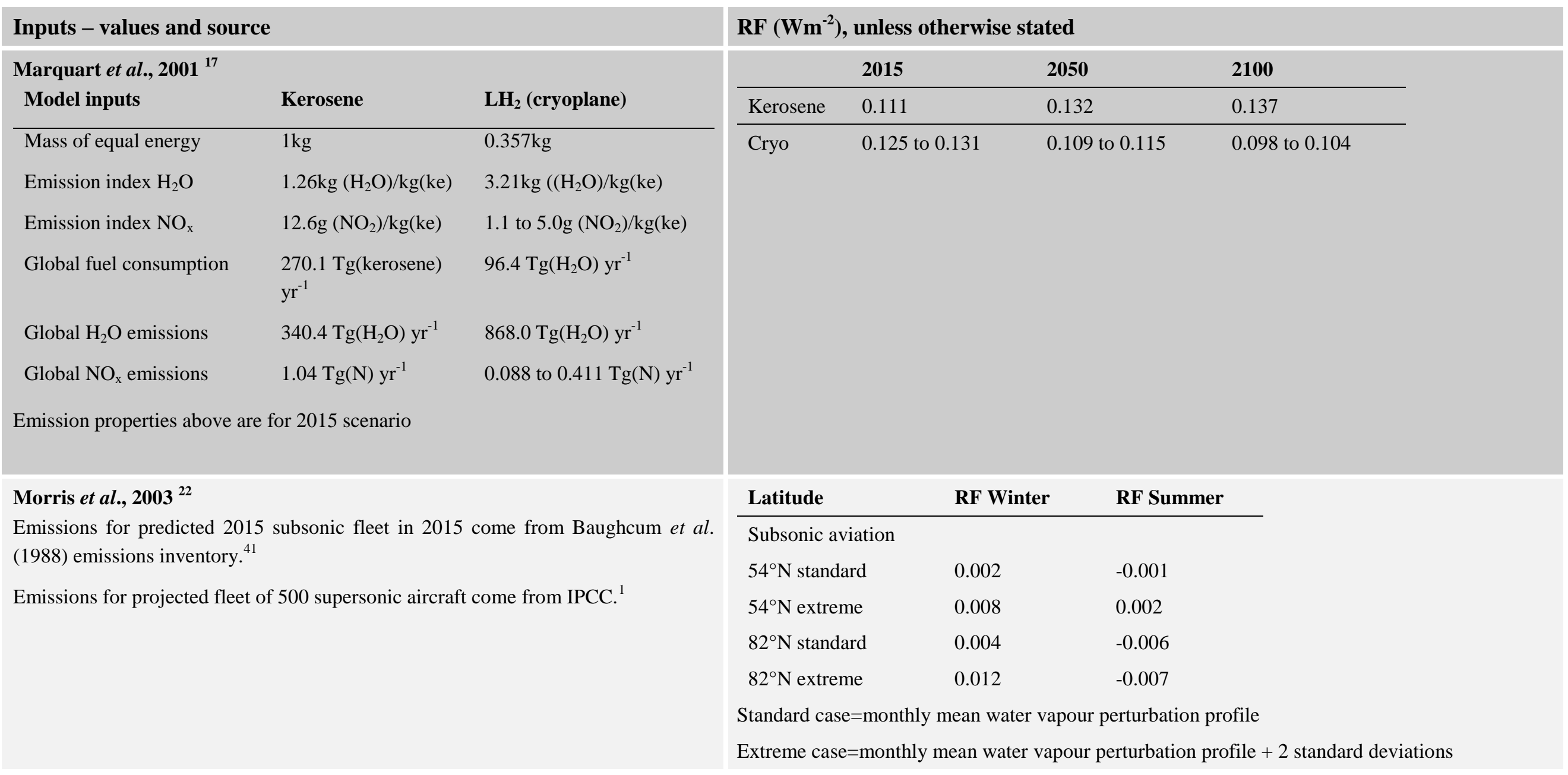




\begin{tabular}{|c|c|c|c|c|c|c|c|}
\hline \multicolumn{2}{|c|}{ Inputs - values and source } & \multicolumn{6}{|c|}{ RF $\left(\mathrm{Wm}^{-2}\right)$, unless otherwise stated } \\
\hline \multicolumn{8}{|c|}{ Penner et al. $1999^{1}$} \\
\hline Scenario & Description & Total RF & 1990 & 2000 & 2015 & 2025 & 2050 \\
\hline \multirow[t]{3}{*}{$\mathrm{Fa} 1$} & \multirow{3}{*}{$\begin{array}{l}\text { Reference scenario developed by ICAO Forecasting and Economic } \\
\text { Support Group (FESG); midrange economic growth from IPCC } \\
\text { (1992); technology for both improved fuel efficiency and NOx } \\
\text { reduction }\end{array}$} & Fa1 & 0.048 & 0.071 & 0.114 & 0.137 & 0.193 \\
\hline & & $\mathrm{Fa} 2$ & 0.048 & 0.071 & 0.114 & 0.136 & 0.192 \\
\hline & & $\mathrm{Fc} 1$ & 0.048 & 0.071 & 0.114 & 0.118 & 0.129 \\
\hline \multirow[t]{2}{*}{$\mathrm{Fa} 2$} & \multirow{2}{*}{$\begin{array}{l}\text { Fa1 traffic scenario; technology with greater emphasis on NOx } \\
\text { reduction, but slightly smaller fuel efficiency improvement }\end{array}$} & $\mathrm{Fe} 1$ & 0.048 & 0.071 & 0.114 & 0.161 & 0.280 \\
\hline & & Eab & 0.048 & 0.068 & 0.103 & 0.184 & 0.385 \\
\hline \multirow{2}{*}{$\begin{array}{l}\mathrm{Fc} 1 \\
\mathrm{Fe} 1\end{array}$} & \multirow{2}{*}{$\begin{array}{l}\text { FESG low-growth scenario; technology as for Fa1 scenario } \\
\text { FESG high-growth scenario; technology as for Fa1 scenario }\end{array}$} & Edh & 0.048 & 0.083 & 0.146 & 0.265 & 0.564 \\
\hline & & & & & & & \\
\hline Eab & $\begin{array}{l}\text { Traffic-growth scenario based on IS92a developed by } \\
\text { Environmental Defence Fund (EDF); technology for very low NOx } \\
\text { assumed }\end{array}$ & \multirow{2}{*}{$\begin{array}{l}\text { Global } \\
\text { mean } \\
\text { surface } \\
\text { temp } \\
\text { increase } \\
(\mathbf{K})\end{array}$} & 1990 & 2000 & 2015 & 2025 & 2050 \\
\hline \multirow[t]{6}{*}{ Edh } & \multirow[t]{6}{*}{$\begin{array}{l}\text { High traffic-growth EDF scenario; technology for very low NOx } \\
\text { assumed }\end{array}$} & & & & & & \\
\hline & & $\mathrm{Fa} 1$ & 0.000 & 0.004 & 0.015 & 0.024 & 0.052 \\
\hline & & $\mathrm{Fc} 1$ & 0.000 & 0.004 & 0.015 & 0.023 & 0.039 \\
\hline & & $\mathrm{Fe} 1$ & 0.000 & 0.004 & 0.015 & 0.026 & 0.070 \\
\hline & & Eab & 0.000 & 0.004 & 0.014 & 0.026 & 0.090 \\
\hline & & Edh & 0.000 & 0.005 & 0.019 & 0.038 & 0.133 \\
\hline \multirow{3}{*}{\multicolumn{2}{|c|}{$\begin{array}{l}\text { Pitari et al. } \mathbf{2 0 0 2}^{24} \\
\text { Scenario } 1 \text { includes } \mathrm{NO}_{\mathrm{x}}, \mathrm{H}_{2} \mathrm{O} \text { and hydrocarbon emissions from aircraft } \\
\text { Scenario } 2 \text { includes } \mathrm{NO}_{\mathrm{x}}, \mathrm{H}_{2} \mathrm{O} \text {, hydrocarbon and sulphur emissions from aircraft } \\
\text { No input values given }\end{array}$}} & Scenario & \multicolumn{3}{|l|}{ Net RF } & & \\
\hline & & 1 & \multirow{2}{*}{\multicolumn{2}{|c|}{$\begin{array}{l}0.018 \\
0 \text { (approximately) }\end{array}$}} & & & \\
\hline & & 2 & & & & & \\
\hline
\end{tabular}




\section{Inputs - values and source}

Ponater et al., $2006^{29}$

Ker - standard, purely kerosene aviation, calculated using IPCC inventories for 1940 to 2050 ;

cryo1 - technology transition begins in 2015, with EU taking the lead followed by North America in 2020 and S. America, Asia and Middle East in 2025. cryoplanes introduction starts with smallest planes, with long-range aircraft following about 10 years later;

cryo 2 - assumes fast transition, starting with gradual world-wide transition of small and medium-sized aircraft in 2015 and of large aircraft in 2025. Scenario results in complete switch to hydrogen fuel by 2050 ;

cryo3 - starts with world-wide transition later (2020), but proceeds as fast as cryo2 towards the end of the period.
RF $\left(\mathbf{W m}^{-2}\right)$, unless otherwise stated

Global RF [W $\left.\mathrm{m}^{-2}\right]$ for 2050

\begin{tabular}{|c|c|c|c|c|}
\hline & $\begin{array}{l}\text { Kerosene } \\
\text { (min, max) }\end{array}$ & Cryo1 & Cryo2 & Cryo3 \\
\hline Sum of global RF & $\begin{array}{l}0.128(0.1023, \\
0.1570)\end{array}$ & $\begin{array}{l}102.2 \\
184.5)\end{array}$ & $\begin{array}{l}90.4 \\
143.4)\end{array}(74.9$, & $\begin{array}{l}107.4 \text { (87.3, } \\
198.3)\end{array}$ \\
\hline
\end{tabular}

Global temp change (mK) for 2050

\begin{tabular}{lllll} 
& kerosene & Cryo1 & Cryo2 & Cryo3 \\
\hline Sum of global temp change & 0.0410 & 0.0383 & 0.0371 & 0.0390 \\
& $(0.0309$, & $(0.0290$, & $(0.0283$, & $(0.0296$, \\
& $0.0829)$ & $0.0731)$ & $0.0422)$ & $0.0755)$
\end{tabular}




\begin{tabular}{|c|c|c|c|c|c|c|c|c|c|c|c|c|}
\hline \multicolumn{2}{|c|}{ Inputs - values and source } & \multicolumn{11}{|c|}{ RF $\left(\mathbf{W m}^{-2}\right)$, unless otherwise stated } \\
\hline \multicolumn{2}{|c|}{ Sausen et al., $2000^{34}$} & \multicolumn{11}{|c|}{ Temperature change $(K)$} \\
\hline Scenario & Description & Year & $\mathbf{R}$ & Fe1 & Fa1 & Fe1 & Eab & Eah & $C_{1995}$ & $\mathrm{C}_{2015}$ & $\mathrm{C}_{2050}$ & $\mathbf{N}_{2015}$ \\
\hline \multirow[t]{2}{*}{$\mathrm{R}$} & \multirow{2}{*}{$\begin{array}{l}\text { Reference case: historical CO2 concentration until 1995, IS92a } \\
\text { thereafter (all natural and anthropogenic sources including aircraft } \\
\text { emissions). }\end{array}$} & 1950 & 0.232 & 0.000 & 0.000 & 0.000 & 0.000 & 0.000 & 0.000 & 0.000 & 0.000 & 0.000 \\
\hline & & 1970 & 0.305 & 0.001 & 0.001 & 0.001 & 0.001 & 0.001 & 0.001 & 0.001 & 0.001 & 0.001 \\
\hline \multirow[t]{3}{*}{$\mathrm{Fa} 1$} & \multirow{3}{*}{$\begin{array}{l}\text { Standard aircraft emissions scenario: historic data (IEA) until } 1995 \text {, } \\
\text { NASA for } 2015 \text {, FESGa (tech option 1) for } 2050,1 \% \text { annual } \\
\text { growth thereafter. }\end{array}$} & 1990 & 0.437 & 0.003 & 0.003 & 0.003 & 0.003 & 0.003 & 0.003 & 0.003 & 0.003 & 0.003 \\
\hline & & 1992 & 0.455 & 0.004 & 0.004 & 0.004 & 0.004 & 0.004 & 0.004 & 0.004 & 0.004 & 0.004 \\
\hline & & 1995 & 0.483 & 0.004 & 0.004 & 0.004 & 0.004 & 0.004 & 0.004 & 0.004 & 0.004 & 0.004 \\
\hline $\mathrm{Fa} 2$ & As FA1, but for tech option 2 & 2000 & 0.532 & 0.006 & 0.006 & 0.006 & 0.006 & 0.006 & 0.006 & 0.006 & 0.006 & 0.006 \\
\hline $\mathrm{Fe} 1$ & $\begin{array}{l}\text { Aircraft emissions scenario: historic data (IEA) until 1995, NASA } \\
\text { for 2015, FESGe (tech option 1) for } 2050^{*}\end{array}$ & 2015 & 0.702 & 0.010 & 0.010 & 0.010 & 0.010 & 0.011 & 0.010 & 0.010 & 0.010 & 0.010 \\
\hline \multirow[t]{2}{*}{$\mathrm{Fc} 1$} & \multirow{2}{*}{$\begin{array}{l}\text { Aircraft emissions scenario: historic data (IEA) until 1995, NASA } \\
\text { for 2015, FESGc (tech option 1) for 2050* }\end{array}$} & 2050 & 1.230 & 0.023 & 0.025 & 0.028 & 0.033 & 0.050 & 0.018 & 0.024 & 0.025 & 0.015 \\
\hline & & 2100 & 2.159 & & 0.047 & & 0.086 & 0.146 & 0.025 & 0.036 & 0.043 & 0.011 \\
\hline Eab & $\begin{array}{l}\text { Aircraft emissions scenario: historic data (IEA) until 1995, EDFa- } \\
\text { base thereafter }\end{array}$ & & & & & & & & & & & \\
\hline Eah & $\begin{array}{l}\text { Aircraft emissions scenario: historic data (IEA) until 1995, EDFa- } \\
\text { high thereafter }\end{array}$ & & & & & & & & & & & \\
\hline $\mathrm{C} \tau$ & As Fa1, but aircraft emissions constant for $\mathrm{t} \geq \tau$. & & & & & & & & & & & \\
\hline N2015 & As Fa1, but no aircraft emissions after 2015 & & & & & & & & & & & \\
\hline \multicolumn{13}{|c|}{ * These two scenarios only run until 2050; others were run until 2100} \\
\hline \multirow{2}{*}{\multicolumn{2}{|c|}{$\begin{array}{l}\text { Sausen et al., } 2005^{35} \\
\text { New estimates of FR from a number of climate models, to update IPCC } 1999 \\
\text { estimates for 2000. Scenarios: } 1992 \text { data scaled to 2000; IPCC } 1999 \text { data scaled to } \\
\text { 2000; } 2000 \text { (TRADEOFF). }\end{array}$}} & & & & \multicolumn{2}{|c|}{$\begin{array}{c}1992 \\
(\text { IPCC, 1999) }\end{array}$} & \multicolumn{4}{|c|}{2000} & \multicolumn{2}{|c|}{$\begin{array}{l}2000 \\
\text { TRADEOFF }\end{array}$} \\
\hline & & \multicolumn{3}{|c|}{$\begin{array}{l}\text { Total } \mathrm{RF}\left(\mathrm{Wm}^{-2}\right) \\
\text { w/o cirrus }\end{array}$} & \multicolumn{2}{|c|}{0.0485} & \multicolumn{4}{|c|}{0.0713} & \multicolumn{2}{|c|}{0.0478} \\
\hline
\end{tabular}


Table 5 Effect of aviation's $\mathrm{CO}_{2}$ on RF, GWP and temperature

Inputs - values and source

Forster et al., $2006^{11}$

Inputs assume an exponential increase in aviation emissions since 1950 to year 2000 of 150

TgC Growth follows the SRES A1B scenario (IPCC, 2000)
RF $\left(\mathbf{W m}^{-2}\right)$, unless otherwise stated

Time horizon (2000 start), Absolute global warming potential due to years

1

20 0.5

2.65

100

9.15

500

\section{Fortuin et al., $1995^{12}$}

Aircraft-induced $\mathrm{CO}_{2}$ enhancement from 1943 to 1990

Lower estimate: $+1.25 \mathrm{ppmv}$

Upper estimate: +1.55 ppmv

\begin{tabular}{lllll} 
& \multicolumn{2}{l}{ Mid-latitude summer } & \multicolumn{2}{l}{ Mid-latitude winter } \\
\hline RF due to $\mathrm{CO}_{2}$ & Fixed temp & $\begin{array}{l}\text { Fixed dynamical } \\
\text { heating }\end{array}$ & Fixed temp & $\begin{array}{l}\text { Fixed dynamical } \\
\text { heating }\end{array}$ \\
\hline Lower estimate & 0.023 & 0.023 & 0.019 & 0.023 \\
Upper estimate & 0.029 & 0.028 & 0.018 & 0.022
\end{tabular}

Johnson et al., $1996^{16}$

Aircraft $\mathrm{CO}_{2}$ emissions $500 \mathrm{Tg} \mathrm{yr}^{-1}$

Response to a $1 \mathrm{Tg} \mathrm{yr}^{-1}$ step-change in aircraft $\mathrm{NO}_{\mathrm{x}}$ emissions After 100 years

Overall step change GWP from aircraft $\mathrm{CO}_{2}$ 
Inputs - values and source

\section{Marquart et al., $2001^{17}$}

\section{Model inputs}

Mass of equal energy

Emission index $\mathrm{H}_{2} \mathrm{O}$

Emission index $\mathrm{NO}_{\mathrm{x}}$

Global fuel consumption

Global $\mathrm{H}_{2} \mathrm{O}$ emissions

Global $\mathrm{NO}_{\mathrm{x}}$ emissions

Kerosene

$\mathrm{LH}_{2}$ (cryoplane)

Emission properties above are for 2015 scenario

\section{Penner et al. 1999}

\section{Scenario}

\section{Description}

Fal

Reference scenario developed by ICAO Forecasting and Economic Support Group (FESG); midrange economic growth from IPCC (1992); technology for both improved fuel efficiency and NOx reduction
RF $\left(\mathbf{W m}^{-2}\right)$, unless otherwise stated

Total aircraft-induced RF due to $\mathrm{CO}_{2}$

\begin{tabular}{llll} 
& $\mathbf{2 0 1 5}$ & $\mathbf{2 0 5 0}$ & $\mathbf{2 1 0 0}$ \\
\hline Kerosene & 0.041 & 0.061 & 0.066 \\
cryoplane & 0.041 & 0.025 & 0.014
\end{tabular}

\begin{tabular}{llllll} 
RF due to $\mathrm{CO}_{\mathbf{2}}$ & $\mathbf{1 9 9 0}$ & $\mathbf{2 0 0 0}$ & $\mathbf{2 0 1 5}$ & $\mathbf{2 0 2 5}$ & $\mathbf{2 0 5 0}$ \\
\hline $\mathrm{Fa} 1$ & 0.016 & 0.025 & 0.038 & 0.048 & 0.074
\end{tabular}




\section{Inputs - values and source}

Ponater et al., $2006{ }^{29}$

Ker - standard, purely kerosene aviation, calculated using IPCC inventories for 1940 to 2050;

cryo1 - technology transition begins in 2015, with EU taking the lead followed by North America in 2020 and S. America, Asia and Middle East in 2025. cryoplanes introduction starts with smallest planes, with long-range aircraft following about 10 years later;

cryo 2 - assumes fast transition, starting with gradual world-wide transition of small and medium-sized aircraft in 2015 and of large aircraft in 2025. Scenario results in complete switch to hydrogen fuel by 2050 ;

cryo3 - starts with world-wide transition later (2020), but proceeds as fast as cryo 2 towards the end of the period.

\section{Sausen et al., $2005^{35}$}

New estimates of RF from a number of climate models, to update IPCC 1999 estimates for 2000. Scenarios: 1992 data scaled to 2000; IPCC 1999 data scaled to 2000; 2000 (TRADEOFF)

\section{Sausen et al., $2000^{34}$}

Fa1: standard aircraft emissions scenario: historic data (IEA) until 1995, NASA for 2015 ,

FESGa (tech option 1) for 2050, 1\% annual growth thereafter.
RF $\left(\mathbf{W m}^{-2}\right)$, unless otherwise stated

\begin{tabular}{|c|c|c|c|c|}
\hline $\begin{array}{l}\text { Global RF }\left[\mathrm{W} \mathrm{m}^{-2}\right] \text { for } 2050 \\
\text { caused by: }\end{array}$ & ker & Cryo1 & Cryo2 & Cryo3 \\
\hline $\mathrm{CO}_{2}$ & 0.0729 & 0.0610 & 0.0563 & 0.0641 \\
\hline $\begin{array}{l}\text { Global temp change }(K) \text { for } \\
2050 \text { caused by: }\end{array}$ & ker & Cryo1 & Cryo2 & Cryo3 \\
\hline $\mathrm{CO}_{2}$ & 0.0206 & 0.0196 & 0.0192 & 0.0200 \\
\hline
\end{tabular}

\begin{tabular}{llll}
$\begin{array}{l}\text { RF }\left(\mathrm{Wm}^{-2}\right) \\
\text { due to: }\end{array}$ & $\begin{array}{l}\text { 1992 }(\text { IPCC, } \\
\mathbf{1 9 9 9})\end{array}$ & $\begin{array}{l}\mathbf{2 0 0 0}(\text { IPCC, } \\
\mathbf{1 9 9 9} \text { scaled to } \\
\mathbf{2 0 0 0})\end{array}$ & 2000 TRADEOFF \\
\hline $\mathrm{CO}_{2}$ & 0.0180 & 0.0250 & 0.0253
\end{tabular}

Year Temperature change (K) since $1800 \quad \mathrm{RF}$ due to $\mathrm{CO}_{2}$ for scenario $\mathrm{Fa} 1$ due to $\mathrm{CO}_{2}$ for scenario $\mathrm{Fa} 1$

\begin{tabular}{lll}
\hline 1990 & 0.003 & 0.021 \\
1995 & 0.004 & 0.024 \\
2000 & 0.006 & 0.029 \\
2015 & 0.010 & 0.046 \\
2050 & 0.024 & 0.068 \\
2100 & 0.047 & 0.082
\end{tabular}


Table 6 Effect of aviation's $\mathrm{H}_{2} \mathrm{O}$ on RF, GWP and temperature

\section{Study and inputs}

Fortuin et al., $1995^{12}$

Aircraft-induced contrail enhancement from 1943 to 1990: 0.5\% cloudiness Aircraft-induced enhancement from 1943 to 1990 due to water vapour

Lower estimate: +0.076 ppmv

Upper estimate: +0.380 ppmv
RF $\left(\mathrm{Wm}^{-2}\right)$, unless otherwise stated

Mid-latitude summer Mid-latitude winter

\begin{tabular}{lllll}
$\begin{array}{l}\text { RF due } \\
\text { water } \\
\text { vapour }\end{array}$ & $\begin{array}{l}\text { Fixed } \\
\text { temperature }\end{array}$ & $\begin{array}{l}\text { Fixed } \\
\text { dynamical } \\
\text { heating }\end{array}$ & $\begin{array}{l}\text { Fixed } \\
\text { temperature }\end{array}$ & $\begin{array}{l}\text { Fixed } \\
\text { dynamical } \\
\text { heating }\end{array}$ \\
\hline $\begin{array}{l}\text { Lower } \\
\text { estimate }\end{array}$ & 0.010 & 0.006 & 0.052 & 0.028 \\
$\begin{array}{l}\text { Upper } \\
\text { estimate }\end{array}$ & 0.048 & 0.023 & 0.241 & 0.131
\end{tabular}




\begin{tabular}{|c|c|}
\hline \multicolumn{2}{|c|}{ Study and inputs } \\
\hline \multicolumn{2}{|c|}{ Gauss et al. $2003^{14}$} \\
\hline \multicolumn{2}{|c|}{$\begin{array}{l}\text { Water vapour from ECMWF meteorological data; fuel consumption estimates from NASA } \\
2015 \text { inventories. }\end{array}$} \\
\hline Model run & Description \\
\hline $\mathrm{H}_{2} \mathrm{O}-\mathrm{C} 1$ & $\begin{array}{l}\text { Water vapour emitted by subsonic aircraft is at a lifetime of } 5 \text { days below } \\
\text { the } 400 \text {-hPa surface. Above } 400 \mathrm{hPa} \text {, no loss mechanisms are applied apart } \\
\text { from transport. }\end{array}$ \\
\hline $\mathrm{H}_{2} \mathrm{O}-\mathrm{C} 2$ & $\begin{array}{l}\text { Reference case. Estimates tropospheric lifetime of aircraft-emitted water } \\
\text { vapour based on meteorological data from ECMWF for } 1997 .\end{array}$ \\
\hline $\mathrm{H}_{2} \mathrm{O}-\mathrm{C}^{+1}$ & As $\mathrm{H}_{2} \mathrm{O}-\mathrm{C} 2$, but cruising altitude of subsonic cryoplanes enhanced by $1 \mathrm{~km}$. \\
\hline $\mathrm{H}_{2} \mathrm{O}-\mathrm{C}^{+2}$ & As $\mathrm{H}_{2} \mathrm{O}-\mathrm{C} 2$, but cruising altitude of subsonic cryoplanes enhanced by $2 \mathrm{~km}$. \\
\hline $\mathrm{H}_{2} \mathrm{O}-\mathrm{C}^{+3}$ & As $\mathrm{H}_{2} \mathrm{O}-\mathrm{C} 2$, but cruising altitude of subsonic cryoplanes enhanced by $3 \mathrm{~km}$. \\
\hline $\mathrm{H}_{2} \mathrm{O}-\mathrm{C} 3$ & $\begin{array}{l}\text { Troposphere lifetime of } 8.75 \text { days is applied up to the tropopause level } \\
\text { defined by NCEP reanalysis data instead of the CTM } 2 \text { tropopause. }\end{array}$ \\
\hline $\mathrm{H}_{2} \mathrm{O}-\mathrm{C} 4$ & $\begin{array}{l}\text { Deals with sensitivity to lifetime of aircraft emitted water vapour in the } \\
\text { troposphere - set here to be } 2 \text { days below the CTM } 2 \text { tropopause. } N b \\
\text { sensitivity analysis rather than realistic simulation }\end{array}$ \\
\hline $\mathrm{H}_{2} \mathrm{O}-\mathrm{C} 5$ & Estimates the significance of freezing and sedimentation of ice crystals. \\
\hline $\mathrm{H}_{2} \mathrm{O}-\mathrm{C} 6$ & $\begin{array}{l}\text { Half of entire water vapour perturbation removed instantaneously if } \\
\text { temperature below ice frost point. }\end{array}$ \\
\hline $\mathrm{H}_{2} \mathrm{O}-\mathrm{K} 1$ & Assesses the impact of subsonic kerosene aircraft \\
\hline $\mathrm{H}_{2} \mathrm{O}-\mathrm{K} 2$ & Assesses the impact of both subsonic and supersonic kerosene aircraft \\
\hline
\end{tabular}

$\mathbf{R F}\left(\mathbf{W m}^{-2}\right)$, unless otherwise stated

Model Mean globally averaged RF at the tropopause

run

$\mathrm{H}_{2} \mathrm{O}-\mathrm{C} 1 \quad 0.0098(0.0036)$

$\mathrm{H}_{2} \mathrm{O}-\mathrm{C} 2 \quad 0.0065(0.0020)$

$\mathrm{H}_{2} \mathrm{O}-\mathrm{C} 2^{+1} \quad 0.0139(0.0033)$

$\mathrm{H}_{2} \mathrm{O}-\mathrm{C} 2^{+2} \quad 0.0297(0.0052)$

$\mathrm{H}_{2} \mathrm{O}-\mathrm{C} 2^{+3} \quad 0.0625(0.0077)$

$\mathrm{H}_{2} \mathrm{O}-\mathrm{C} 3 \quad 0.0058(0.0020)$

$\mathrm{H}_{2} \mathrm{O}-\mathrm{C} 4 \quad 0.0043(0.0010)$

$\mathrm{H}_{2} \mathrm{O}-\mathrm{C} 5 \quad 0.0062(0.0020)$

$\mathrm{H}_{2} \mathrm{O}-\mathrm{C} 6 \quad 0.0058(0.0018)$

$\mathrm{H}_{2} \mathrm{O}-\mathrm{K} 1 \quad 0.0026(0.0008)$

$\mathrm{H}_{2} \mathrm{O}-\mathrm{K} 2 \quad 0.0495(0.0003)$

Values in parentheses are the global averaged RF at the top of the atmosphere 
Study and inputs

\begin{tabular}{lll}
$\begin{array}{l}\text { Marquart } \text { et al., 2001 } \\
\text { Model inputs }\end{array}$ & Kerosene & LH2 (cryoplane) \\
\hline Mass of equal energy & $1 \mathrm{~kg}$ & $0.357 \mathrm{~kg}$ \\
Emission index $\mathrm{H}_{2} \mathrm{O}$ & $1.26 \mathrm{~kg}\left(\mathrm{H}_{2} \mathrm{O}\right) / \mathrm{kg}(\mathrm{ke})$ & $3.21 \mathrm{~kg}\left(\left(\mathrm{H}_{2} \mathrm{O}\right) / \mathrm{kg}(\mathrm{ke})\right.$ \\
Emission index $\mathrm{NO}_{\mathrm{x}}$ & $12.6 \mathrm{~g}\left(\mathrm{NO}_{2}\right) / \mathrm{kg}(\mathrm{ke})$ & 1.1 to $5.0 \mathrm{~g}\left(\mathrm{NO}_{2}\right) / \mathrm{kg}(\mathrm{ke})$ \\
Global fuel consumption & $270.1 \mathrm{Tg}\left(\mathrm{kerosene} \mathrm{yr}^{-1}\right.$ & $96.4 \mathrm{Tg}\left(\mathrm{H}_{2} \mathrm{O}\right) \mathrm{yr}^{-1}$ \\
Global $\mathrm{H}_{2} \mathrm{O}$ emissions & $340.4 \mathrm{Tg}\left(\mathrm{H}_{2} \mathrm{O}\right) \mathrm{yr}^{-1}$ & $868.0 \mathrm{Tg}\left(\mathrm{H}_{2} \mathrm{O}\right) \mathrm{yr}^{-1}$ \\
Global $\mathrm{NO}_{\mathrm{x}}$ emissions & $1.04 \mathrm{Tg}(\mathrm{N}) \mathrm{yr}^{-1}$ & 0.088 to $\left.0.411 \mathrm{Tg}^{-1}\right) \mathrm{yr}^{-1}$
\end{tabular}

Emission properties above are for 2015 scenario

\section{Penner et al. $1999^{1}$}

Fa1: reference scenario developed by ICAO Forecasting and Economic Support Group (FESG); mid-range economic growth from IPCC (1992); technology for both improved fuel efficiency and $\mathrm{NO}_{\mathrm{x}}$ reduction

\section{Ponater et al., $2006^{29}$}

Ker - standard, purely kerosene aviation, calculated using IPCC inventories for 1940 to 2050

cryo1 - technology transition begins in 2015, with EU taking the lead followed by North America in 2020 and S. America, Asia and Middle East in 2025. cryoplanes introduction starts with smallest planes, with long-range aircraft following about 10 years later;

cryo 2 - assumes fast transition, starting with gradual world-wide transition of small and medium-sized aircraft in 2015 and of large aircraft in 2025. Scenario results in complete switch to hydrogen fuel by 2050 ;

cryo3 - starts with world-wide transition later (2020), but proceeds as fast as cryo 2 towards the end of the period.

\section{RF $\left(\mathbf{W m}^{-2}\right)$, unless otherwise stated}

\begin{tabular}{l|l|l}
$\begin{array}{l}\text { Aircraft induced change } \\
\text { in RF due to: }\end{array}$ & $\mathbf{2 0 1 5}$ kerosene & $\mathbf{2 0 1 5}$ cryoplane \\
\hline $\mathrm{H}_{2} \mathrm{O}$ & 0.0008 & 0.0019
\end{tabular}

Results for 2050 and 2100 were identical to those for 2015 for these outcome measures.

\section{RF due to $\mathrm{H}_{2} \mathrm{O}$}

\begin{tabular}{lllll}
$\mathbf{1 9 9 0}$ & $\mathbf{2 0 0 0}$ & $\mathbf{2 0 1 5}$ & $\mathbf{2 0 2 5}$ & $\mathbf{2 0 5 0}$ \\
\hline 0.002 & 0.002 & 0.003 & 0.003 & 0.004
\end{tabular}

\section{Global RF [W $\mathrm{m}^{-2}$ ] for 2050 caused $\mathrm{byH}_{2} \mathrm{O}$}

\begin{tabular}{lllllll} 
ker & Cryo1 & & Cryo2 & \multicolumn{3}{c}{ Cryo3 } \\
\hline $0.0019(0.0010$, & 0.0038 & $(0.0020$, & 0.0048 & $(0.0025$, & 0.0035 & $(0.0018$, \\
$0.0042)$ & $0.0085)$ & & $0.0107)$ & & $0.0078)$ &
\end{tabular}

\section{Global temp change (K) for 2050 caused by $\mathrm{H}_{2} \mathrm{O}$}

$\begin{array}{llll}\text { ker } & \text { Cryo1 } & \text { Cryo2 } & \text { Cryo3 }\end{array}$

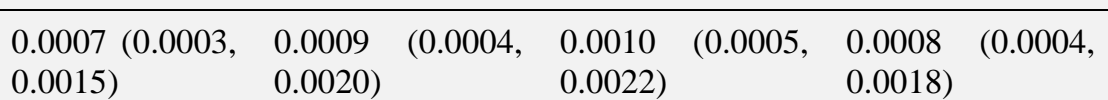




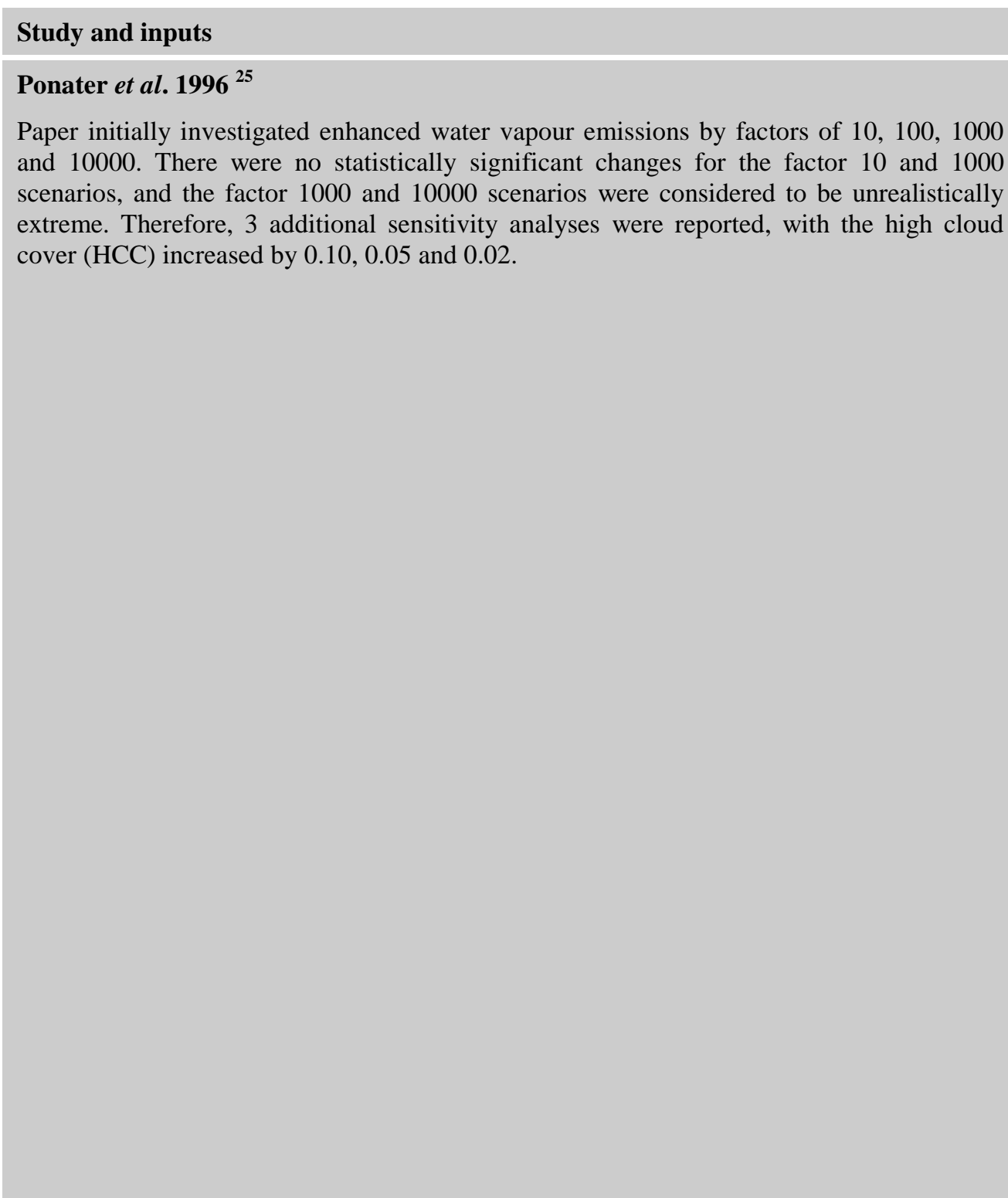

$\mathbf{R F}\left(\mathbf{W m}^{-2}\right)$, unless otherwise stated

\begin{tabular}{|c|c|c|c|c|}
\hline $\begin{array}{l}\text { Global radiation } \\
\left(\mathbf{W m}^{-2}\right) \text { JULY }\end{array}$ & $\begin{array}{l}\text { Control } \\
\text { experiment }\end{array}$ & $\begin{array}{l}\text { Response } \\
\text { to } \quad+0.10 \\
\text { increase in } \\
\text { HCC }\end{array}$ & $\begin{array}{l}\text { Response } \\
\text { to } \quad+0.05 \\
\text { increase in } \\
\text { HCC }\end{array}$ & $\begin{array}{l}\text { Response } \\
\text { to } \quad+0.02 \\
\text { increase in } \\
\text { HCC }\end{array}$ \\
\hline Top solar radiation & $233.6 \pm 0.5$ & -2.3 & $\mathrm{n} / \mathrm{s}$ & $\mathrm{n} / \mathrm{s}$ \\
\hline $\begin{array}{l}\text { Top thermal } \\
\text { radiation }\end{array}$ & $-236.9 \pm 0.5$ & +1.3 & +0.7 & $\mathrm{n} / \mathrm{s}$ \\
\hline Top net radiation & $-3.4 \pm 0.6$ & -1.0 & $\mathrm{n} / \mathrm{s}$ & $\mathrm{n} / \mathrm{s}$ \\
\hline $\begin{array}{l}\text { Atmospheric solar } \\
\text { radiation }\end{array}$ & $65.7 \pm 0.2$ & $\mathrm{n} / \mathrm{s}$ & $\mathrm{n} / \mathrm{s}$ & $\mathrm{n} / \mathrm{s}$ \\
\hline $\begin{array}{l}\text { Atmospheric thermal } \\
\text { radiation }\end{array}$ & $-166.8 \pm 0.6$ & $\mathrm{n} / \mathrm{s}$ & $\mathrm{n} / \mathrm{s}$ & $\mathrm{n} / \mathrm{s}$ \\
\hline $\begin{array}{l}\text { Atmospheric net } \\
\text { radiation }\end{array}$ & $-101.1 \pm 0.5$ & $\mathrm{n} / \mathrm{s}$ & $\mathrm{n} / \mathrm{s}$ & $\mathrm{n} / \mathrm{s}$ \\
\hline $\begin{array}{l}\text { Global radiation } \\
\left(\mathbf{W m}^{-2}\right) \text { JANUARY }\end{array}$ & $\begin{array}{l}\text { Control } \\
\text { experiment }\end{array}$ & $\begin{array}{l}\text { Response } \\
\text { to }+0.10 \\
\text { increase in } \\
\text { HCC }\end{array}$ & $\begin{array}{l}\text { Response } \\
\text { to }+0.05 \\
\text { increase in } \\
\text { HCC }\end{array}$ & $\begin{array}{l}\text { Response } \\
\text { to }+0.02 \\
\text { increase in } \\
\text { HCC }\end{array}$ \\
\hline Top solar radiation & $243.0 \pm 0.8$ & $\mathrm{n} / \mathrm{s}$ & $\mathrm{n} / \mathrm{s}$ & $\mathrm{n} / \mathrm{s}$ \\
\hline $\begin{array}{l}\text { Top thermal } \\
\text { radiation }\end{array}$ & $-227.6 \pm 0.6$ & +1.3 & $\mathrm{n} / \mathrm{s}$ & $\mathrm{n} / \mathrm{s}$ \\
\hline Top net radiation & $15.4 \pm 0.5$ & $\mathrm{n} / \mathrm{s}$ & $\mathrm{n} / \mathrm{s}$ & $\mathrm{n} / \mathrm{s}$ \\
\hline $\begin{array}{l}\text { Atmospheric solar } \\
\text { radiation }\end{array}$ & $72.5 \pm 0.2$ & $\mathrm{n} / \mathrm{s}$ & $\mathrm{n} / \mathrm{s}$ & $\mathrm{n} / \mathrm{s}$ \\
\hline $\begin{array}{l}\text { Atmospheric thermal } \\
\text { radiation }\end{array}$ & $-166.8 \pm 0.5$ & $\mathrm{n} / \mathrm{s}$ & $\mathrm{n} / \mathrm{s}$ & $\mathrm{n} / \mathrm{s}$ \\
\hline $\begin{array}{l}\text { Atmospheric net } \\
\text { radiation }\end{array}$ & $-94.2 \pm 0.6$ & $\mathrm{n} / \mathrm{s}$ & $\mathrm{n} / \mathrm{s}$ & $\mathrm{n} / \mathrm{s}$ \\
\hline
\end{tabular}




\section{RF $\left(\mathbf{W m}^{-2}\right)$, unless otherwise stated}

\section{Ponater et al., $2005^{28}$}

Model of climate sensitivity parameter to contrail cirrus, using ECHAM4 global climate model with amendments for contrails and with a mixed layer ocean model.

Model results (single scenario)

Cirrus change (contrail coverage) $3.2 \%$

Net RF $0.19 \mathrm{Wm}^{-2}(0.29)^{*}$

Surface temperature response, $0.082 \mathrm{~K}$

* value in parenthesis indicates a $25 \%$ increase in longwave RF for consistency with work by Marquart et al. $(2003)^{18}$

The global climate sensitivity parameter to contrail cirrus was $0.43 \mathrm{~K}\left(\mathrm{Wm}^{-2}\right)^{-1}$

\begin{tabular}{ll}
$\begin{array}{l}\text { Rind } \text { et al., } \\
\text { Scenario }\end{array} \mathbf{~}^{\mathbf{3 1}}$ & Water vapour input \\
\hline 1 & $1.17 \times 10^{14} \mathrm{~kg} \mathrm{yr}^{-1}$ \\
2 & $5.85 \times 10^{12} \mathrm{~kg} \mathrm{yr}^{-1}$ \\
3 & $5.85 \times 10^{11} \mathrm{~kg} \mathrm{yr}^{-1}$ \\
4 & $5.85 \times 10^{10} \mathrm{~kg} \mathrm{yr}^{-1}$ \\
Background water mass for control run with no aircraft emissions is $1.6 \times 10^{16} \mathrm{~kg} ;$ \\
background water vapour mass at $12 \mathrm{~km}$ is approximately $1.2 \times 10^{14} \mathrm{~kg}$.
\end{tabular}

\begin{tabular}{|c|c|c|c|c|c|}
\hline & & $\begin{array}{l}\text { Change } \\
\text { run }\end{array}$ & e con & ared $w$ & ith control \\
\hline & Control & 1 & 2 & 3 & 4 \\
\hline Surface air temperature, ${ }^{\circ} \mathrm{C}$ & 13.46 & 1.03 & 0.24 & -0.07 & 0.07 \\
\hline Vertically integrated temperature, ${ }^{\circ} \mathrm{C}$ & -23.0 & 1.26 & 0.29 & -0.07 & 0.08 \\
\hline
\end{tabular}

\section{Sausen et al., $2005^{35}$}

\section{RF $\left(\mathrm{Wm}^{-2}\right)$ due $\mathrm{H}_{2} \mathrm{O}$}

New estimates of FR from a number of climate models, to update IPCC 1999 estimates for 2000. Scenarios: 1992 data scaled to 2000; IPCC 1999 data scaled to 2000; 2000 (TRADEOFF).

1992 (IPCC, 1999)

0.0015

2000 (IPCC, 1999 scaled to 2000$)$

0.0020
2000 TRADEOFF

0.0020 
Table 7 Effect of contrails on RF, GWP and temperature

\section{Study and inputs}

Fichter et al. 2005

DLR-2 database and TRADEOFF emissions scenarios for different cruising altitudes

\begin{tabular}{ll} 
Scenario & Distan \\
\hline DLR2 & 18.0 \\
TRADEOFF basecase & 2.9 \\
TRADEOFF+2kft & 3.1 \\
TRADEOFF-2kft & 2.5 \\
TRADEOFF-4kft & 2.0 \\
TRADEOFF-6kft & 1.6
\end{tabular}

$\mathrm{Kft}=1000$ feet

\section{Forster et al., $2006^{11}$}

Inputs assume an exponential increase in aviation emissions since 1950 to year 2000 of 150 TgC Growth follows the SRES A1B scenario (IPCC, 2000)

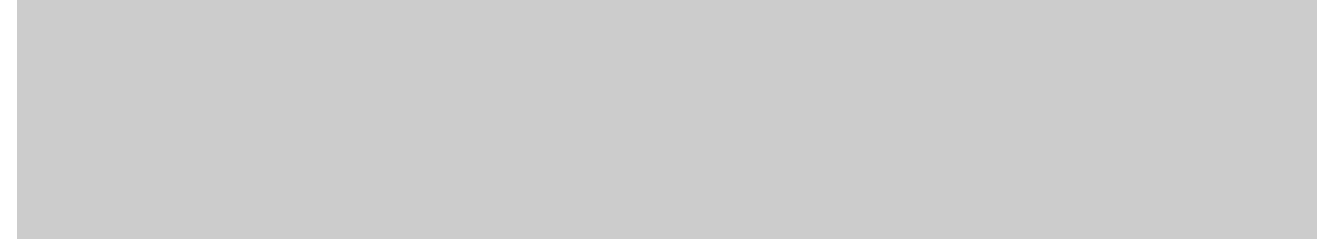

\section{Fortuin et al., $1995^{12}$}

Aircraft-induced contrail enhancement from 1943 to 1990: 0.5\% cloudiness

Aircraft-induced enhancement from 1943 to 1990 due to water vapour

Lower estimate: +0.076 ppmv

Upper estimate: +0.380 ppmv
$\mathbf{R F}\left(\mathbf{W m}^{-2}\right)$, unless otherwise stated

\begin{tabular}{ll} 
Scenario & $\begin{array}{l}\text { Mean net RF by contrail forcing, based on distance travelled. } \\
\text { Values in parenthesis represent best estimate for contrail RF }\end{array}$ \\
\hline DLR2 & $2.1(3.2)$ \\
$\begin{array}{l}\text { TRADEOFF } \\
\text { basecase }\end{array}$ & $1.9(2.9)$ \\
TRADEOFF+2kft & $2.0(3.1)$ \\
TRADEOFF-2kft & $1.6(2.5)$ \\
TRADEOFF-4kft & $1.3(2.0)$ \\
TRADEOFF-6kft & $1.0(1.6)$
\end{tabular}

Time horizon (2000 start), Absolute global warming potential due to years contrails $\left[10^{-14} \mathrm{~W} \mathrm{~m}^{-2} \mathrm{~kg} \mathrm{CO}_{2}^{-1} \mathrm{yr}\right]$

$\begin{array}{ll}1 & 6.7 \\ 20 & 6.7 \\ 100 & 6.7 \\ 500 & 6.7\end{array}$

\begin{tabular}{|c|c|c|}
\hline $\begin{array}{l}\text { RF due } \\
\text { contrails }\end{array}$ & $\begin{array}{l}\text { Mid-latitude } \\
\text { summer }\end{array}$ & $\begin{array}{l}\text { Mid-latitude } \\
\text { winter }\end{array}$ \\
\hline Lower estimate & -0.15 & 0.05 \\
\hline Upper estimate & 0.3 & 0.3 \\
\hline
\end{tabular}

Minimal and maximum forcing for an effective crystal radius. Fixed temperature model used 


\begin{tabular}{|c|c|c|}
\hline \multicolumn{3}{|l|}{ Study and inputs } \\
\hline \multicolumn{3}{|l|}{ Marquart et al., $2001{ }^{17}$} \\
\hline Model inputs & Kerosene & $\mathbf{L H}_{2}$ (cryoplane) \\
\hline Mass of equal energy & $1 \mathrm{~kg}$ & $0.357 \mathrm{~kg}$ \\
\hline Emission index $\mathrm{H}_{2} \mathrm{O}$ & $1.26 \mathrm{~kg}\left(\mathrm{H}_{2} \mathrm{O}\right) / \mathrm{kg}(\mathrm{ke})$ & $3.21 \mathrm{~kg}\left(\left(\mathrm{H}_{2} \mathrm{O}\right) / \mathrm{kg}(\mathrm{ke})\right.$ \\
\hline Emission index $\mathrm{NO}_{\mathrm{x}}$ & $12.6 \mathrm{~g}\left(\mathrm{NO}_{2}\right) / \mathrm{kg}(\mathrm{ke})$ & 1.1 to $5.0 \mathrm{~g}\left(\mathrm{NO}_{2}\right) / \mathrm{kg}(\mathrm{ke})$ \\
\hline Global fuel consumption & $270.1 \mathrm{Tg}($ kerosene $) \mathrm{yr}^{-1}$ & $96.4 \mathrm{Tg}\left(\mathrm{H}_{2} \mathrm{O}\right) \mathrm{yr}^{-1}$ \\
\hline Global $\mathrm{H}_{2} \mathrm{O}$ emissions & $340.4 \mathrm{Tg}\left(\mathrm{H}_{2} \mathrm{O}\right) \mathrm{yr}^{-1}$ & $868.0 \mathrm{Tg}\left(\mathrm{H}_{2} \mathrm{O}\right) \mathrm{yr}^{-1}$ \\
\hline Global $\mathrm{NO}_{\mathrm{x}}$ emissions & $1.04 \mathrm{Tg}(\mathrm{N}) \mathrm{yr}^{-1}$ & 0.088 to $0.411 \mathrm{Tg}(\mathrm{N}) \mathrm{yr}^{-1}$ \\
\hline
\end{tabular}

\section{RF $\left(\mathbf{W m}^{-2}\right)$, unless otherwise stated}

Aircraft induced change in RF due to contrails

\begin{tabular}{ll}
$\begin{array}{l}2015 \\
\text { kerosene }\end{array}$ & $\mathbf{2 0 1 5}$ cryoplane \\
\hline 0.052 & 0.081
\end{tabular}

Results for 2050 and 2100 were identical to those for 2015 for these outcome measures.

\section{Marquart et al., $2003{ }^{18}$}

Parameterization of contrail formation for the ECHAM GCM. Fuel consumption data for 1992 and 2015 from DLR and Schmitt and Brunner 3D inventories ${ }^{42}$. Fuel consumption data for 2050 from NASA inventory (FESGa), Baughcum et al. $1998^{41}$ and Penner et al. (1999) ${ }^{1}$.

\begin{tabular}{llll}
$\mathbf{R F}$ & $\mathbf{1 9 9 2}$ & $\mathbf{2 0 1 5}$ & $\mathbf{2 0 5 0}$ \\
\hline Longwave & 0.0037 & 0.0098 & 0.0155 \\
& $(0.0049)$ & $(0.0131)$ & $(0.0207)$ \\
Short wave & -0.0014 & -0.0037 & -0.0059 \\
net & 0.0023 & 0.0061 & 0.0096 \\
& $(0.0035)$ & $(0.0094)$ & $(0.0148)$
\end{tabular}

Values in parentheses are adjusted by a $25 \%$ offset to the longwave contrail radiative forcing.

Other results presented in paper, but only most likely scenarios included here (i.e. best estimate for propulsion efficiency increases, and model including climate change). 


\section{Study and inputs}

\section{Marquart et al., $2005{ }^{19}$}

Model simulations assume contrail formation at $11 \mathrm{~km}(247 \mathrm{hPa})$ altitude. Fuel consumption figures for 2015 are from DLR 3D inventory; those for 2050 are from NASA scenario FESGa.

\section{Meerkötter et al. $1999^{20}$}

\section{Inputs for the reference case:}

\begin{tabular}{ll}
\hline Ice water content & $21 \mathrm{mg} \mathrm{m}^{-3}$ \\
Ice water path & $4.4 \mathrm{~g} \mathrm{~m}^{-2}$ \\
Optical depth & 0.52
\end{tabular}

\section{Minnis et al., $1999^{21}$}

Global distribution of contrail cover computed for present meteorological conditions, a 1992 traffic database and an air traffic scenario of 2050. Contrail formation depends on the propulsion efficiency of the aircraft, assumed to be 0.3 for 1992 and for 2050. In the 2050 scenario, total aviation fuel consumption increases 3.2-fold compared to 1992 (4.4 for 500 $\mathrm{hPa}$ ). Contrail cover expected to increase by a factor of 5 over present values.

RF $\left(\mathbf{W m}^{-2}\right)$, unless otherwise stated

\section{Global mean net RF}

Contrail properties

Non-spherical

Non-spherical, half size

Spherical, half size particle

2015

conventional

0.0098
$(0.0064)$

$(0.0064)$

0.0102

(0.0056)

0.0127

(0.0082)
2050

Values in parenthesis are original values calculated from ECHAM4 radiation scheme. Other values are the best estimate, and are adjusted by a $25 \%$ offset to the longwave global mean contrail RF.

At the top of the atmosphere, a mean contrail cover of $0.1 \%$ with average optical depth of 0.2 to 0.5 causes about 0.01 to $0.03 \mathrm{Wm}^{-2}$ daily mean $\mathrm{RF}$.

The authors note that values are uncertainty in contrail cover and optical depth values gives an uncertainty of factor 5 around these values.

\begin{tabular}{lll} 
Ice water content & $\mathbf{1 9 9 2}$ & $\mathbf{2 0 5 0}$ \\
\hline 0.1 & 0.008 & 0.049 \\
0.3 & 0.017 & 0.099 \\
0.5 & 0.020 & 0.122 \\
Variable* $^{*}$ & 0.010 & 0.060
\end{tabular}

* variable ice water content calculated as a function of ambient temperature 


\section{Study and inputs}

\section{Myhre et al. $2001{ }^{2.3}$}

European Centre for Medium Range Weather Forecasts (ECMWF) for 1996 used for monthly mean global distribution of temperature, water vapour, clouds, and surface albedo.

Optical properties of hexagonal ice crystals for contrails are from Strauss et al (1997), with optical depth of 0.3 at $0.55 \mu \mathrm{m}$. Altitude of the top of the contrails is $11 \mathrm{~km}$.

Distributions without diurnal variation were adopted from those by Sausen et al (1998), based on fuel consumption, moisture and temperature constrained to satellite observations of contrail cover. The annual mean contrail cover was used $(0.09 \%)$.

Diurnal variation used the same data, but scaled using Schmitt and Brunner (1997) data on air traffic diurnal to infer a variation in the contrail cover.

\section{Penner et al. $1999^{1}$}

Fa1: rreference scenario developed by ICAO Forecasting and Economic Support Group (FESG); mid-range economic growth from IPCC (1992); technology for both improved fuel efficiency and $\mathrm{NO}_{\mathrm{x}}$ reduction
$\mathbf{R F}\left(\mathbf{W m}^{-2}\right)$, unless otherwise stated

\section{RF due to contrails for a $1 \%$ Cloudy conditions Clear conditions} homogeneous contrail cover

\begin{tabular}{lll}
\hline Long wave RF & 0.21 & 0.27 \\
Short wave RF & -0.09 & -0.15 \\
Net RF & 0.12 & 0.12
\end{tabular}

Net RF

RF due to contrails for Diurnal cycle Diurnal cycle Maximum

a realistic contrail excluded included shortwave effect* cover

$\begin{array}{llll}\text { Long wave RF } & 0.020 & 0.020 & 0.020 \\ \text { Short wave RF } & -0.009 & -0.011 & -0.020 \\ \text { Net RF } & 0.011 & 0.009 & 0.000\end{array}$

*assumes that contrails occur at the time of day which maximizes the shortwave forcing.

RF due to contrails

\begin{tabular}{lllll}
$\mathbf{1 9 9 0}$ & $\mathbf{2 0 0 0}$ & $\mathbf{2 0 1 5}$ & $\mathbf{2 0 2 5}$ & $\mathbf{2 0 5 0}$ \\
\hline 0.021 & 0.034 & 0.060 & 0.071 & 0.100
\end{tabular}




\section{Study and inputs}

\section{Ponater et al., $20022^{27}$}

Radiative transfer and heating rates in the GCM were calculated using the radiation parameterization of Fouquart and Bonnel (1980) ${ }^{43}$ and Morcrette (1991) ${ }^{44}$ for the solar and terrestrial spectrum, respectively.

Sea surface temperature and sea ice extent in the reference experiment were prescribed by a mean annual cycle derived for the Atmospheric Model Intercomparison Project (AMIP) period 1979-1994.

The version 2 DLR aircraft emission data set used to calculate the actual contrail coverage from the potential coverage reflects the air traffic density distribution at the beginning of the 1990 s.

\section{Ponater et al., $2006^{29}$}

Ker - standard, purely kerosene aviation, calculated using IPCC inventories for 1940 to 2050 ;

cryo1 - technology transition begins in 2015, with EU taking the lead followed by North America in 2020 and S. America, Asia and Middle East in 2025. cryoplanes introduction starts with smallest planes, with long-range aircraft following about 10 years later;

cryo 2 - assumes fast transition, starting with gradual world-wide transition of small and medium-sized aircraft in 2015 and of large aircraft in 2025. Scenario results in complete switch to hydrogen fuel by 2050 ;

cryo3 - starts with world-wide transition later (2020), but proceeds as fast as cryo2 towards the end of the period.

\section{Sausen et al., $2005^{35}$}

New estimates of FR from a number of climate models, to update IPCC 1999 estimates for 2000. Scenarios: 1992 data scaled to 2000; IPCC 1999 data scaled to 2000; 2000 (TRADEOFF).

\section{RF $\left(\mathbf{W m}^{-2}\right)$, unless otherwise stated}

\section{Case}

Stratosphere-adjusted net RF at the tropopause due to contrails

Reference experiment $\quad 0.2 *$

January $\quad 0.4$

April $\quad 0.3$

July $\quad 0.3$

October $\quad 0.3$

Annual mean $\quad 0.4$

*instantaneous radiative forcing at top of the atmosphere

\section{Global RF [W $\mathbf{m}^{-2}$ ] for 2050 caused by contrails}

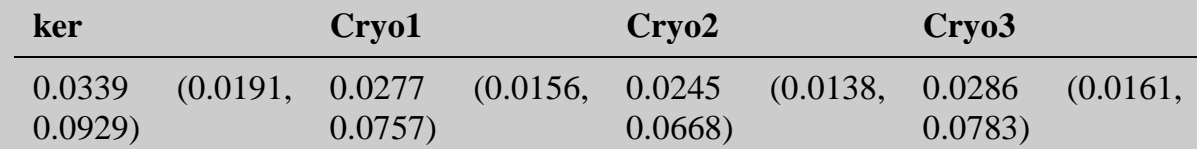

\section{Global temp change (K) for 2050 caused by contrails}

\begin{tabular}{llllllll} 
ker & \multicolumn{3}{c}{ Cryo1 } & \multicolumn{3}{c}{ Cryo2 } & \multicolumn{2}{c}{ Cryo3 } & \\
\hline 0.0056 & $(0.0032$, & 0.0053 & $(0.0030$, & 0.0051 & $(0.0029$, & 0.0053 & $(0.0030$, \\
$0.0153)$ & & $0.0144)$ & & $0.0140)$ & & $0.0146)$ &
\end{tabular}

$\mathrm{RF}\left(\mathrm{Wm}^{-2}\right)$ due to contrails

1992 (IPCC, 1999) 2000 (IPCC, 1999 scaled to 2000) 2000

TRADEOFF

$\begin{array}{lll}0.0200 & 0.0339 & 0.0100\end{array}$


Study and inputs

Strauss et al. $1997^{38}$

Modelled outputs (July and October) from a 1D radiative convective model
RF $\left(\mathbf{W m}^{-2}\right)$, unless otherwise stated

\begin{tabular}{lll} 
& July & October \\
\hline Surface temperature increases & $1.1 \mathrm{~K}$ & $0.8 \mathrm{~K}$ \\
$\begin{array}{l}\text { Increases in surface temperature, using an estimate of } 0.5 \% \text { of } \\
\text { current cloud cover being due to contrails }\end{array}$ & $0.06 \mathrm{~K}$ & $0.05 \mathrm{~K}$ \\
& &
\end{tabular}


Table 8 Effect of aviation-induced cirrus clouds' effect on RF, GWP and temperature

\begin{tabular}{|c|c|c|c|c|c|c|c|}
\hline \multicolumn{2}{|c|}{ Study and inputs } & \multicolumn{6}{|c|}{$\mathbf{R F}\left(\mathbf{W m}^{-2}\right)$, unless otherwise stated } \\
\hline Rind et al., & $2000^{32}$ & \multirow{4}{*}{ Scenario } & \multirow{4}{*}{$\begin{array}{l}\Delta \quad \text { net } \\
\text { radiation at } \\
\text { top of model }\end{array}$} & \multirow{4}{*}{$\begin{array}{l}\Delta \quad \text { net } \\
\text { radiation at } \\
\text { tropopause }\end{array}$} & \multirow{4}{*}{$\begin{array}{l}\Delta \text { initial surface } \\
\text { temperature, }{ }^{\circ} \mathbf{C}\end{array}$} & \multirow{4}{*}{\multicolumn{2}{|c|}{$\begin{array}{l}\Delta \text { equilibrium } \\
\text { surface } \\
\text { temperature, } \\
{ }^{\circ} \mathbf{C}\end{array}$}} \\
\hline Scenario & description & & & & & & \\
\hline \multirow{3}{*}{$\begin{array}{l}\text { Control } \\
1 / 200 \\
1 / 150\end{array}$} & \multirow[t]{2}{*}{ CCI in the clear-sky hour after 200 clear-sky hours } & & & & & & \\
\hline & & & & & & & \\
\hline & CCI after 100 clear-sky hours & $1 / 150$ & -0.1 & $0(0.1)$ & 0.01 & \multicolumn{2}{|c|}{0.1} \\
\hline $1 / 100$ & CCI after 99 clear-sky hours & $1 / 100$ & 0 & $0.1(0.19)$ & 0.09 & \multicolumn{2}{|c|}{0.3} \\
\hline $1 / 99$ & CCI for the 2 clear-sky hours after 98 clear-sky hours & $1 / 99$ & 0.2 & $0.4(0.49)$ & 0.09 & \multicolumn{2}{|c|}{0.6} \\
\hline $1 / 98$ & CCI for the 3 clear-sky hours after 97 clear-sky hours & $1 / 98$ & 0 & $0.2(0.18)$ & -0.02 & \multicolumn{2}{|c|}{0.6} \\
\hline $1 / 97$ & CCI for the 4 clear-sky hours after 96 clear-sky hours & $1 / 97$ & 0.6 & $0.8(0.93)$ & 0.13 & \multicolumn{2}{|c|}{1.1} \\
\hline $1 / 96$ & CCI for the 5 clear-sky hours after 95 clear-sky hours & $1 / 96$ & 0.9 & $1.2(1.4)$ & 0.21 & \multicolumn{2}{|c|}{1.4} \\
\hline \multirow[t]{2}{*}{$1 / 95$} & \multirow{2}{*}{$\begin{array}{l}\mathrm{CCI} \text { varying between the insertion procedure for the } 1 / 200 \text { and } 1 / 95 \\
\text { experiments, proportional to flight density }\end{array}$} & $1 / 95$ & 1.3 & $1.8(2.0)$ & 0.23 & \multicolumn{2}{|c|}{1.7} \\
\hline & & Scaled & 1.6 & $2.2(2.4)$ & 0.25 & 2.2 & \\
\hline \multirow{2}{*}{\multicolumn{2}{|c|}{$\begin{array}{l}\text { Scaled } \quad \text { CCI in the clear-sky hour after } 200 \text { clear-sky hours } \\
\text { CCI }=\text { cirrus cloud insertion }\end{array}$}} & \multicolumn{6}{|c|}{$\begin{array}{l}\mathrm{Nb} \text {, results were not presented for } 1 / 20 \text { run as it was reported to have been close to the } \\
\text { control run. }\end{array}$} \\
\hline & & \multicolumn{6}{|c|}{$\begin{array}{l}\text { Values in parentheses are corrected for the radiation imbalance for the initial temperature } \\
\text { warming, since radiative forcing should be calculated without any temperature response } \\
\text { and there was a small but non-zero response in these results. }\end{array}$} \\
\hline \multicolumn{2}{|c|}{ Sausen et al., $2005^{35}$} & \multirow{2}{*}{\multicolumn{2}{|c|}{$\mathbf{R F}\left(\mathbf{W m}^{-2}\right)$}} & & & & \\
\hline $\begin{array}{l}\text { New estima } \\
\text { 2000. Scen } \\
\text { (TRADEOF }\end{array}$ & $\begin{array}{l}\text { es of RR from a number of climate models, to update IPCC } 1999 \text { estimates for } \\
\text { rios: } 1992 \text { data scaled to 2000; IPCC } 1999 \text { data scaled to 2000;2000 } \\
\text { F). }\end{array}$ & & & $\begin{array}{l}1992 \text { (IPC } \\
\text { 1999) }\end{array}$ & $\begin{array}{ll}2000 & (\text { IPC } \\
1999 & \text { scaled } \\
2000) & \end{array}$ & to & $\begin{array}{l}2000 \\
\text { TRADEOFF }\end{array}$ \\
\hline & & $\begin{array}{l}\text { Estimated } \\
\text { to aviation }\end{array}$ & $\begin{array}{l}\text { mean for RF due } \\
\text { induced cirrus }\end{array}$ & & - & & 0.030 \\
\hline & & $\begin{array}{l}\text { Upper bou } \\
\text { aviation-in }\end{array}$ & $\begin{array}{l}\text { nd for RF due to } \\
\text { duced cirrus }\end{array}$ & 0.040 & & & 0.080 \\
\hline
\end{tabular}


Stordal et al. $2005^{37}$

Modelled cirrus cloud cover due to aircraft traffic, and calculations of radiative forcing due

to aircraft using three different values for this relationship.

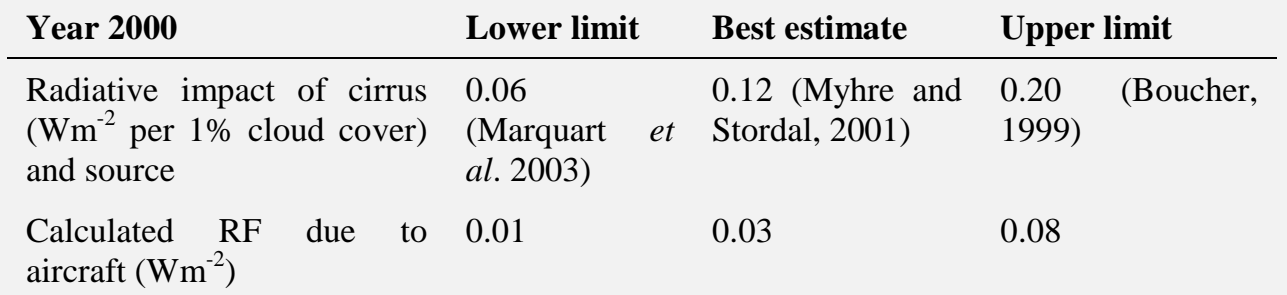

Gauss et al. $2003^{14}$

2015 inventories.

See Table 6 for details of scenarios

\begin{tabular}{ll} 
Model run & $\begin{array}{l}\text { Mean globally averaged RF at the } \\
\text { tropopause }\end{array}$ \\
\hline $\mathrm{H}_{2} \mathrm{O}-\mathrm{C} 1$ & $0.0098(0.0036)$ \\
$\mathrm{H}_{2} \mathrm{O}-\mathrm{C} 2$ & $0.0065(0.0020)$ \\
$\mathrm{H}_{2} \mathrm{O}-\mathrm{C} 2^{+1}$ & $0.0139(0.0033)$ \\
$\mathrm{H}_{2} \mathrm{O}-\mathrm{C} 2^{+2}$ & $0.0297(0.0052)$ \\
$\mathrm{H}_{2} \mathrm{O}-\mathrm{C} 2^{+3}$ & $0.0625(0.0077)$ \\
$\mathrm{H}_{2} \mathrm{O}-\mathrm{C} 3$ & $0.0058(0.0020)$ \\
$\mathrm{H}_{2} \mathrm{O}-\mathrm{C} 4$ & $0.0043(0.0010)$ \\
$\mathrm{H}_{2} \mathrm{O}-\mathrm{C} 5$ & $0.0062(0.0020)$ \\
$\mathrm{H}_{2} \mathrm{O}-\mathrm{C} 6$ & $0.0058(0.0018)$ \\
$\mathrm{H}_{2} \mathrm{O}-\mathrm{K} 1$ & $0.0026(0.0008)$ \\
$\mathrm{H}_{2} \mathrm{O}-\mathrm{K} 2$ & $0.0495(0.0003)$ \\
$\mathrm{Values}$ in parentheses are the global averaged $\mathrm{RF}$ at the top of the atmosphere
\end{tabular}


Table 9 Effects of ozone, $\mathrm{NO}_{\mathrm{x}}$ and aerosols on RF, GWP and temperature

\begin{tabular}{|c|c|}
\hline Study a & d inputs \\
\hline Bernste & et al. $2000^{7}$ \\
\hline Date & Global $\mathrm{NO}_{\mathrm{x}}$ emissions $\mathrm{Tg}(\mathrm{N}) \mathrm{yr}^{-1}$ \\
\hline 1990 & 36.5 \\
\hline $\begin{array}{l}\mathrm{NO}_{x} \text { en } \\
\text { assumir } \\
\text { aircraft }\end{array}$ & $\begin{array}{l}\text { ssions from aircraft set to } 0 \text { befo } \\
\text { an increase of } 7.8 \% \mathrm{yr}^{-1} \text { from } 195 \\
\text { ame from DLR-2 database. }\end{array}$ \\
\hline Danilin & tal., $1998^{8}$ \\
\hline
\end{tabular}

\section{RF $\left(\mathbf{W m}^{-2}\right)$, unless otherwise stated}

\begin{tabular}{ll} 
Date & Global mean RF \\
\hline 1990 & 0.34
\end{tabular}

RF up to 0.006 due to soot emissions and -0.013 for sulphur emissions

\section{Dessens et al. $2002^{9}$}

\begin{tabular}{lll} 
& $\mathbf{1 9 9 5}$ & $\mathbf{2 0 1 5}$ \\
\hline $\mathrm{CO}_{2}$ & $353 \mathrm{ppmv}$ & $405 \mathrm{ppmv}$ \\
$\mathrm{N}_{2} \mathrm{O}$ & $313 \mathrm{ppbv}$ & $335 \mathrm{ppbv}$ \\
$\mathrm{CH}_{4}$ & $1650 \mathrm{ppbv}$ & $1825 \mathrm{ppbv}$
\end{tabular}

5 scenarios: reference case (1995); predicted 2015 subsonic fleet (offline model); predicted 2015 subsonic fleet (online model); supersonic fleet added to subsonic fleet (offline model); supersonic fleet added to subsonic fleet (online model).

\begin{tabular}{|c|c|c|}
\hline Reference case & Online subsonic & Online super+subsonic \\
\hline $\begin{array}{l}\text { Troposphere warms, max of } \\
+1.5 \mathrm{~K} \text { in March. } \\
\text { Stratosphere cools, reaching } \\
-10 \mathrm{~K} \text { at } 25 \mathrm{~km} \text {. Ozone hole } \\
\text { healing over the Antarctic } \\
\text { in November leads to an } \\
\text { increase in heating of the } \\
\text { polar stratosphere }(+6 \mathrm{~K}) \text {. }\end{array}$ & $\begin{array}{l}\text { In the winter northern } \\
\text { polar case with } \\
\text { subsonic } \\
\text { emissions, fleet } \\
\text { decrease cools lower } \\
\text { stratosphere (-1.6K at } \\
22 \mathrm{~km} \text { over the North } \\
\text { Pole). }\end{array}$ & $\begin{array}{l}\text { For both fleets, cooling in } \\
\text { the Antarctic is seen in July } \\
\text { (-3K for the supersonic } \\
\text { case). In July NOx increase } \\
\text { over northern hemisphere } \\
\text { increases ozone, causing } \\
\text { warming of } 3 \mathrm{~K} \text { over North } \\
\text { Pole. }\end{array}$ \\
\hline
\end{tabular}

Temperature results in the paper were only presented for the online model. 


\section{Study and inputs}

Forster et al., $2006^{11}$

Inputs assume an exponential increase in aviation emissions since 1950 to year 2000 of 150 TgC Growth follows the SRES A1B scenario (IPCC, 2000)

\section{Fortuin et al., $1995^{12}$}

Aircraft-induced enhancement from 1943 to 1990

\begin{tabular}{l|l|l} 
& Lower estimate & Upper estimate \\
\hline Sulphate aerosol & $+10 \%$ & $+30 \%$ \\
$\mathrm{NO}_{2}$ & $+20 \mathrm{pptv}$ & $\mathrm{n} / \mathrm{a}$ \\
$\mathrm{O}_{3}$ & $+5 \mathrm{ppbv}$ & $+20 \mathrm{ppbv}$
\end{tabular}

\section{RF $\left(\mathbf{W m}^{-2}\right)$, unless otherwise stated}

Time horizon (2000 NET absolute global warming potential start), years due to $\mathrm{CH}_{4}$ and $\mathrm{O}_{3}\left[10^{-14} \mathrm{~W} \mathrm{~m}^{-2} \mathrm{~kg} \mathrm{CO}_{2}^{-1}\right.$

\begin{tabular}{ll} 
& $\mathbf{y r}]$ \\
\hline 1 & 2.0 \\
20 & 0.37 \\
100 & 0.012 \\
500 & -0.009
\end{tabular}

\begin{tabular}{|c|c|c|c|c|}
\hline & \multicolumn{2}{|c|}{ Mid-latitude summer } & \multicolumn{2}{|c|}{ Mid-latitude winter } \\
\hline & Fixed temp & $\begin{array}{l}\text { Fixed dyn. } \\
\text { heating }\end{array}$ & $\begin{array}{l}\text { Fixed } \\
\text { temp }\end{array}$ & $\begin{array}{l}\text { Fixed dyn. } \\
\text { heating }\end{array}$ \\
\hline \multicolumn{5}{|c|}{ RF due to sulphate aerosol } \\
\hline Lower estimate & -0.182 & -0.132 & -0.141 & -0.118 \\
\hline Upper estimate & -0.550 & -0.401 & -0.421 & -0.352 \\
\hline \multicolumn{5}{|l|}{$\mathrm{RF}$ due to $\mathrm{NO}_{2}$} \\
\hline Lower estimate & 0.003 & $\mathrm{n} / \mathrm{a}$ & -0.001 & $\mathrm{n} / \mathrm{a}$ \\
\hline Upper estimate & $\mathrm{n} / \mathrm{a}$ & $\mathrm{n} / \mathrm{a}$ & $\mathrm{n} / \mathrm{a}$ & $\mathrm{n} / \mathrm{a}$ \\
\hline \multicolumn{5}{|l|}{$\mathrm{RF}$ due to $\mathrm{O}_{3}$} \\
\hline Lower estimate & 0.034 & 0.028 & 0.012 & 0.013 \\
\hline Upper estimate & 0.135 & 0.111 & 0.046 & 0.050 \\
\hline
\end{tabular}




\begin{tabular}{|c|c|c|c|c|}
\hline \multicolumn{5}{|l|}{ Study and inputs } \\
\hline \multicolumn{5}{|l|}{ Fuglesvedt $1996{ }^{13}$} \\
\hline \multicolumn{5}{|c|}{ Baseline emissions data used unclear - present day. } \\
\hline \multicolumn{5}{|c|}{$\begin{array}{l}\text { Sustained step function increases in emissions used, from baseline: } 1.1 \text { to } 1.7 \text { times } \mathrm{NO}_{x} \text {, } \\
\text { and } 1.1 \text { to } 2 \text { times } \mathrm{CH}_{4} \text { and } \mathrm{CO} \text {. }\end{array}$} \\
\hline \multicolumn{5}{|c|}{ Figures for GWP from 1 to 500 years use $110 \%$ sustained step function increases. } \\
\hline \multicolumn{5}{|l|}{ Isaksen et al., $2001{ }^{15}$} \\
\hline Inputs & 1992 & 2015 & 2050 medium & 2050 high \\
\hline $\begin{array}{l}\mathrm{NO}_{\mathrm{x}} \text { emissions, } \\
\mathrm{Tg}\left(\mathrm{Nyr}^{-1}\right)\end{array}$ & 0.5 & 1.27 & 2.17 & 3.46 \\
\hline $\begin{array}{l}\text { Source of } \mathrm{NO}_{\mathrm{x}} \\
\text { data }\end{array}$ & $\begin{array}{l}\text { Current } \\
\text { atmosphere }\end{array}$ & IPCC 1999 & \multicolumn{2}{|c|}{$\begin{array}{l}\text { IPCC } 1999 \text { - extrapolations of } \\
2015 \text { emissions* }\end{array}$} \\
\hline $\mathrm{CH}_{4}$ (ppbv) & 1714 & 2052 & \multicolumn{2}{|l|}{2793} \\
\hline
\end{tabular}

\section{RF $\left(\mathbf{W m}^{-2}\right)$, unless otherwise stated}

\begin{tabular}{llll|l}
$\begin{array}{l}\text { Time } \\
\text { horizon } \\
\text { (years) }\end{array}$ & $\begin{array}{l}\text { Sustained } \\
\text { warming potential due } \\
\text { to aircraft } \text { NO }_{\mathbf{x}}\end{array}$ & $\begin{array}{l}\text { global } \\
\text { warming potential due } \\
\text { to aircraft } \\
\text { (direct) }\end{array}$ & $\begin{array}{l}\text { Sustained } \mathbf{C H}_{\mathbf{4}} \\
\text { warming potential } \\
\text { due to aircraft } \mathbf{C H}_{\mathbf{4}} \\
\text { (direct + indirect) }\end{array}$ \\
\hline 20 & 1576 & 35 & 63 \\
\hline 50 & 751 & 24 & 44 \\
\hline 100 & 441 & 16 & 30 \\
\hline 200 & 268 & 10 & 19 \\
\hline 500 & 148 & 2 & 1 \\
\hline
\end{tabular}

\begin{tabular}{|c|c|c|c|c|c|}
\hline $\begin{array}{l}\text { RF for } \\
\text { emissions }\end{array}$ & aircraft & 1992 & 2015 & 2050 & $2050 *$ \\
\hline Methane & & -0.015 & -0.032 & -0.053 & NR \\
\hline Ozone & & 0.020 & 0.047 & 0.077 & 0.068 \\
\hline
\end{tabular}

These figures are relative to a model run with no aircraft emissions

* result for a model run where different regional growth rates between 1992 and 2050 in background emission are taken into account - rates not stated. 


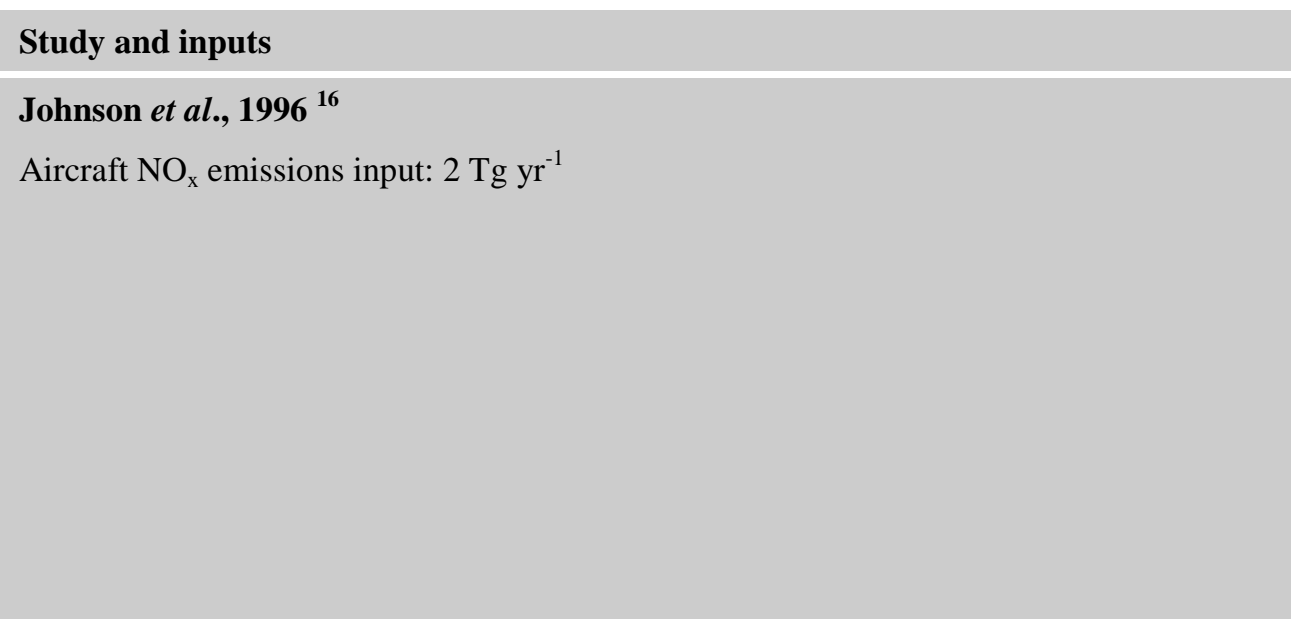

\section{Marquart et al., $2001^{17}$}

\section{Model inputs}

Mass of equal energy

Emission index $\mathrm{H}_{2} \mathrm{O}$

Emission index $\mathrm{NO}_{\mathrm{x}}$

Global fuel consumption

\section{Global $\mathrm{H}_{2} \mathrm{O}$ emissions}

Global $\mathrm{NO}_{\mathrm{x}}$ emissions

Emission properties above are for 2015 scenario

\section{RF $\left(\mathbf{W m}^{-2}\right)$, unless otherwise stated}

\begin{tabular}{lll}
$\begin{array}{l}\text { Response to a } \mathbf{1} \mathbf{T g} \mathbf{y r}^{-1} \text { step-change in } \\
\text { aircraft } \mathbf{N O}_{\mathbf{x}} \text { emissions }\end{array}$ & After 10 years & After 100 years \\
\hline $\begin{array}{l}\text { RF forcing due to changes in ozone } \\
\begin{array}{l}\text { Step change GWP for indirect radiative impact } \\
\text { of methane }\end{array}\end{array}$ & -32 \\
$\begin{array}{l}\text { Step change GWP for indirect radiative impact } \\
\text { of tropospheric ozone }\end{array}$ & 488 \\
$\begin{array}{l}\text { Overall step change GWP from aircraft } \mathrm{NO}_{\mathrm{x}} \\
\text { Overall step change GWP from aircraft } \mathrm{CO}_{2}\end{array}$ & 456.0 \\
\end{tabular}

\begin{tabular}{lll}
$\begin{array}{l}\text { Aircraft induced change in } \mathbf{R F} \text { due } \\
\text { to: }\end{array}$ & $\begin{array}{l}\mathbf{2 0 1 5} \\
\text { kerosene }\end{array}$ & $\mathbf{2 0 1 5}$ cryoplane \\
\hline $\mathrm{O}_{3}$ & 0.054 & 0.005 to 0.021 \\
$\mathrm{CH}_{4}$ & -0.036 & -0.004 to -0.014 \\
Sulphate aerosols & -0.006 & $*$ \\
soot & 0.006 & $*$ \\
\hline
\end{tabular}

Results for 2050 and 2100 were identical to those for 2015 for these outcome measures.

* not given in paper, but assumed to be 0 . 


\section{Study and inputs}

Penner et al. $1999^{1}$

Fa1 = rreference scenario developed by ICAO Forecasting and Economic Support Group (FESG); mid-range economic growth from IPCC (1992); technology for both improved fuel efficiency and $\mathrm{NO}_{\mathrm{x}}$ reduction

\section{Pitari et al $2002^{24}$}

Scenario 1 includes $\mathrm{NO}_{\mathrm{x}}, \mathrm{H}_{2} \mathrm{O}$ and hydrocarbon emissions from aircraft

Scenario 2 includes $\mathrm{NO}_{\mathrm{x}}, \mathrm{H}_{2} \mathrm{O}$, hydrocarbon and sulphur emissions from aircraft

No input values given

\begin{tabular}{|c|c|}
\hline \multicolumn{2}{|c|}{ Ponater et al. $1999^{26}$} \\
\hline \multicolumn{2}{|c|}{1992 scenarios: } \\
\hline CTRL-92 & Control run \\
\hline $1 * \mathrm{MOG}$ & Aircraft ozone from MOGUNTIA \\
\hline $2 * \mathrm{MOG}$ & Aircraft ozone from MOGUNTIA $\times 2$ \\
\hline $5 * \mathrm{MOG}$ & Aircraft ozone from MOGUNTIA $\times 5$ \\
\hline equiv. $\mathrm{CO}_{2}$ & Aircraft ozone from MOGUNTIA, equivalent $\mathrm{CO}_{2}$ \\
\hline ECH3-92 & Aircraft ozone using Dameris et $a l^{45} 1992$ scenario \\
\hline \multicolumn{2}{|c|}{2015 scenarios: } \\
\hline CTRL-15 & $\begin{array}{l}\text { Control run, using background conditions predicted by IPCC } \\
\text { scenario IS92a for } 2015 \text {. }\end{array}$ \\
\hline ECH3-15 & Aircraft ozone using Dameris et $a l^{45} 1992$ scenario \\
\hline
\end{tabular}

RF $\left(\mathbf{W m}^{-2}\right)$, unless otherwise stated

\begin{tabular}{llllll} 
RF due to: & $\mathbf{1 9 9 0}$ & $\mathbf{2 0 0 0}$ & $\mathbf{2 0 1 5}$ & $\mathbf{2 0 2 5}$ & $\mathbf{2 0 5 0}$ \\
\hline $\mathrm{O}_{3}$ & 0.024 & 0.029 & 0.040 & 0.046 & 0.060 \\
$\mathrm{CH}_{4}$ & -0.015 & -0.018 & -0.027 & -0.032 & -0.045 \\
Sulphate aerosol & -0.003 & -0.004 & -0.006 & -0.007 & -0.009 \\
Soot $(\mathrm{BC})$ aerosol & 0.003 & 0.004 & 0.006 & 0.007 & 0.009
\end{tabular}

\begin{tabular}{lll} 
RF due to: & Scenario 1 & Scenario 2 \\
\hline $\mathrm{O}_{3}$ & 0.027 & 0.015 \\
$\mathrm{SO}_{4}$ & 0.00 & -0.007 \\
$\mathrm{CH}_{4}$ & -0.008 & -0.008
\end{tabular}

\begin{tabular}{lll} 
Scenario & RF & $\begin{array}{l}\text { Annual mean }[95 \% \text { CI] surface air temperature } \\
(\mathbf{K})\end{array}$ \\
\hline CTRL-92 & NR & NR (SD of monthly mean is 0.05) \\
1 *MOG & 0.068 & $0.096[0.081,0.111]$ \\
2*MOG & 0.135 & $0.090[0.075,0.105]$ \\
5*MOG & 0.331 & $0.728[0.263,0.293]$ \\
equiv.CO 2 & 0.069 & $0.061[0.046,0.076]$ \\
ECH3-92 & 0.031 & $0.062[0.047,0.077]$ \\
CTRL-15 & NR & 0.90 \\
ECH3-15 & NR & 0.14
\end{tabular}




\section{Study and inputs}

\section{Ponater et al., $2006{ }^{29}$}

Ker - standard, purely kerosene aviation, calculated using IPCC inventories for 1940 to 2050

cryo1 - technology transition begins in 2015, with EU taking the lead followed by North America in 2020 and S. America, Asia and Middle East in 2025. Cryoplanes introduction starts with smallest planes, with long-range aircraft following about 10 years later;

cryo 2 - assumes fast transition, starting with gradual world-wide transition of small and medium-sized aircraft in 2015 and of large aircraft in 2025. Scenario results in complete switch to hydrogen fuel by 2050 ;

cryo3 - starts with world-wide transition later (2020), but proceeds as fast as cryo 2 towards the end of the period.

\section{Rind et al., $1995^{30}$}

GISS/CAM model investigates two scenarios of interest to the present study- ozone changes estimated from potential aircraft emissions by 2015 , and more realistic water vapour changes from high-speed aircraft emissions.

\section{RF $\left(\mathbf{W m}^{-2}\right)$, unless otherwise stated}

\section{Global RF [W $\left.\mathbf{m}^{-2}\right]$ for 2050 caused by:}

\begin{tabular}{lllll} 
& ker & Cryo1 & Cryo2 & Cryo3 \\
\hline $\mathrm{O}_{3}$ & $0.0364(0.0175$, & $0.0184(0.0088$, & $0.0091(0.0044$, & $0.0211(0.0101$, \\
& $0.1821)$ & $0.0741)$ & $0.0182)$ & $0.0903)$ \\
$\mathrm{CH}_{4}$ & -0.0171 & -0.0087 & -0.0043 & -0.0099 \\
& $(-0.0082$, & $(-0.0042$, & $(-0.0021$, & $(-0.0048$, \\
& $-0.0856)$ & $-0.0348)$ & $-0.0086)$ & $-0.0422)$ \\
\hline
\end{tabular}

Global temp change $(\mathrm{K})$ for 2050 caused by:

\begin{tabular}{|c|c|c|c|c|}
\hline & ker & Cryo1 & Cryo2 & Cryo3 \\
\hline $\mathrm{O}_{3}$ & $\begin{array}{l}0.0237 \\
0.0764)\end{array}$ & $\begin{array}{l}0.0209 \\
(0.0100 \\
0.0622)\end{array}$ & $\begin{array}{l}0.0198 \\
(0.0095 \\
0.0566)\end{array}$ & $\begin{array}{l}0.0216 \\
0.0657)\end{array}$ \\
\hline $\mathrm{CH}_{4}$ & $\begin{array}{l}-0.0096 \\
(-0.0046 \\
-0.0309)\end{array}$ & $\begin{array}{l}-0.0084 \\
(-0.0040 \\
-0.0251)\end{array}$ & $\begin{array}{l}-0.0080 \\
(-0.0038 \\
-0.0229)\end{array}$ & $\begin{array}{l}-0.0087 \\
(-0.0042, \\
-0.0266)\end{array}$ \\
\hline
\end{tabular}

Ozone changes for the year 2015 from aircraft emissions involve stratospheric ozone decreases and tropospheric ozone increases. The stratosphere generally cools, by up to $0.5^{\circ} \mathrm{C}$. However, at the poles, stratospheric warming and mesospheric cooling of up to $2^{\circ} \mathrm{C}$ is experienced in the northern hemisphere.

With the stratospheric water vapour increase of $0.2 \mathrm{ppmv}$ by 2015 in the more realistic scenario, the stratosphere cools by $0.5^{\circ} \mathrm{C}$ or less, and regions of polar warming arise. 


\section{Sausen et al., $1997^{33}$}

Mean temperatures calculated by ECHAM4 GCM for different ozone scenarios, computed using $1 \times$ ozone change simulated by MOGUNTIA; $5 \times$ ozone change simulated by MOGUNTIA; $1 \times$ ozone change simulated by KNMI and $5 \times$ ozone change simulated by KNMI.

\begin{tabular}{ll}
$\begin{array}{l}\text { Sausen } \text { et al., } \\
\text { Scenario }\end{array}$ & Description \\
\hline Fa1 & $\begin{array}{l}\text { Standard aircraft emissions scenario: historic data (IEA) until 1995, } \\
\text { NASA for 2015, FESGa (tech option 1) for 2050, 1\% annual growth } \\
\text { thereafter. }\end{array}$ \\
C $\tau$ & As Fa1, but aircraft emissions constant for $\mathrm{t} \geq \tau$. \\
N2015 & As Fa1, but no aircraft emissions after 2015 \\
These two scenarios only run until 2050; others were run until 2100 \\
\end{tabular}

\section{Sausen et al., $2005^{35}$}

New estimates of FR from a number of climate models, to update IPCC 1999 estimates for 2000. Scenarios: 1992 data scaled to 2000; IPCC 1999 data scaled to 2000; 2000 (TRADEOFF).
In July, each scenario's changed temperature exceeded the $90 \%$ significance level at least once. The $1 \times$ MOGUNTIA and 5×MOGUNTIA runs exceeded the $95 \%$ and $99 \%$ levels, respectively. In January, only the $1 \times$ MOGUNTIA and $5 \times$ MOGUNTIA scenarios produce significant signals.

The magnitude of the signal appears to depend nonlinearly on the magnitude of the ozone increase. The zonal mean temperature changes are in the range of $\pm 0.2 \mathrm{~K}$, which is about 5$10 \%$ of the response the same model simulates for doubling $\mathrm{CO}_{2}$, in the upper troposphere. However, the signal due to the ozone changes is less coherent.

Temperature change (K) due to $\mathrm{O}_{3}$

\begin{tabular}{llllll} 
& Fa1 & & & $\mathbf{C}_{\mathbf{2 0 1 5}}$ & $\mathbf{N}_{\mathbf{2 0 1 5}}$ \\
Year & $\mathbf{S = 0 . 0 1}$ & $\mathbf{S = 0 . 0 5}$ & $\mathbf{S}=\mathbf{0 . 1 0}$ & $\mathbf{S = 0 . 0 1}$ & $\mathbf{S = 0 . 0 5}$ \\
\hline 1995 & 0.005 & 0.023 & 0.045 & 0.005 & 0.023 \\
2015 & 0.010 & 0.048 & 0.097 & 0.010 & 0.048 \\
2050 & 0.022 & 0.111 & 0.221 & 0.022 & 0.111 \\
2100 & 0.043 & 0.215 & 0.431 & 0.043 & 0.215
\end{tabular}

Scaling factor $\mathrm{S}$ is the equilibrium temperature response (in $\mathrm{K}$ ) due to $\mathrm{O}_{3}$ induced by aircraft $\mathrm{NO}_{\mathrm{x}}$ emissions for 1992 .

\begin{tabular}{llll} 
RF $\left(\mathbf{W m}^{-2}\right)$ due to: & $\mathbf{1 9 9 2}($ IPCC, 1999) & $\begin{array}{l}\mathbf{2 0 0 0}(\text { IPCC, 1999 } \\
\text { scaled to 2000) }\end{array}$ & 2000 TRADEOFF \\
\hline $\mathrm{O}_{3}$ & 0.0230 & 0.0289 & 0.0219 \\
$\mathrm{CH}_{4}$ & -0.0140 & -0.0185 & -0.0104 \\
Direct sulphate & -0.0030 & -0.0040 & -0.0035 \\
Direct soot & 0.0030 & 0.0040 & 0.0025
\end{tabular}




\section{Study and inputs}

Stevenson et al., $2004^{36}$

Model uses global annual mean emissions for 1990 to investigate 4 runs: control; NO increased by $\times 10$ for January; $\mathrm{NO}_{\mathrm{x}}$ increased by $\times 10$ for April; $\mathrm{NO}_{\mathrm{x}}$ increased by $\times 10$ for July; $\mathrm{NO}_{\mathrm{x}}$ increased by $\times 10$ for October

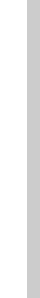

\section{Valks et al., $1999^{39}$}

Calculation of RF due to ozone changes caused by $\mathrm{NO}_{\mathrm{x}}$ from aircraft, with values of 0.55 $\mathrm{Tg} \mathrm{Ny}^{-1}$ for 1990 and $1.06 \mathrm{Tg} \mathrm{Ny}^{-1}$ for 2015 .

\section{Williams et al., $2002{ }^{40}$}

Model of the effect of cruising altitude on the climate change impacts of aviation.

\section{RF $\left(\mathbf{W m}^{-2}\right)$, unless otherwise stated}

\begin{tabular}{ll} 
Run & Net $\mathbf{R F ~} \mathbf{~} \mathbf{W m}^{-\mathbf{2}} \mathbf{y r}^{-\mathbf{1}}$ \\
\hline January & -0.90 \\
April & -0.89 \\
July & -0.99 \\
October & -0.89 \\
Mean & -0.92 \\
Lifetime corrected* & -0.95
\end{tabular}

RF due to ozone from aircraft $\mathrm{NO}_{\mathrm{x}}$

\section{January July 1990 January 2015 July 2015}

1990

0.014

0.026

0.019

0.037

The model gave an annual mean increase in fuel burn of $3.9 \%$ for flying at restricted altitudes. The authors report that the initial impact of a $3.9 \%$ fuel burn increase on $\mathrm{CO}_{2} \mathrm{RF}$ by aviation would be less than $3.9 \%$ as the current forcing includes the impact of historic aviation emissions. 


\subsubsection{Summary of effects of aviation emissions}

In this section 35 papers have been reviewed, describing the effect of aviation and its emissions on the environment and reporting RF, GWP and/or temperature changes as outputs. Upper and lower bounds for radiative forcing due to aviation studies aiming to provide plausible future scenarios, i.e. excluding artificial parameter study results, are shown in Table 10. Table 11 shows the percentage difference between lower and upper bounds for RF, to give an indication of the range of estimates for each contributing component. Summary results showing lower and upper bounds for surface temperature increase, relative to 1990, are shown in Table 13.

Predictions for overall RF due to aviation emissions for 2050 varied from $0.129 \mathrm{Wm}^{-2}$ for a low-growth subsonic only case $(F c 1)$, to $0.564 \mathrm{Wm}^{-2}$ for a high growth scenario $(E d h)$, with technology focus on low $\mathrm{NO}_{\mathrm{x}}$ emissions (Penner et $\mathrm{al}^{1}$ ). More recent studies (Marquart et $\mathrm{al}^{17}$ and Ponater et $a l^{29}$ ) reported RF in 2050 of between 0.128 and $0.132 \mathrm{Wm}^{-2}$ respectively, compared with the mid-range Fal scenario of $0.193 \mathrm{Wm}^{-2}$ (Penner et al ${ }^{29}$ ). In Table 10, the lower bound for RF in 2050 is the lowest bound from Ponater $e t a l^{29}$, with the highest being that of the Edh high growth /low NOx technology scenario of Penner et al ${ }^{1}$. Table 11 shows that there is a difference between lower and upper bound of 149\% and 142\% for 2000 and 2015 respectively. The difference for 2050 of $551 \%$ reflects the large difference between the scenario used from Marquart et $\mathrm{al}^{17}$, based on IPCC Fal, and the highest emission Edh case from Penner $e t \mathrm{al}^{1}$. The overall effect of aviation on surface temperature varies from between $0.004 \mathrm{~K}$ and $0.005 \mathrm{~K}$ for 2000 , to between $0.039 \mathrm{~K}$ and $0.133 \mathrm{~K}$ in 2050 , being highly dependent on the scenario in question.

The science around the direct effect of carbon dioxide on RF, GWP and temperature is established, with good correlation between RF due to carbon dioxide between Penner et al ${ }^{1}$ and the more recent EU TRADEOFF project (Sausen et $a l^{35}$ ); $0.025 \mathrm{Wm}^{-2}$ and $0.0253 \mathrm{Wm}^{-2}$ respectively. The predicted result for 2050 is $0.074 \mathrm{Wm}^{-2}$ (Penner et $a l^{1}$ ). Seasonal variation of RF due to carbon dioxide is also of importance (Fortuin et $a l^{12}$ ). The lower and upper bounds are those from the different growth and technology scenarios of Penner $e a^{1} l^{1}$, and the more recent results of Sausen $e a^{34}$ for the IPCC Fal scenario for 1990-2015. The lower bound for 2050 is provided by Marquart et $a l^{17}$, for kerosene fuelled aircraft. The relatively small differences between lower and upper bound estimates in Table 11, and temperature effect in Table 13, are indicative of the higher level of confidence in modelling the effect of $\mathrm{CO}_{2}$ on the global climate than other components.

Water vapour is a greenhouse gas, but its effect is minimal (Sausen $e a^{35}$, (Penner $e a^{1} l^{1}$ ) or not significant (Ponater $e t a l^{25}$, Rind $e t a l^{31}$ ). The effect from cryoplanes is, however, more significant and dependent on cruising altitude (Marquart et $a l^{17}$, Ponater $e t a l^{29}$, Gauss $e a^{14}$ ). Modelling the direct effect of water on the climate is subject to significant variation, as indicated by the variations in Table 11, and the percentage variation of up to $420 \%$ in 2050 shown in Table 12. The difference in the modelled surface temperature effect is a factor of five higher for the upper versus lower bound, shown in Table 13.

Much of the current uncertainty around the effect of aviation on the climate is based around contrails and the indirect effect on cirrus cloud formation. The level of uncertainty around cirrus cloud effects is reflected in the exclusion of this from the IPCC reported overall RF 
figures (Penner $e a^{1} l^{1}$ ). More recently, a number of climate models were used to estimate the RF effect of cirrus clouds for 2000 to be between 0.030 and $0.080 \mathrm{Wm}^{-2}$ (Sausen $e t a l^{35}$ ), a difference of $800 \%$. It has also been noted that global temperature responds linearly with high-level cloud cover (Rind $e t a l^{32}$ ).

Prediction of RF due to contrails varies widely, from 0.0148 to $0.100 \mathrm{Wm}^{-2}$ in 2050 (Marquart et $a l^{19}$, Penner et $a l^{1}$, Marquart et $a l^{17}$, Ponater et $a l^{29}$ ) Variation in ice particle size assumptions results in large variations in calculated RF, from non-spherical particles inducing an RF of $0.0092 \mathrm{Wm}^{-2}$ in 2050, versus $0.0127 \mathrm{Wm}^{-2}$ for spherical, half-size particles $\left(\right.$ Marquart $e t a l^{46}$ ).Variations in ice water content are also important (Minis $e t a l^{21}$, Meerkötter et $a l^{20}$ ). The latter paper stresses that the level of uncertainty over contrail RF is a factor of five, due to the lack of contrail cover and optical depth values. The balance of short wave and long wave RF contributions from contrail cover results in a net positive RF (Myhre et $a l^{23}$ ) which is reduced when the diurnal cycle is included. Variations in the lower and upper bound results, shown in Table 11, range from $340 \%$ for 2000 , to $676 \%$ for 2050 estimates, with difference in surface temperature estimates for 2050 varying by $478 \%$.

The effect of $\mathrm{NO}_{\mathrm{x}}$ and methane on atmospheric ozone is a significant factor in climate dynamics with estimates for the RF due to ozone in 2050 ranging from 0.017 to $0.182 \mathrm{Wm}^{-2}$ (Ponater $e t a l^{29}$ ), a difference of over $1000 \%$, with an associated temperature increase of between 0.0114 and $0.076 \mathrm{~K}$. The RF range for methane in 2050 is from -0.0082 to -0.0856 $\mathrm{Wm}^{-2}$ (Ponater et $a l^{29}$, Marquart et $a l^{17}$ ), varying by over $1000 \%$. These results indicate the high level of variability between simulations for ozone and methane effects.

The effect of sulphate aerosols is slight cooling on climate, with estimates for 2000 ranging from -0.0035 to $-0.004 \mathrm{Wm}^{-2}$ (Sausen $e a^{35}$ ) and predictions for 2015 being $-0.006 \mathrm{Wm}^{-2}$. It has also been shown that excluding sulphate chemistry from climate models can increase the RF due to ozone by over 55\%, although no measurable effect on methane is detected (Pitari et $\left.a l^{24}\right)$.

Soot can have a forcing effect on climate, with RF estimates ranging from 0.003 to 0.006 $\mathrm{Wm}^{-2}$ for 1992 (Danilin $e t a l^{8}$, Penner $e a \mathrm{l}^{1}$ ). Future predictions of soot effects for 2015 range from $0.004 \mathrm{Wm}^{-2}$ for Penner et al ${ }^{1}$ to $0.006 \mathrm{Wm}^{-2}$ from a different scenario in Penner et al and Marquart et $a l^{17}$. Variation in the modelled effect of soot is over 150\% for 200, 2015 and 2050.

Table 12 shows the contribution from aviation as an overall portion of global emissions for three different scenarios. The AlFl scenario ${ }^{1}$ describes a future world of rapid economic growth, a peak of global population mid-century, followed a by a decline, and rapid introduction of new, efficient technologies, although remaining fossil-intensive. The $B 1$ scenario ${ }^{1}$ has the same population growth profile as $A 1 F 1$, but with reductions in material intensity, and introduction of clean, efficient technologies. The older IS92a scenario is included as reference ${ }^{1}$

It can be seen that in relation to both the $A 1 F 1$ and $B 1$ scenarios, aviation's contribution to global radiative forcing remains between 3.59 and $5.34 \%$ for 2000 , and $5.31 \%$ and $7.67 \%$ for 2015. The range for the predicted scenarios for 2050 becomes more significant, being as low as $2.12 \%$ for the $A 1 F 1$ scenario, and a worst case of $17.09 \%$ as the upper bound relative to the $B 1$ scenario. This demonstrates the difficulty in estimating future emissions on such large 
timescales, given the difficulty in estimating growth and technology trends, and the complex nature of the interactions between aviation emissions and the global climate. 
Table 10. Lower and upper bounds for radiative forcing results

\begin{tabular}{|c|c|c|c|c|c|c|c|c|}
\hline \multirow[t]{3}{*}{ Effect } & \multicolumn{8}{|c|}{ Radiative Forcing due to aircraft, $\mathrm{Wm}^{-2}$} \\
\hline & \multicolumn{2}{|c|}{1990} & \multicolumn{2}{|c|}{2000} & \multicolumn{2}{|c|}{2015} & \multicolumn{2}{|c|}{2050} \\
\hline & Low & High & Low & High & Low & High & Low & High \\
\hline $\mathrm{CO}_{2}$ & $0.016^{1}$ & $0.021^{34}$ & $0.025^{1}$ & $0.029^{34}$ & $0.038^{1}$ & $0.046^{34}$ & $0.061^{17}$ & $0.074^{1}$ \\
\hline Water & $0.002^{1}$ & - & $0.002^{1 ; 35}$ & - & $0.0008^{17}$ & $0.003^{1}$ & $0.0010^{29}$ & $0.0042^{29}$ \\
\hline Contrails & $0.021^{1}$ & - & $0.010^{35}$ & $0.034^{1}$ & $0.0102^{19}$ & $0.060^{1}$ & $0.0148^{18}$ & $0.100^{1}$ \\
\hline Cirrus & - & - & $0.010^{37}$ & $0.080^{35 ; 37}$ & - & - & - & - \\
\hline Ozone & $0.024^{1}$ & - & $0.0219^{35}$ & $0.029^{1}$ & $0.04^{1}$ & $0.054^{17}$ & $0.017^{29}$ & $0.182^{29}$ \\
\hline $\mathrm{NO}_{\mathrm{x}}$ & $0.014^{39}$ & $0.026^{39}$ & - & - & $0.019^{39}$ & $0.037^{39}$ & - & - \\
\hline Methane & $-0.015^{1}$ & - & $-0.0104^{35}$ & $-0.018^{1}$ & $-0.027^{1}$ & $-0.036^{17}$ & $-0.0082^{29}$ & $-0.0856^{29}$ \\
\hline Soot & $-0.003^{1}$ & - & $0.0025^{35}$ & $0.004^{1}$ & $0.004^{1}$ & $0.006^{1 ; 17}$ & $0.006^{1 ; 17}$ & $0.009^{1}$ \\
\hline $\mathrm{SO}_{\mathrm{x}}$ & $-0.003^{1}$ & - & $-0.0035^{35}$ & $-0.004^{1}$ & $-0.006^{1 ; 17}$ & - & $-0.007^{1}$ & - \\
\hline Overall & $0.048^{1}$ & - & $0.0478^{35}$ & $0.071^{1}$ & $0.103^{1}$ & $0.146^{1}$ & $0.1023^{29}$ & $0.564^{1}$ \\
\hline
\end{tabular}


Table 11. Percentage variation of radiative forcing results (high versus low bound)

\begin{tabular}{|c|c|c|c|c|}
\hline \multirow[t]{2}{*}{ Effect } & \multicolumn{4}{|c|}{ Percentage variation of radiative forcing results (high versus low bound) } \\
\hline & 1990 & 2000 & 2015 & 2050 \\
\hline $\mathrm{CO}_{2}$ & $131 \%$ & $116 \%$ & $121 \%$ & $112 \%$ \\
\hline Water & - & - & $375 \%$ & $420 \%$ \\
\hline Contrails & - & $340 \%$ & $588 \%$ & $676 \%$ \\
\hline Cirrus & - & - & $800 \%$ & - \\
\hline Ozone & - & $132 \%$ & $135 \%$ & $1071 \%$ \\
\hline $\mathrm{NO}_{\mathrm{x}}$ & $186 \%$ & - & $195 \%$ & - \\
\hline Methane & - & $173 \%$ & $133 \%$ & $1044 \%$ \\
\hline Soot & - & $160 \%$ & $150 \%$ & $150 \%$ \\
\hline $\mathrm{SO}_{\mathrm{x}}$ & - & $114 \%$ & - & - \\
\hline Overall & - & $149 \%$ & $142 \%$ & $551 \%$ \\
\hline
\end{tabular}


Table 12. Aviation's contribution to global emissions

\begin{tabular}{|c|c|c|c|c|c|c|c|c|}
\hline \multirow[t]{3}{*}{ Effect } & \multicolumn{8}{|c|}{ Percentage of global radiative forcing } \\
\hline & \multicolumn{2}{|c|}{1990} & \multicolumn{2}{|c|}{2000} & \multicolumn{2}{|c|}{2015} & \multicolumn{2}{|c|}{2050} \\
\hline & Low & High & Low & High & Low & High & Low & High \\
\hline$\%$ global RF, A1F1 ${ }^{1}$ & $4.66 \%$ & - & $3.59 \%$ & $5.34 \%$ & $5.34 \%^{\dagger}$ & $7.56 \%{ }^{\dagger}$ & $2.12 \%$ & $11.68 \%$ \\
\hline$\%$ global RF, B $1^{1}$ & $4.66 \%$ & - & $3.59 \%$ & $5.34 \%$ & $5.31 \%^{\dagger}$ & $7.67 \%{ }^{\dagger}$ & $3.10 \%$ & $17.09 \%$ \\
\hline$\%$ global RF, IS92a ${ }^{1}$ & $4.66 \%$ & - & $3.65 \%$ & $5.42 \%$ & $5.67 \%{ }^{\dagger}$ & $8.04 \% \%^{\dagger}$ & $3.15 \%$ & $17.35 \%$ \\
\hline
\end{tabular}

${ }^{\dagger}$ Based linearly interpolated value for global radiative forcing between 2010 and $2020 .{ }^{1}$ 
Table 13. Lower and upper bounds for surface temperature results

\begin{tabular}{|c|c|c|c|c|c|c|c|c|}
\hline \multirow[t]{3}{*}{ Effect } & \multicolumn{8}{|c|}{ Surface temperature increase since 1990 due to aircraft, $K$} \\
\hline & \multicolumn{2}{|c|}{1990} & \multicolumn{2}{|c|}{2000} & \multicolumn{2}{|c|}{2015} & \multicolumn{2}{|c|}{2050} \\
\hline & Low & High & Low & High & Low & High & Low & High \\
\hline $\mathrm{CO}_{2}$ & 0 & 0 & $0.003^{34}$ & - & $0.007^{34}$ & - & $0.0206^{29}$ & $0.021^{34}$ \\
\hline Water & 0 & 0 & - & - & - & - & $0.0003^{29}$ & $0.0015^{29}$ \\
\hline Contrails & 0 & 0 & - & - & - & - & $0.0032^{29}$ & $0.0153^{29}$ \\
\hline Cirrus & 0 & 0 & - & - & - & - & - & - \\
\hline Ozone & 0 & 0 & - & - & $0.010^{34}$ & $0.097^{34}$ & $0.0114^{29}$ & $0.0764^{29}$ \\
\hline $\mathrm{NO}_{\mathrm{x}}$ & 0 & 0 & - & - & - & - & $-0.0046^{29}$ & $-0.0309^{29}$ \\
\hline Methane & 0 & 0 & - & - & - & - & - & - \\
\hline Soot & 0 & 0 & - & - & - & - & - & - \\
\hline $\mathrm{SO}_{\mathrm{x}}$ & 0 & 0 & - & - & - & - & - & - \\
\hline Overall & 0 & 0 & $0.004^{1}$ & $0.005^{1}$ & $0.015^{1}$ & $0.019^{1}$ & $0.039^{1}$ & $0.133^{1}$ \\
\hline
\end{tabular}




\section{DISCUSSION}

This study aimed to provide an overview of the current state of research into the effects of aviation on current and future climate. As outlined in Section 3, a systematic and objective search and data extraction strategy was developed and applied to research outputs from 1995 to 2007. Here we discuss the results presented in Section 4, assumptions and limitations of the approach, and suggestions for future research.

IPCC produced a comprehensive report on the effect of aviation on the environment in $1999^{1}$. The nature of IPCC is that it aims to include the research of significant scientific groups worldwide. The focus of this review was therefore to provide a picture of the current state of research in light of this major study in an objective way. The rapid increase in computational power, and hence simulation accuracy, scope and fidelity, has had a major effect on climate model research, meaning that more recent research may be seen as more relevant. Hence the timescale of 1995-2007 was chosen to be far enough before IPCC to include original research that was likely to be included, and bring this up to the present day. It is interesting to note that $25 \%$ of the studies pre-date the 1999 IPCC report.

The methodology aimed to identify the studies from which data were extracted in an objective and replicable manner. The criteria described in section 3.2 were developed a priori to include all types of aviation, and major global warming contributors with outcomes. The inclusion criteria were revised after an initial search, due to the large volume of references, to only include papers describing a climate model. This was justifiable as the focus of the research was to investigate future climate impact of aviation. Inclusion of papers that estimate existing and historical effects of aviation were included, as this is an important factor in determining the accuracy of climate models for predicting future behaviour. As one of the secondary outcomes of this research was to test the applicability of the systematic review methodology in this context, the revised inclusion criteria is considered pragmatic given the resources available. The advantage of the systematic search strategy was to minimise identification or selection bias, which is a risk of a less structured literature review approach.

The included articles were restricted to original research, including review articles that provided new interpretation of existing results. Many reports and articles in the public domain, such as the press, cite a limited number of sources. The aim was therefore to include original source material, rather than derivative work. Conference abstracts were searched for the last two years, as it was assumed that relevant research presented at conferences would appear within two years as published papers. The overall quality of the included papers was high, as discussed in Section 3.1, and primarily comprised peer-reviewed journal publications.

As discussed in Section 3.1, the papers were prioritised for data extraction so that some meaningful comparisons could be made of RF, GWP and temperature effects and due to limited resources to carry out the review. The priority B-D papers are listed in Appendix 4, and include recent studies that use, for instance, increases in carbon dioxide emissions as outcomes.

Two problems affecting review papers are reviewer and publication biases. Reviewer bias is minimised by using two independent reviewers who do not communicate when screening papers. Only if there is disagreement as to whether a paper should be included or excluded, is 
discussion entered into. While this doubles the resource requirement, which is significant in this case in which 579 papers were screened, it aims to ensure that bias is reduced.

Publication bias, also known as positive outcome bias, is the phenomenon of papers tending to only be published when a statistically significant result is achieved. This can be due to researchers not submitting papers in which results are not statistically significant, and/or journal editors tending to reject them for publication. In this case it is difficult to perform any analysis of publication bias. The IPCC report of Penner et al ${ }^{1}$ can be seen as a meta-study, and is perhaps the only attempt to perform such a direct comparison in this particular context. No discussion of publication bias within the IPCC report is given, however. Restriction of the search to English language papers introduces a degree of publication bias, since much significant research is eventually published in the English language for international dissemination.

The results of the present review were considered in four groups, as dictated by the differences in model design, inputs and outcomes. The first set of papers reviewed was those which study the overall effect of aviation emissions on the climate. The IPCC report $^{1}$ provided a cross-comparison of several different climate models from different research groups. Two papers reported an update to the IPCC figures for $2000^{34 ; 35}$, using five different climate models, reflecting ongoing research to incorporate new scientific understanding and modelling. The only other works that studied overall effects were concerned with modelling the effect of hydrogen-powered cryoplanes. While not the focus of this study, they do report baseline cases for kerosene aircraft ${ }^{17 ; 29}$ and hence provide comparison with the other reports cited here. This supports the view that the IPCC report on aviation may be considered as comprehensive, and that its methodology and results are perhaps accepted by the research community.

Eight papers include extractable data on the effect of carbon dioxide from aviation on the atmosphere. These include the papers reporting overall effects ${ }^{1 ; 17 ; 29 ; 34 ; 35}$, as $\mathrm{CO}_{2}$ is the major climate driver. Fortuin et $a l^{12}$ studied seasonal and latitudinal variation of $\mathrm{CO}_{2}$ effects, which provides a more detailed breakdown of temporal and regional behaviour, for historical period 1943-1990. There is debate within the climate science community as to the validity of using Radiative Forcing Index ${ }^{1}$ as an indicator for climate change, as there is no accounting for the differing timescales associated with greenhouse gases and their products. While it is useful as a single measure to show the equivalent effect of non- $\mathrm{CO}_{2}$ emissions related to $\mathrm{CO}_{2}$, it can be deemed over-simplistic when used to guide, for instance, changes in operational and design of aircraft. For example, when trading off the cumulative effect of $\mathrm{CO}_{2}$ emissions versus the short-term effect of contrails. This is specifically tackled by Forster $e a^{11}$, who demonstrated that GWP may be a better metric when taking into account non- $\mathrm{CO}_{2}$ emissions on the environment. This is contrary to the discussion by Penner $e{ }^{a} l^{1}$, who concluded that RFI is a better metric for aviation.

The majority of the papers surveyed (57\%) were concerned with the effect of water, contrails and cirrus cloud cover on climate. This reflects the uncertainty in the science surrounding these factors, as highlighted by Penner $e t a l^{1}$. The effect of water vapour, where isolated as a separate component, was shown to be an order of magnitude lower than that of carbon dioxide. The level of understanding regarding contrails and cirrus cloud formation, and how aviation emissions can affect these, is incomplete. This is reflected in the large variation in 
results from the studies reviewed, which can differ by an order of magnitude in RF for similar scenarios, or over $500 \%$ across the different studies reviewed here. The effect of cirrus clouds was excluded from the estimates given by IPCC in $1999^{1}$, and there is still sufficient uncertainty to mean that it remains an active area of research. This is largely due to the complex physics and dependence on, for instance, contrail cover, and ice particle shape \& size, which can lead to differences by a factor of five on $\mathrm{RF}^{20}$. It is only more recently that detailed contrail models have been incorporated into climate models ${ }^{27}$, in an attempt to provide more accurate estimates. The importance of this topic is significant for the aircraft industry to guide mitigating strategies, such as changing cruising altitude or developing cryoplanes, that trade-off carbon dioxide emissions with water vapour, contrail and cirrus cloud impacts.

$40 \%$ of the papers reviewed here were concerned with the effects of nitrogen oxides, sulphur oxides and aerosols from aviation on the climate. The chemistry related to these emissions is complex, as indirect effects due to their participation in ozone and methane chemistry must be considered. $\mathrm{NO}_{\mathrm{x}}$ has a major influence on ozone chemistry, depending on altitude and temperature. It also affects the lifetime and concentration of methane. It is the nature, and modelling, of these indirect effects that provides scope for uncertainty. The effect of sulphur emissions is a net cooling effect, both directly and due to its on ozone and methane. The overall methane chemistry is complex, and for simulations to 2050, variations of over $1000 \%$ between studies is reported. As discussed above, the use of an RFI to account for both direct and indirect effects of non- $\mathrm{CO}_{2}$ emissions is debatable ${ }^{11}$, and GWP may be a better metric, although not without its own problems ${ }^{1}$.

The systematic review methodology has been shown to provide an objective way of quantifying climate research, although meta-analysis remains difficult due to the nature and scope of the identified studies. It demonstrates the ongoing development of climate models to investigate and incorporate new science as understanding of physical processes improves, and computational resources allow more detailed simulations to be attempted. It highlights the focus of studies on the effect of $\mathrm{NO}_{\mathrm{x}}$, sulphates, contrails and cirrus cloud cover, showing how the community is trying to improve its knowledge and understanding of these complex topics. The priority B-D studies provide further detail of research in such areas, but do not provide RF, GWP and temperature as outcomes. The ongoing development of climate science is a necessary step in guiding the aerospace industry in the right direction to find sustainable solutions for the future. 


\section{CONCLUSIONS}

In this study we have used the systematic review methodology to investigate the effect of aviation on global climate. An appropriate protocol was developed and applied by two independent reviewers, to identify research that met the inclusion criteria. These studies were prioritised and data extracted using a standard process. The 35 studies reviewed here reported radiative forcing, global warming potential and/or temperature changes as outcomes, allowing direct comparisons to be made.

Tabulated results and a narrative commentary were provided for overall effects on climate, and the individual effects of carbon dioxide, water, contrails, cirrus clouds, ozone, nitrogen oxides, methane, soot and sulphur oxides. Lower and upper bounds for these effects, and their relative contributions compared to overall radiative forcing and surface temperature changes, have been described.

This review shows that the most recent estimates for the contribution of aviation to global climate are highly dependent on the level of scientific understanding and modelling, and predicted scenarios for social and economic growth. Estimates for the future contribution of aviation to global radiative forcing in 2015 range from $5.31 \%$ to $8.04 \%$. For 2050, the estimates have a wider spread, from $2.12 \%$ to $17.33 \%$, the latter being for the most extreme technology and growth scenario. These global estimates should be considered within the context of uncertainties in accounting for the direct and indirect effects of different contributions. Variations between lower and upper bounds for estimates of radiative forcing are relatively low for carbon dioxide, around $131 \%$, to $800 \%$ for cirrus clouds effects, and $1044 \%$ for soot. Advances in climate research, particularly in the area of contrail and cloud effects, has led to some revision of the 1999 IPCC estimates ${ }^{1}$, and demonstrates that the research community is actively working to further understand the underlying science.

The approaches assumptions, limitations and future work were discussed in detail. We have demonstrated how the systematic review methodology can be applied to climate science, in a replicable and transparent manner. 


\section{REFERENCES}

(1) Penner JE, Lister D, Griggs D, Dokken D, McFarland M, (eds.). Aviation and the global atmosphere: Summary for policymakers. 1999. Geneva, IPCC. IPCC Special Report.

(2) Bows AAKaUP. Contraction \& Convergence: UK carbon emissions and the implications for UK air traffic. Tyndall Centre Technical Report [40], 1-80. 2006. Tyndall Centre for Climate Change Research.

(3) Egger M, Davey Smith G. Systematic Reviews in Health Care. 2nd ed. BMJ Books; 2001.

(4) NHS Centre for Reviews and Dissemination. Undertaking Systematic Reviews of Research on Effectiveness. CRD Report 4 (2nd Edition). 2001. York, University of York.

(5) Drummond MF, O'Brien BJ, Torrance GW, Stoddart GL. Methods for the economic evaluation of health care programmes. Oxford: Oxford University Press; 1997.

(6) Higgins J, Green S, (eds.). Cochrane Handbook for Systematic Reviews of Interventions 4.2.6 [updated September 2006]. Chichester, UK: John Wiley \& Sons, Ltd; 2006.

(7) Berntsen TK, Myhre G, Stordal F, Isaksen ISA. Time evolution of tropospheric ozone and its radiative forcing. Journal of Geophysical Research-Atmospheres 2000; 105(D7):8915-8930.

(8) Danilin MY, Fahey DW, Schumann U, Prather MJ, Penner JE, Ko MKW et al. Aviation fuel tracer simulation: Model intercomparison and implications.

Geophysical Research Letters 1998; 25(21):3947-3950.

(9) Dessens O, Simon P. The importance of dynamics/chemistry coupling in the evaluation of aircraft emission impact studies. Meteorologische Zeitschrift 2002; 11(3):161-175.

(10) Fichter C, Marquart S, Sausen R, Lee DS. The impact of cruise altitude on contrails and related radiative forcing. Meteorologische Zeitschrift 2005; 14(4):563-572.

(11) Forster PMD, Shine KP, Stuber N. It is premature to include non-CO2 effects of aviation in emission trading schemes. Atmospheric Environment 2006; 40(6):11171121.

(12) Fortuin JPF, Vandorland R, Wauben WMF, Kelder H. Greenhouse Effects of Aircraft Emissions As Calculated by A Radiative-Transfer Model. Annales GeophysicaeAtmospheres Hydrospheres and Space Sciences 1995; 13(4):413-418.

(13) Fuglestvedt JS, Isaksen ISA, Wang WC. Estimates of indirect global warming potentials for CH4, CO AND NOX. Climatic Change 1996; 34(3-4):405-437.

(14) Gauss M, Isaksen ISA, Wong S, Wang WC. Impact of $\mathrm{H} 2 \mathrm{O}$ emissions from cryoplanes and kerosene aircraft on the atmosphere. Journal of Geophysical Research-Atmospheres 2003; 108(D10):4304. 
(15) Isaksen ISA, Berntsen TK, Wang WC. NOx emissions from aircraft: Its impact on the global distribution of $\mathrm{CH} 4$ and $\mathrm{O}-3$ and on radiative forcing. Terrestrial Atmospheric and Oceanic Sciences 2001; 12(1):63-78.

(16) Johnson CE, Derwent RG. Relative radiative forcing consequences of global emissions of hydrocarbons, carbon monoxide and NOx from human activities estimated with a zonally-averaged two-dimensional model. Climatic Change 1996; 34(3-4):439-462.

(17) Marquart S, Sausen R, Ponater M, Grewe V. Estimate of the climate impact of cryoplanes. Aerospace Science and Technology 2001; 5(1):73-84.

(18) Marquart S, Ponater M, Mager F, Sausen R. Future development of contrail cover, optical depth, and radiative forcing: Impacts of increasing air traffic and climate change. Journal of Climate 2003; 16(17):2890-2904.

(19) Marquart S, Ponater M, Strom L, Glerens K. An upgraded estimate of the radiative forcing of cryoplane contrails. Meteorologische Zeitschrift 2005; 14(4):573-582.

(20) Meerkotter R, Schuman U, Doelling D, Minnis P, Nakajima T, Tsushuma Y. Radiative forcing by contrails. Annales Geophysicae 1999; 17:1080-1094.

(21) Minnis P, Schumann U, Doelling DR, Gierens KM, Fahey DW. Global distribution of contrail radiative forcing. Geophysical Research Letters 1999; 26(13):1853-1856.

(22) Morris GA, Rosenfield JE, Schoeberl MR, Jackman CH. Potential impact of subsonic and supersonic aircraft exhaust on water vapor in the lower stratosphere assessed via a trajectory model. Journal of Geophysical Research-Atmospheres 2003; 108(D3).

(23) Myhre G, Stordal F. On the tradeoff of the solar and thermal infrared radiative impact of contrails. Geophysical Research Letters 2001; 28(16):3119-3122.

(24) Pitari G, Mancini E, Bregman A. Climate forcing of subsonic aviation: Indirect role of sulfate particles via heterogeneous chemistry. Geophysical Research Letters 2002; 29(22):14-1.

(25) Ponater M, Brinkop S, Sausen R, Schumann U. Simulating the global atmospheric response to aircraft water vapour emissions and contrails: A first approach using a GCM. Annales Geophysicae-Atmospheres Hydrospheres and Space Sciences 1996; 14(9):941-960.

(26) Ponater M, Sausen R, Feneberg B, Roeckner E. Climate effect of ozone changes caused by present and future air traffic. Climate Dynamics 1999; 15(9):631-642.

(27) Ponater M, Marquart S, Sausen R. Contrails in a comprehensive global climate model: Parameterization and radiative forcing results. Journal of Geophysical Research 2002; 107(D13):2-1.

(28) Ponater M, Marquart S, Sausen R, Schumann U. On contrail climate sensitivity. Geophysical Research Letters 2005; 32(10):10706.

(29) Ponater M, Pechtl S, Sausen R, Schumann U, Hüttig G. Potential of the cryoplane technology to reduce aircraft climate impact: a state of the art assessment.

Atmospheric Environment 2006; 40:6928-6944. 
(30) Rind D, Lonergan P. Modeled Impacts of Stratospheric Ozone and Water-Vapor Perturbations with Implications for High-Speed Civil Transport Aircraft. Journal of Geophysical Research-Atmospheres 1995; 100(D4):7381-7396.

(31) Rind D, Lonergan P, Shah K. Climatic effect of water vapor release in the upper troposphere. Journal of Geophysical Research-Atmospheres 1996; 101(D23):2939529405.

(32) Rind D, Lonergan P, Shah K. Modeled impact of cirrus cloud increases along aircraft flight paths. Journal of Geophysical Research-Atmospheres 2000; 105(D15):1992719940.

(33) Sausen R, Feneberg B, Ponater M. Climatic impact of aircraft induced ozone changes. Geophysical Research Letters 1997; 24(10):1203-1206.

(34) Sausen R, Schumann U. Estimates of the climate response to aircraft CO2 and NOx emissions scenarios. Climatic Change 2000; 44(1-2):27-58.

(35) Sausen R, Isaksen I, Hauglustaine D, Lee DS, Myhre G, Köhler M et al. Aviation radiative forcing in 2000: an update on IPCC (1999). Meteorologische Zeitschrift 2005; 14(4):555-561.

(36) Stevenson DS, Doherty RM, Sanderson MG, Collins WJ, Johnson CE, Derwent RG. Radiative forcing from aircraft NOx emissions: Mechanisms and seasonal dependence. Journal of Geophysical Research D: Atmospheres 2004; 109(17):13.

(37) Stordal F, Myhre G, Stordal E, Rossow D, Lee DS, Arlander D. Is there a trend in cirrus cloud cover due to aircraft traffic? Atmos Chem Phys 2005; 5:2155-2162.

(38) Strauss B, Meerkoetter R, Wissinger B, Wendling P, Hess M. On the regional climatic impact of contrails: microphysical and radiative properties of contrails and natural cirrus clouds. Annales Geophysicae 1997; 15(11):1457-1467.

(39) Valks PJM, Velders GJM. The present-day and future impact of NOx emissions from subsonic aircraft on the atmosphere in relation to the impact of NOx surface sources. Annales Geophysicae-Atmospheres Hydrospheres and Space Sciences 1999; 17(8):1064-1079.

(40) Williams V, Noland RB, Toumi R. Reducing the climate change impacts of aviation by restricting cruise altitudes. Transportation Research Part D: Transport and Environment 2002; 7(6):451-464.

(41) Baughcum S, et al. Scheduled aircraft emission inventories for 1992. Database development and analysis. NASA CR-4700 . 1996.

(42) Schmitt A, Brunner B. Emissions from aviation and their development over time. 3752. 1997. DLR, Cologne, Germany. Mitteilung - Deutsche Forschungsanstalt fuer Luft- und Raumfahrt.

(43) Foquart Y, Bonnel B. Computations of solar heating of the Earth's atmosphere: A new paramaterization. Beitr Phys Atmos 1980; 53:35-62.

(44) Morcrette J-J. Radiation and cloud radiative properties in the European Centre for Medium Range Weather Forecasts forecasting system. J Geophys Res 1991; 96:91219132. 
(45) Dameris M, Grewe V, Kohler I, Sausen R, Bruhl C, Grooss JU et al. Impact of aircraft NOx emissions on tropospheric and stratospheric ozone. Part II: 3-D model results. Atmospheric Environment 1998; 32(18):3185-3199.

(46) Rotman DA, Tannahill JR, Kinnison DE, Connell PS, Bergmann D, Proctor D et al. Global Modeling Initiative assessment model: Model description, integration, and testing of the transport shell. Journal of Geophysical Research-Atmospheres 2001; 106(D2):1669-1691. 


\section{Appendix 1 - search strategy}

The search strategy for Web of Science is given below.

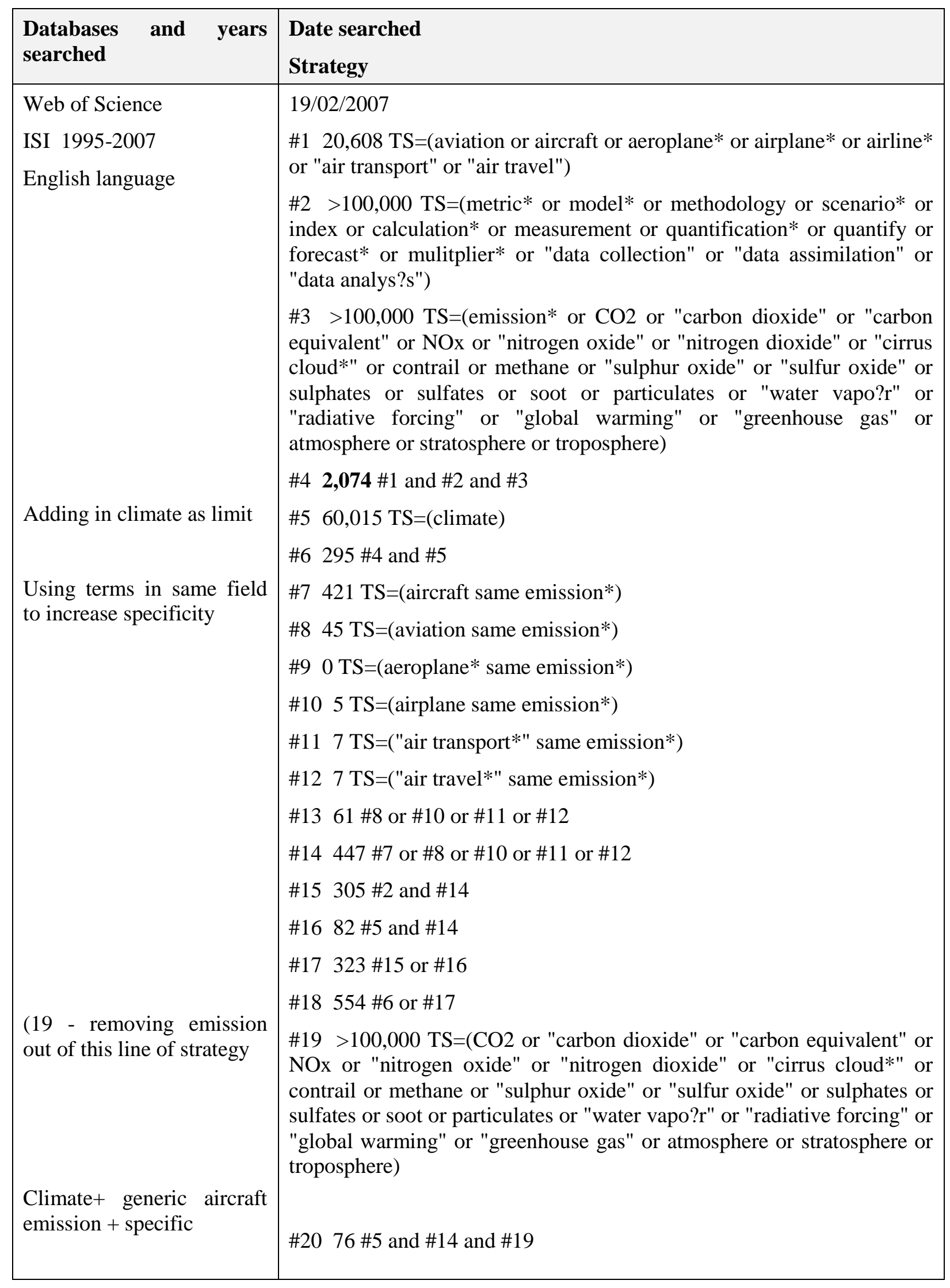




\begin{tabular}{|c|c|}
\hline $\begin{array}{l}\text { Model etc }+ \text { generic } \\
\text { aircraft emission OR } \\
\text { climate }+ \text { generic emission } \\
\text { OR climate + generic } \\
\text { aircraft + specific }\end{array}$ & $\# 21 \mathbf{3 2 3} \# 15$ or $\# 16$ or \#20 \\
\hline
\end{tabular}




\section{Appendix 2 - Data extraction form}

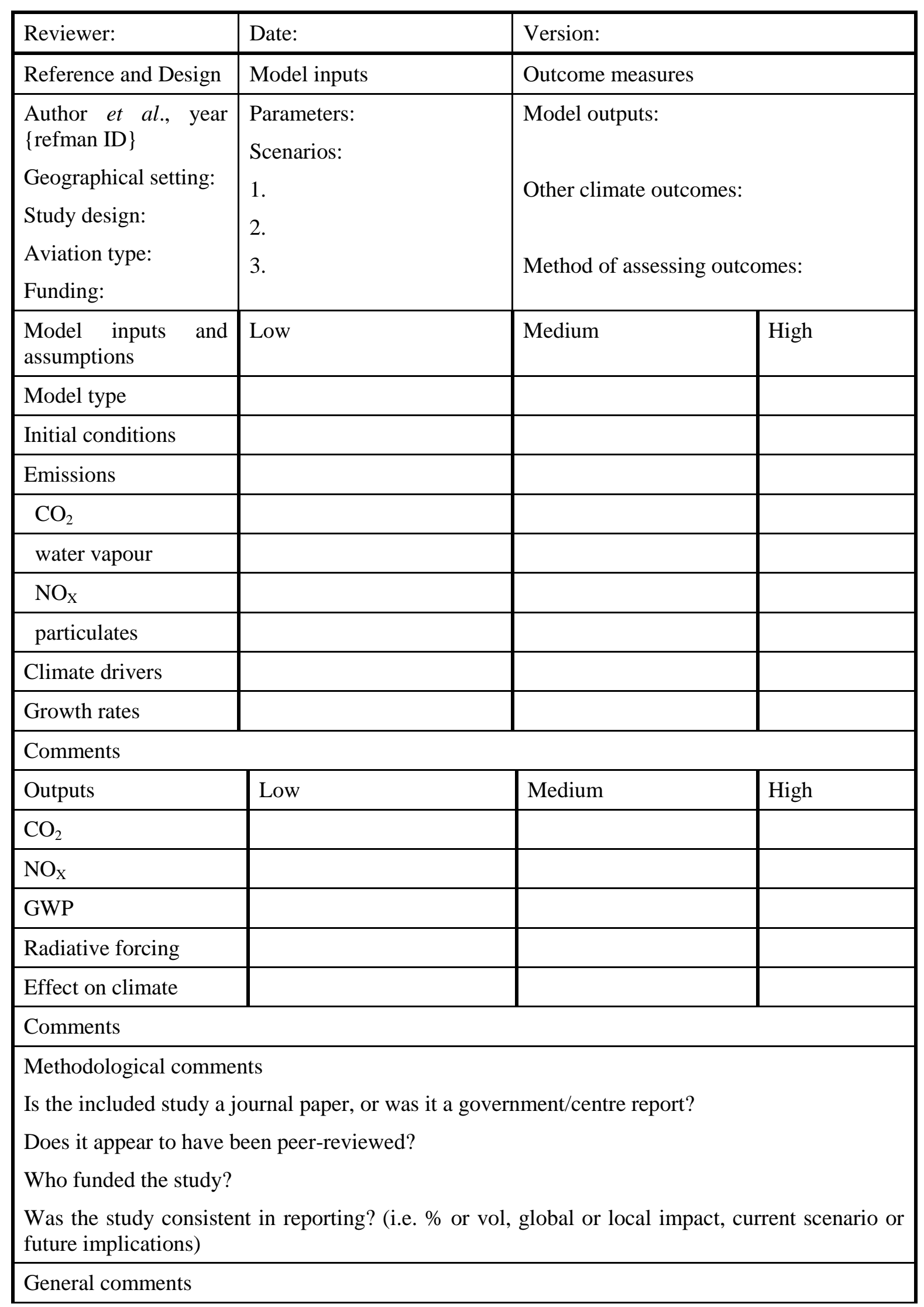




\section{Appendix 3 - Excluded studies}

Many of the studies below were excluded for more than one reason, but for conciseness are listed under the prime exclusion criterion only.

\section{Study type not meeting inclusion criteria:}

Anable J, Lane B, Kelay T. An evidence base review of public attitudes to climate change and transport behaviour. Report for the Department of Transport. 2006.

Armstrong FW, Allen JE, Denning RM. Fuel-related issues concerning the future of aviation. Proceedings of the Institution of Mechanical Engineers Part G-Journal of Aerospace Engineering 1997; 211(G1):1-11.

Baumgardner D, Kok G, Raga G. Warming of the Arctic lower stratosphere by light absorbing particles. Geophysical Research Letters 2004; 31(6).

Brasseur GP, Cox RA, Hauglustaine D, Isaksen I, Lelieveld J, Lister DH et al. European scientific assessment of the atmospheric effects of aircraft emissions. Atmospheric Environment 1998; 32(13):2329-2418.

Colvile RN, Hutchinson EJ, Mindell JS, Warren RF. The transport sector as a source of air pollution. Atmospheric Environment 2001; 35(9):1537-1565.

Commission of the European Communities. Reducing the climate change impact of aviation. COM (2005) 459 final. 2005. Brussels. Communication from the Comission to the Council, the European Parliament, the European Economic and Social Committee and the Committee of the Regions.

Department for Transport. Aviaiton and global warming. 2004. London, DfT.

Eddington R. A different line. Engineer 2006; 293(7714):16.

Facanha C, Horvath A. Environmental assessment of freight transportation in the US. International Journal of Life Cycle Assessment 2006; 11(4):229-239.

Flatoy F, Hov O. NOx from lightning and the calculated chemical composition of the free troposphere. Journal of Geophysical Research-Atmospheres 1997; 102(D17):21373-21381.

Furger M. AEROCHEM II - Modelling the impact of aircraft emissions on ozone and other chemical compounds in the atmosphere. Meteorologische Zeitschrift 2002; 11(3):139-140.

Gao RS, Fahey DW, Del Negro LA, Donnelly SG, Keim ER, Neuman JA et al. A comparison of observations and model simulations of NOx/NOy in the lower stratosphere. Geophysical Research Letters 1999; 26(8):1153-1156.

Gettelman A. The evolution of aircraft emissions in the stratosphere. Geophysical Research Letters 1998; 25(12):2129-2132.

Green JE. Civil aviation and the environmental challenge. Aeronautical Journal 2003; 107(1072):281-300.

Green JE. Civil aviation and the environment - the next frontier for the aerodynamicist. Aeronautical Journal 2006; 110(1110):469-486.

Grewe V, Reithmeier C, Shindell DT. Dynamic-chemical coupling of the upper troposphere and lower stratosphere region. Chemosphere 2002; 47(8):851-861. 
Grewe V, Dameris M, Hein R, Sausen R, Steil B. Future changes of the atmospheric composition and the impact of climate change. Tellus Series B-Chemical and Physical Meteorology 2001; 53(2):103-121.

Hendricks J, Lippert E, Petry H, Ebel A. Implications of subsonic aircraft NOx emissions for the chemistry of the lowermost stratosphere: Model studies on the role of bromine. Journal of Geophysical Research-Atmospheres 2000; 105(D5):6745-6759.

HM Treasury. Stern Review: The economics of climate change. http://www.hmtreasury.gov.uk/independent_reviews/stern_review_economics_climate_change/stern_review _report.cfm . 2006. 10-1-2007.

Jones AE, Law KS, Pyle JA. Subsonic aircraft and ozone trends. Journal of Atmospheric Chemistry 1996; 23(1):89-105.

Karol IL. The impact of the world's transport aircraft flights on the ozonosphere and climate. Russian Meteorology and Hydrology 2000;(7):10-21.

Kärcher B, Turco RP, Yu F, Danilin MY, Weisenstein DK, Miake-Lye RC et al. A unified model for ultrafine aircraft particle emissions. Journal of Geophysical Research-Atmospheres 2000; 105(D24):29379-29386.

Koroneos C, Dompros A, Roumbas G, Moussiopoulos N. Life cycle assessment of kerosene used in aviation. International Journal of Life Cycle Assessment 2005; 10(6):417-424.

Lee DS, Brunner B, Dopelheuer A, Falk RS, Gardner RM, Lecht M et al. Aviation emissions: present-day and future. Meteorologische Zeitschrift 2002; 11(3):141-150.

Lee DS, Sausen R. New directions: Assessing the real impact of $\mathrm{CO} 2$ emissions trading by the aviation industry. Atmospheric Environment 2000; 34(29-30):5337-5338.

Lee JJ, Lukachko SP, Waitz IA, Schafer A. Historical and future trends in aircraft performance, cost, and emissions. Annual Review of Energy and the Environment 2001; 26:167-200.

Lee SH, LeDilosquer M, Singh R, Hobbs SE, Giannakopoulos C, Plantevin PH et al. Implications of NOy emissions from subsonic aircraft at cruise altitude. Proceedings of the Institution of Mechanical Engineers Part G-Journal of Aerospace Engineering 1997; 211(G3):157-168.

Ma JZ, Zhou XJ, Hauglustaine D. Summertime tropospheric ozone over China simulated with a regional chemical transport model. 2. Source contributions and budget. Journal of Geophysical Research-Atmospheres 2002; 107(D22).

Ma JZ, Liu HL, Hauglustaine D. Summertime tropospheric ozone over China simulated with a regional chemical transport model - 1. Model description and evaluation. Journal of Geophysical Research-Atmospheres 2002; 107(D22).

Pison I, Menut L. Quantification of the impact of aircraft traffic emissions on tropospheric ozone over Paris area. Atmospheric Environment 2004; 38(7):971-983.

Pitari G, Mancini E, Bregman A, Rogers HL, Sundet JK, Grewe V et al. Sulphate particles from subsonic aviation: Impact on upper tropospheric and lower stratospheric ozone. Physics and Chemistry of the Earth Part C-Solar-Terrestial and Planetary Science 2001; 26(8):563569. 
Plumb RA, Ko MKW, Shia RL. Representation of Localized Aircraft Noy Emissions in A 2Dimensional Model of Stratospheric Ozone. Journal of Geophysical Research-Atmospheres 1995; 100(D10):20901-20911.

Romano D, Gaudioso D, De Lauretis R. Aircraft emissions: A comparison of methodologies based on different data availability. Environmental Monitoring and Assessment 1999; 56(1):51-74.

Royal Commission on Environmental Pollution. The environmental effects of civil aviation in flight. 2002.

Schoeberl MR, Morris GA. A Lagrangian simulation of supersonic and subsonic aircraft exhaust emissions. Journal of Geophysical Research-Atmospheres 2000; 105(D9):1183311839.

Schumann U, Schlager H, Arnold F, Ovarlez J, Kelder H, Hov O et al. Pollution from aircraft emissions in the North Atlantic flight corridor: Overview on the POLINAT projects. Journal of Geophysical Research-Atmospheres 2000; 105(D3):3605-3631.

Sen O. The effect of aircraft engine exhaust gases on the environment. International Journal of Environment and Pollution 1997; 8(1-2):148-157.

Shia RL, Ko MKW, Weisenstein DK, Scott C, Rodriguez J. Transport between the tropical and midlatitude lower stratosphere: Implications for ozone response to high-speed civil transport emissions. Journal of Geophysical Research-Atmospheres 1998; 103(D19):2543525446.

Shine KP. Comments on "Contrails, cirrus trends, and climate". Journal of Climate 2005; 18(14):2781-2782.

Simoes AF, Schaeffer R. The Brazilian air transportation sector in the context of global climate change: $\mathrm{CO} 2$ emissions and mitigation alternatives. Energy Conversion and Management 2005; 46(4):501-513.

Smyshlyaev SP, Dvortsov VL, Geller MA, Yudin VA. A two-dimensional model with input parameters from a general circulation model: Ozone sensitivity to different formulations for the longitudinal temperature variation. Journal of Geophysical Research-Atmospheres 1998; 103(D21):28373-28387.

Smyshlyaev SP, Geller MA, Yudin VA. Sensitivity of model assessments of high-speed civil transport effects on stratospheric ozone resulting from uncertainties in the NOx production from lightning. Journal of Geophysical Research-Atmospheres 1999; 104(D21):26401-26417.

Stevenson DS, Collins WJ, Johnson CE, Derwent RG. The impact of aircraft nitrogen oxide emissions on tropospheric ozone studied with a 3D Lagrangian model including fully diurnal chemistry. Atmospheric Environment 1997; 31(12):1837-1850.

Stuber N, Forster P, Radel G, Shine K. The importance of the diurnal and annual cycle of air traffic for contrail radiative forcing. Nature 2006; 441(7093):864-867.

Suntharalingam P, Jacob DJ, Palmer PI, Logan JA, Yantosca RM, Xiao YP et al. Improved quantification of Chinese carbon fluxes using $\mathrm{CO} 2 / \mathrm{CO}$ correlations in Asian outflow. Journal of Geophysical Research-Atmospheres 2004; 109(D18). 
Travis DJ, Carleton AM, Lauritsen RG. Regional variations in U.S. diurnal temperature range for the 11-14 September 2001 aircraft groundings: Evidence on jet contrail influence on climate. Journal of Climate 2004; 17(5):1123-1134.

Tremmel HG, Schlager H, Konopka P, Schulte P, Arnold F, Klemm M et al. Observations and model calculations of jet aircraft exhaust products at cruise altitude and inferred initial OH emissions. Journal of Geophysical Research-Atmospheres 1998; 103(D9):10803-10816.

Tsai FJ, Sun WS, Chen JP. A composite modeling study of civil aircraft impacts on ozone and sulfate over the Taiwan area. Terrestrial Atmospheric and Oceanic Sciences 2001; 12(1):109135.

Tsai FJ, Walcek CJ. Estimating chemical errors in large-scale simulations of aircraft emissions. Terrestrial Atmospheric and Oceanic Sciences 2001; 12(1):79-108.

Tyndall Researchers (various). The Stern Review on the Economics of Climate Change. http://www.tyndall.ac.uk/publications/stern_review.pdf . 2006. 22-2-2007.

Upham P. Climate change and the UK aviation white paper. 10. 2003. Manchester, Tyndall Centre (North), UMIST. Tyndall Briefing Note.

Upham P. Environmental capacity of aviation: theoretical issues and basic research directions. Journal of Environmental Planning and Management 2001; 44(5):721-734.

Upham P. Climate Change and Planning and consultation for the UK Aviation White Paper. Journal of Environmental Planning and Management 2003; 46(6):911-918.

vanVelthoven PFJ, Sausen R, Johnson CE, Kelder H, Kohler I, Kraus AB et al. The passive transport of NOx emissions from aircraft studied with a hierarchy of models. Atmospheric Environment 1997; 31(12):1783-1799.

Vedantham A, Oppenheimer M. Long-term scenarios for aviation: Demand and emissions of CO2 and NOx. Energy Policy 1998; 26(8):625-641.

Wang,Hanjie; Ying,Lin; Jianguo,Zhang. Short-term aviation climate prediction study and some preliminary results around China. 11th Conference on Aviation, Range, and Aerospace Meterology, Oct 4-8 2004; Key Lab. of RCE-TEA, CAS, Beijing 100085, China. Hyannis, MA, United States: American Meteorological Society, Boston, MA 02108-3693, United States; 2004.

Wang YXX, McElroy MB, Wang T, Palmer PI. Asian emissions of CO and NOx: Constraints from aircraft and Chinese station data. Journal of Geophysical Research-Atmospheres 2004; 109(D24).

Wauben WMF, vanVelthoven PFJ, Kelder H. A 3D chemistry transport model study of changes in atmospheric ozone due to aircraft NOx emissions. Atmospheric Environment 1997; 31(12):1819-1836.

Weaver CJ, Douglass AR, Considine DB. A 5-year simulation of supersonic aircraft emission transport using a three-dimensional model. Journal of Geophysical Research-Atmospheres 1996; 101(D15):20975-20984.

Weaver CJ, Douglass AR, Rood RB. Tracer Transport for Realistic Aircraft Emission Scenarios Calculated Using A 3-Dimensional Model. Journal of Geophysical ResearchAtmospheres 1995; 100(D3):5203-5214. 
Williams V, Noland R. Comparing the $\mathrm{CO} 2$ emissions and contrail formation from short and long haul air traffic routes from London Heathrow. Environmental Science and Policy 2006; 9:487-495.

Williams V, Noland RB, Toumi R. Air transport cruise altitude restrictions to minimize contrail formation. Climate Policy 2003; 3(3):207-219.

Williams V, Noland RB. Variability of contrail formation conditions and the implications for policies to reduce the climate impacts of aviation. Transportation Research Part D: Transport and Environment 2005; 10(4):269-280.

Wyser K, Strom J. A possible change in cloud radiative forcing due to aircraft exhaust. Geophysical Research Letters 1998; 25(10):1673-1676.

Zerefos C, Eleftheratos K, Balis D, Zanis P, Tselioudis G, Meletti C. Evidence of impact of aviation on cirrus cloud formation. Atmos Chem Phys 2003; 3:1633-1644.

\section{Study reported estimates of emissions rather than modelling effect of aviation on climate:}

Allen D, Pickering K, Stenchikov G, Thompson A, Kondo Y. A three-dimensional total odd nitrogen (NOy) simulation during SONEX using a stretched-grid chemical transport model. Journal of Geophysical Research-Atmospheres 2000; 105(D3):3851-3876.

Åkerman J. Sustainable air transport - On track in 2050. Transportation Research Part D: Transport and Environment 2005; 10(2):111-126.

Bekki S. The possible role of aircraft-generated soot in the middle latitude ozone depletion. Journal of Geophysical Research-Atmospheres 1997; 102(D9):10751-10758.

Bieberbach G, Fuelberg HE, Thompson AM, Schmitt A, Hannan JR, Gregory GL et al. Mesoscale numerical investigations of air traffic emissions over the North Atlantic during SONEX flight 8: A case study. Journal of Geophysical Research-Atmospheres 2000; 105(D3):3821-3832.

Farias F, ApSimon H. Relative contributions from traffic and aircraft NOx emissions to exposure in West London. Environmental Modelling \& Software 2006; 21(4):477-485.

Gettelman A, Baughcum SL. Direct deposition of subsonic aircraft emissions into the stratosphere. Journal of Geophysical Research-Atmospheres 1999; 104(D7):8317-8327.

Kentarchos AS, Roelofs GJ. Impact of aircraft NOx emissions on tropospheric ozone calculated with a chemistry-general circulation model: Sensitivity to higher hydrocarbon chemistry. Journal of Geophysical Research-Atmospheres 2002; 107(D13).

Kiselev AA, Karol IL. Model study of tropospheric composition response to NOx and CO pollution. Environmental Modelling \& Software 2000; 15(6-7):583-588.

Lee SH, LeDilosquer M, Singh R, Hobbs SE, Giannakopoulos C, Plantevin PH et al. Implications of NOy emissions from subsonic aircraft at cruise altitude. Proceedings of the Institution of Mechanical Engineers Part G-Journal of Aerospace Engineering 1997; 211(G3):157-168. 
Schumann U. The impact of nitrogen oxides emissions from aircraft upon the atmosphere at flight altitudes - Results from the AERONOX project. Atmospheric Environment 1997; 31(12):1723-1733.

\section{Studies not in the English language or otherwise unavailable:}

Ebel A. Overview on workpackage 400: impact upon ozone and climate; regional and global modelling. 225-227. 1997. DLR, Cologne, Germany. Mitteilung - Deutsche Forschungsanstalt fuer Luft- und Raumfahrt.

Land C. Untersuchungen zum globalen Spurenstofftransport mit dem Atmosphaerenmodell ECHAM4.L39(DLR)

Examining the global transport of trace species with the atmosphere general circulation model ECHAM4.L39(DLR). 99, 1-131. 1999. DLR, Cologne, Germany. D L R Forschungsberichte.

Marquart S. Klimawirkung von Kondensstreifen: Untersuchungen mit einem globalen atmosph [per mille] rischen Zirkulationsmodell Climate impact of contrails: Investigations by means of an atmospheric general circulation model. D L R - Forschungsberichte 2003;(16):1-148.

Ponater M, Gierens K. Quantification of key parameters for treating contrails in a large scale climate model. 207-213. 1997. DLR, Cologne, Germany. Mitteilung - Deutsche Forschungsanstalt fuer Luft- und Raumfahrt.

Sausen R. Simulating the global climate impact of aircraft emissions. Mitteilung - Deutsche Forschungsanstalt fuer Luft- und Raumfahrt 1997;(4):243-253.

Schmitt A, Brunner B. Emissions from aviation and their development over time. 37-52. 1997. DLR, Cologne, Germany. Mitteilung - Deutsche Forschungsanstalt fuer Luft- und Raumfahrt.

Schmitz G. Climate Impact of Aircraft Emissions in the Upper Troposphere. Studies with a 2D-Model. Mitteilung - Deutsche Forschungsanstalt fuer Luft- und Raumfahrt 1997;(4):255261.

Huebsch,W.W.; Lewellent,D.C. Sensitivity study on contrail evolution. 2006. Collection of Technical Papers - 36th AIAA Fluid Dynamics Conference 


\section{Appendix 4 - Priority B-D studies}

\section{Priority B studies:}

Andronache C, Chameides WL. Interactions between sulfur and soot emissions from aircraft and their role in contrail formation 2. Development. Journal of Geophysical ResearchAtmospheres 1998; 103(D9):10787-10802.

Bows A, Anderson K. Policy clash: Can projected aviation growth be reconciled with the UK Government's 60\% carbon-reduction target? Transport Policy 2006; doi: 10.1016/j.tranpol.2006.10.002.

Cairns S, Newson C, Boardman B, Anable J. Predict and Decide: aviation, climate change and UK policy. Final Report. 2006. Oxford, Environmental Change Institute.

Gierens K, Sausen R, Schumann U. A diagnostic study of the global distribution of Contrails Part II: Future air traffic scenarios. Theoretical and Applied Climatology 1999; 63(1-2):1-9.

Hendricks J, Karcher B, Lohmann U, Ponater M. Do aircraft black carbon emissions affect cirrus clouds on the global scale? Geophysical Research Letters 2005; 32(12).

Hendricks J, Karcher B, Dopelheuer A, Feichter J, Lohmann U, Baumgardner D. Simulating the global atmospheric black carbon cycle: a revisit to the contribution of aircraft emissions. Atmospheric Chemistry and Physics 2004; 4:2521-2541.

Kjellstrom E, Feichter J, Sausen R, Hein R. The contribution of aircraft emissions to the atmospheric sulfur budget. Atmospheric Environment 1999; 33(21):3455-3465.

Plumb IC, Ryan KR. Effect of aircraft on ultraviolet radiation reaching the ground. Journal of Geophysical Research-Atmospheres 1998; 103(D23):31231-31239.

\section{Priority C studies:}

Berntsen TK, Isaksen ISA. Effects of lightning and convection on changes in tropospheric ozone due to NOx emissions from aircraft. Tellus Series B-Chemical and Physical Meteorology 1999; 51(4):766-788.

Brasseur GP, Muller JF, Granier C. Atmospheric impact of NOx emissions by subsonic aircraft: A three-dimensional model study. Journal of Geophysical Research-Atmospheres 1996; 101(D1):1423-1428.

Dameris M, Grewe V, Kohler I, Sausen R, Bruhl C, Grooss JU et al. Impact of aircraft NOx emissions on tropospheric and stratospheric ozone. Part II: 3-D model 
Flatoy F, Hov O. Three-dimensional model studies of the effect of NOx emissions from aircraft on ozone in the upper troposphere over Europe and the North Atlantic. Journal of Geophysical Research-Atmospheres 1996; 101(D1):1401-1422.

Gauss M, Isaksen ISA, Lee DS, Sovde OA. Impact of aircraft NOx emissions on the atmosphere - tradeoffs to reduce the impact. Atmospheric Chemistry and Physics 2006; 6:1529-1548.

Giannakopoulos C, Good P, Law KS, Shallcross DF, Wang KY. Modelling the impacts of aircraft traffic on the chemical composition of the upper troposphere. Proceedings of the Institution of Mechanical Engineers Part G-Journal of Aerospace Engineering 2003; 217(G5):237-243.

Grewe V, Dameris M, Fichter C, Sausen R. Impact of aircraft NOx emissions. Part 1: Interactively coupled climate-chemistry simulations and sensitivities to climate-chemistry feedback, lightning and model resolution. Meteorologische Zeitschrift 2002; 11(3):177-186.

Grewe V, Dameris M, Fichter C, Lee DS. Impact of aircraft NOx emissions. Part 2: Effects of lowering the flight altitude. Meteorologische Zeitschrift 2002; 11(3):197-205.

Grewe V, Dameris M, Hein R, Kohler I, Sausen R. Impact of future subsonic aircraft NOx emissions on the atmospheric composition. Geophysical Research Letters 1999; 26(1):47-50.

Grooss JU, Bruhl C, Peter T. Impact of aircraft emissions on tropospheric and stratospheric ozone. Part I: Chemistry and 2-D model results. Atmospheric Environment 1998; 32(18):3173-3184.

Karlsdottir S, Isaksen ISA, Myhre G, Berntsen TK. Trend analysis of O-3 and CO in the period 1980-1996: A three-dimensional model study. Journal of Geophysical ResearchAtmospheres 2000; 105(D23):28907-28933.

Kohler I, Sausen R, Reinberger R. Contributions of aircraft emissions to the atmospheric NOx content. Atmospheric Environment 1997; 31(12):1801-1818.

Kraabol AG, Flatoy F, Stordal F. Impact of NOx emissions from subsonic aircraft: Inclusion of plume processes in a three-dimensional model covering Europe, North America, and the North Atlantic. Journal of Geophysical Research-Atmospheres 2000; 105(D3):3573-3581.

Kraabol AG, Berntsen TK, Sundet JK, Stordal F. Impacts of NOx emissions from subsonic aircraft in a global three-dimensional chemistry transport model including plume processes. Journal of Geophysical Research-Atmospheres 2002; 107(D22).

Kraus AB, Rohrer F, Grobler ES, Ehhalt DH. The global tropospheric distribution of NOx estimated by a three-dimensional chemical tracer model. Journal of Geophysical ResearchAtmospheres 1996; 101(D13):18587-18604.

Liu Y, Isaksen ISA, Sundet JK, Zhou XJ, Ma JZ. Impact of aircraft NOx emission on NOx and ozone over China. Advances in Atmospheric Sciences 2003; 20(4):565-574. 
Meijer EW, van Velthoven PFJ, Thompson AM, Pfister L, Schlager H, Schulte P et al. Model calculations of the impact of NOx from air traffic, lightning, and surface emissions, compared with measurements. Journal of Geophysical Research-Atmospheres 2000; 105(D3):38333850 .

Meijer EW, vanVelthoven PFJ, Wauben WMF, Beck JP, Velders GJM. The effects of the conversion of nitrogen oxides in aircraft exhaust plumes in global models. Geophysical Research Letters 1997; 24(23):3013-3016.

Penner JE, Bergmann DJ, Walton JJ, Kinnison D, Prather MJ, Rotman D et al. An evaluation of upper troposphere NOx with two models. Journal of Geophysical Research-Atmospheres 1998; 103(D17):22097-22113.

Rotman DA, Tannahill JR, Kinnison DE, Connell PS, Bergmann D, Proctor D et al. Global Modeling Initiative assessment model: Model description, integration, and testing of the transport shell. Journal of Geophysical Research-Atmospheres 2001; 106(D2):1669-1691.

Strand A, Hov O. The impact of man-made and natural NOx emissions on upper tropospheric ozone: A two-dimensional model study. Atmospheric Environment 1996; 30(8):1291-1303.

\section{Priority D studies:}

Considine DB, Douglass AR, Jackman CH. Sensitivity of 2-Dimensional Model Predictions of Ozone Response to Stratospheric Aircraft - An Update. Journal of Geophysical ResearchAtmospheres 1995; 100(D2):3075-3090.

Danilin MY, Rodriguez JM, Ko MKW, Weisenstein DK, Brown RC, MiakeLye RC et al. Aerosol particle evolution in an aircraft wake: Implications for the high-speed civil transport fleet impact on ozone. Journal of Geophysical Research-Atmospheres 1997; 102(D17):2145321463.

Douglass AR, Prather MJ, Hall TM, Strahan SE, Rasch PJ, Sparling LC et al. Choosing meteorological input for the global modeling initiative assessment of high-speed aircraft. Journal of Geophysical Research 1999; 104(D22):27545-27564.

Fleming EL, Jackman CH, Considine DB, Stolarski RS. Sensitivity of tracers and a stratospheric aircraft perturbation to two-dimensional model transport variations. Journal of Geophysical Research-Atmospheres 2001; 106(D13):14245-14263.

Pitari G, Mancini E. Climatic impact of future supersonic aircraft: Role of water vapour and ozone feedback on circulation. Physics and Chemistry of the Earth Part C-Solar-Terrestial and Planetary Science 2001; 26(8):571-576.

Pitari G, Mancini E. Impact of future supersonic aircraft on the distribution of stratospheric tracers: Chemical and dynamical perturbations. Meteorologische Zeitschrift 2002; 11(3):215223. 
Rahmes TF, Omar AH, Wuebbles DJ. Atmospheric distributions of soot particles by current and future aircraft fleets and resulting radiative forcing on climate. Journal of Geophysical Research-Atmospheres 1998; 103(D24):31657-31667.

Rogers HL, Chipperfield MP, Bekki S, Pyle JA. The effects of future supersonic aircraft on stratospheric chemistry modeled with varying meteorology. Journal of Geophysical Research 2000; 105(D24):29359-29367.

Weisenstein DK, Ko MKW, Dyominov IG, Pitari G, Ricciardulli L, Visconti G et al. The effects of sulfur emissions from HSCT aircraft: A 2-D model intercomparison. Journal of Geophysical Research-Atmospheres 1998; 103(D1):1527-1547. 


\section{Systematic review of the impact of emissions from aviation on current and future climate}

A technical report by the University of Southampton

Air Travel - Greener by Design is an independent advisory body administered by the Royal Aeronautical Society

For further information contact:

Air Travel - Greener by Design

Royal Aeronautical Society

4 Hamilton Place

London WIJ 7BQ, UK

Tel: $+44(0) 2076704300$

Fax: $+44(0) 2076704309$

www.greenerbydesign.co.uk 